UNIVERSIDAD SAN IGNACIO DE LOYOLA

ESCUELA DE POSTGRADO

\title{
FACTORES QUE INCIDEN EN LA INTENCIÓN DE EMPRENDIMIENTO DE UNIVERSITARIOS ADULTOS CON EXPERIENCIA LABORAL
}

Disertación Presentada para Obtener el Grado de Doctor en Administración Mención en Dirección Estratégica

Por:

Jessika Milagros Vásquez Neyra

Marzo, 2017 
FACTORES QUE INCIDEN EN LA INTENCIÓN DE EMPRENDIMIENTO DE UNIVERSITARIOS ADULTOS CON EXPERIENCIA LABORAL

Jessika Milagros Vásquez Neyra

Aprobada por Miembros del Jurado:

Dr. Luis Lizárraga Pérez

Dr. Miguel Panez Bendezú

Presidente

Miembro

Dr. José Solano Morales

Dr. Carlos Mejía Bejarano

Miembro

Miembro

Dra. Niria Goñi Avila

Asesora 


\section{Dedicatoria}

A mis padres Marina Neyra y Segundo Vásquez por su invalorable apoyo y cariño. 


\section{Resumen}

El objetivo del estudio es identificar los factores motivacionales y factores ambientales que inciden en la intención de emprendimiento de universitarios adultos con experiencia laboral, por lo que se propone un modelo de intención de emprendimiento teóricamente basado en la Teoría del Comportamiento Planificado de Ajzen (1991) y el Modelo de Intención de Emprendimiento de Liñán, Urbano y Guerrero (2011), a la cual se le agregó las dimensiones de Educación Emprendedora e Instituciones y Normas Legales. El análisis estadístico se realizó con la técnica de ecuaciones estructurales sobre 784 estudiantes que cursan el último año de estudios de todas las carreras de la Universidad San Ignacio de Loyola, la Universidad Tecnológica del Perú y la Universidad de Ciencias Aplicadas. Los resultados indican que el factor motivacional actitud hacia la conducta y el factor ambiental valoración cercana son los que tienen mayor impacto positivo y significativo sobre la intención de emprender. Los resultados de este estudio tienen implicaciones importantes en el rol promotor en emprendimiento que desempeñan las universidades privadas y las instituciones públicas y privadas.

\section{Palabras clave:}

Intención de emprendimiento, Emprendimiento, Estudiantes universitarios adultos, Educación emprendedora, Marco legal. 


\begin{abstract}
The main objective of this study is to identify some of the motivational and environmental factors that may explain the entrepreneurial intention in adult university students with labor experience. Thus, an entrepreneurial intention model is developed theoretically based on Ajzen Planned Behavior Theory (1991) and Liñán, Urbano \& Guerrero Entrepreneurial Intention Model (2011), which adds the dimensions Entrepreneurship Education and Institutions \& Legal Entrepreneurial Environment. The statistical analysis is carried out using structural equations techniques over a sample of 784 final year adult university students from Universidad San Ignacio de Loyola, Universidad Tecnológica del Perú and Universidad de Ciencias Aplicadas. Results confirm that attitude towards the behavior as motivational factor and closer valuation as environmental factor have higher positive and significant impact in entrepreneurial intention. These results support the importance that private universities and public \& private institutions play a sponsor role in entrepreneurship.
\end{abstract}

\title{
Key Words:
}

Entrepreneurial intention, Entrepreneurship, Adult university students, Entrepreneurship education, Legal entrepreneurial environment. 


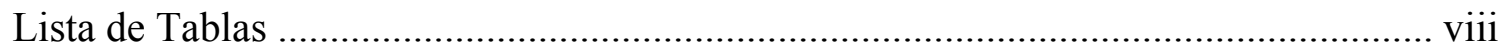

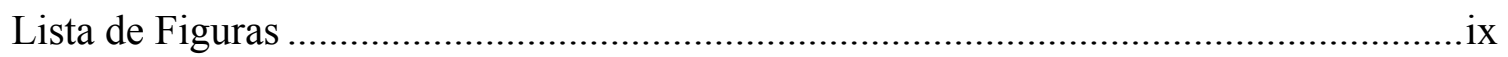

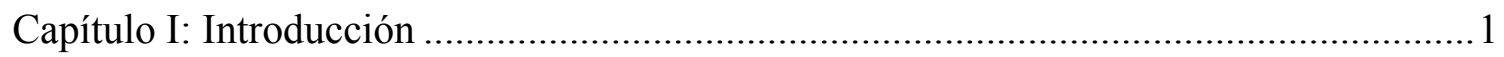

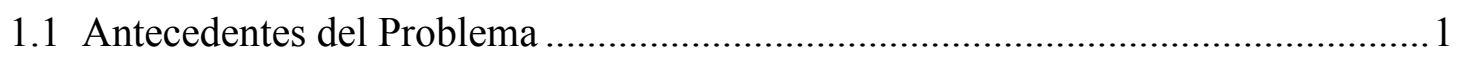

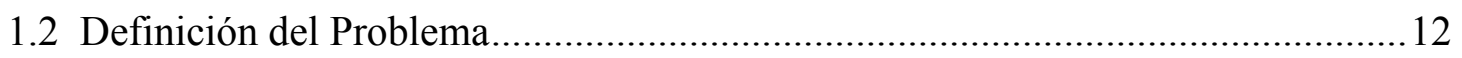

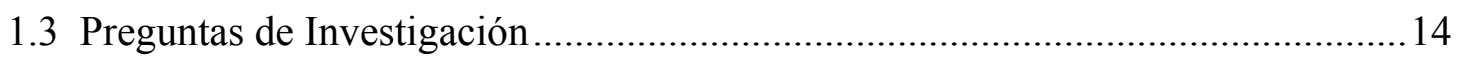

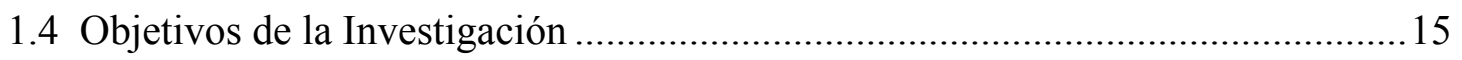

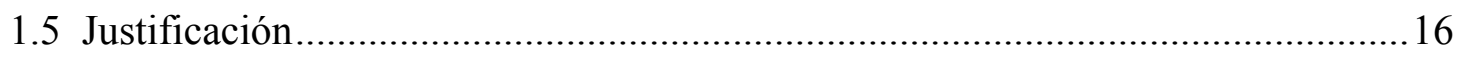

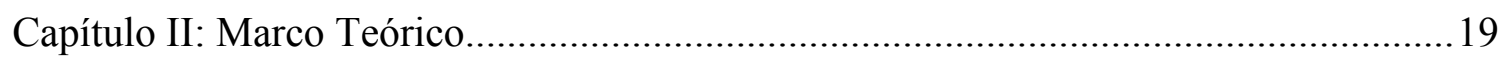

2.1 Definiciones Conceptuales .......................................................................... 19

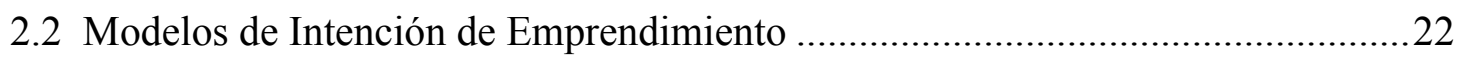

2.2.1 La teoría del comportamiento planificado de Ajzen.................................23

2.2.2 El modelo de intención de emprendimiento de Liñán, Urbano y Guerrero. 25

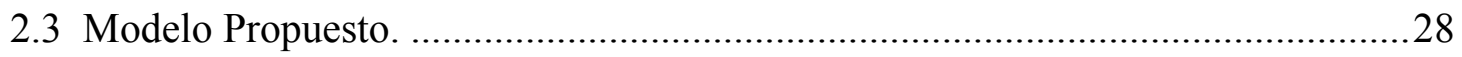

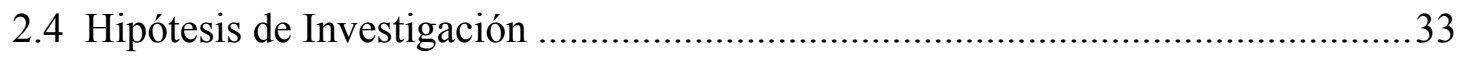

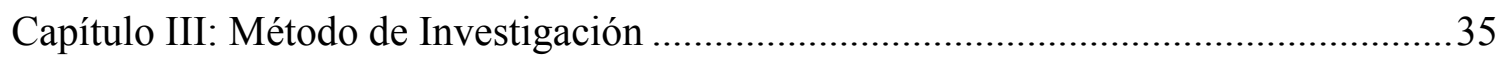

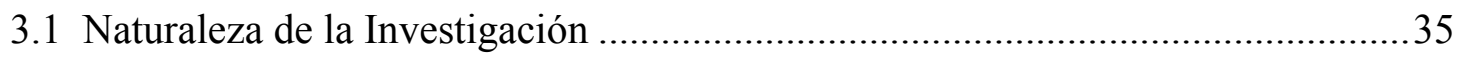

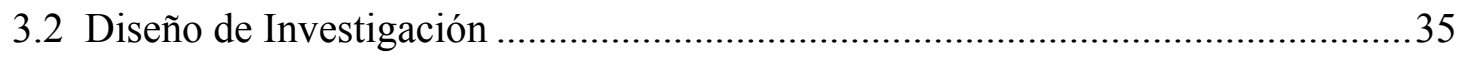

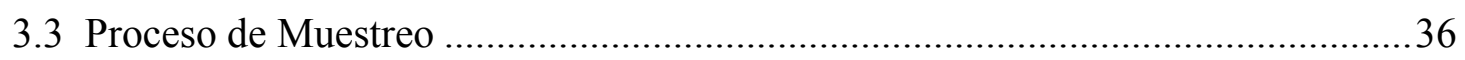

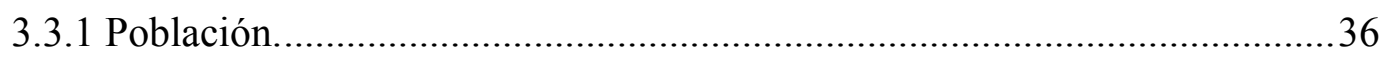




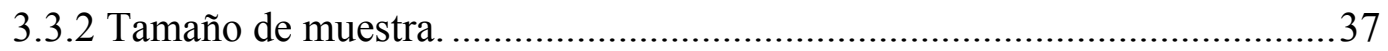

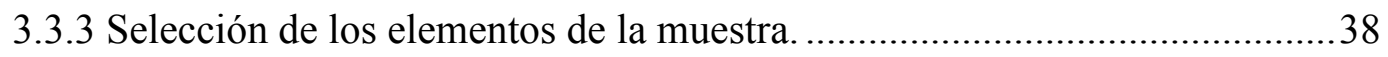

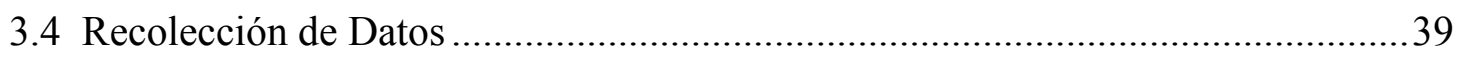

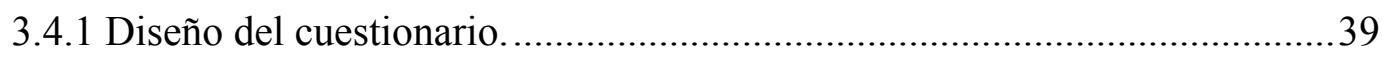

3.4.2 Validez del contenido - Juicio de expertos.........................................42

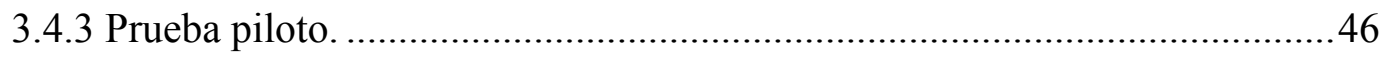

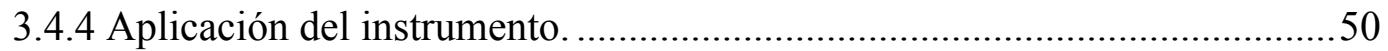

3.5 Procesamiento y Análisis de Datos .....................................................................51

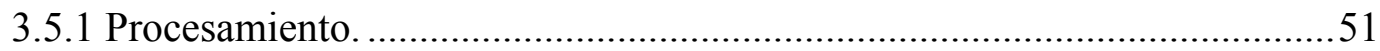

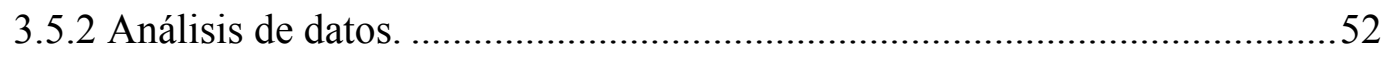

Capítulo IV: Análisis y Discusión de Resultados .........................................................56

4.1 Análisis Descriptivo para las Características de los Participantes .......................56

4.2 Análisis Factorial Exploratorio para Validar el Instrumento ..............................60

4.3 Ecuaciones Estructurales para la Validez Empírica del Modelo...........................64

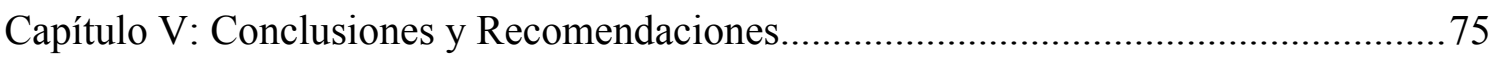

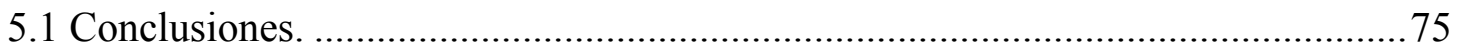

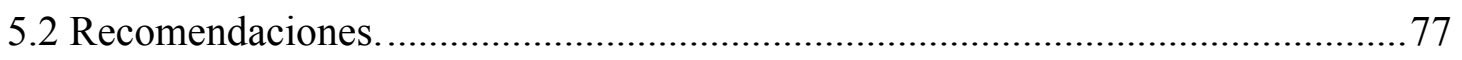

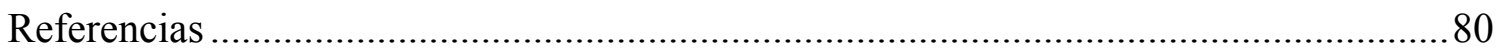

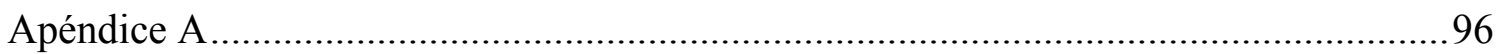

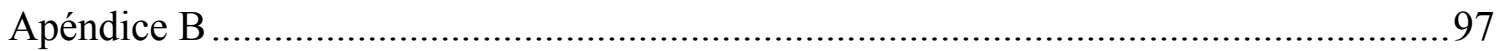

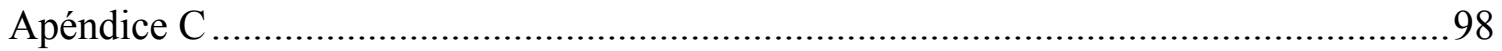

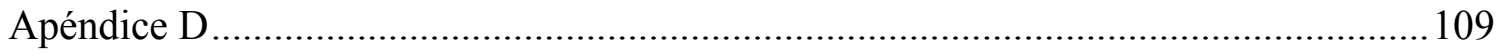

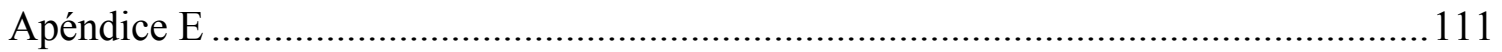




\section{Lista de Tablas}

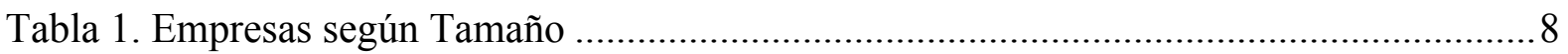

Tabla 2. Universidades en Perú según Tipo de Universidad ................................................10

Tabla 3. Concepto de Emprendimiento según Rivera y Pizarro (2009) ................................ 19

Tabla 4. Construcción de los Constructos del Modelo de Análisis Propuesto ........................32

Tabla 5. Cantidad de Alumnos Matriculados en el Último Ciclo Académico 2016................37

Tabla 6. Tamaño de Muestra y Cantidad de Participantes...........................................................38

Tabla 7. Cantidad de Afirmaciones para las Variables de Estudio.........................................41

Tabla 8. Cantidad de Preguntas para las Variables de Control.............................................42

Tabla 9. Relación de Expertos para la Validez de Contenido.................................................44

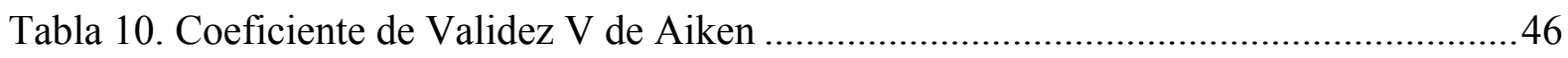

Tabla 11. Prueba Piloto - Características Generales ................................................................49

Tabla 12. Prueba Piloto - Fiabilidad y Validez ....................................................................50

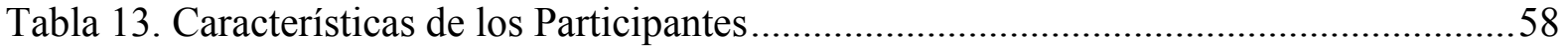

Tabla 14. Fiabilidad y Validez del Instrumento..................................................................61

Tabla 15. Matriz de Configuración Factorial Rotado y Comunalidad de los Factores Ambientales

Tabla 16. Matriz de Configuración Factorial Rotado y Comunalidad de los Factores Motivacionales .63

Tabla 17. Prueba de Normalidad .64

Tabla 18. Análisis de Fiabilidad y Validez Convergente del Modelo de Estudio Propuesto Final 


\section{Lista de Figuras}

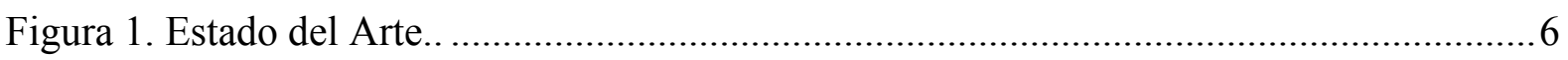

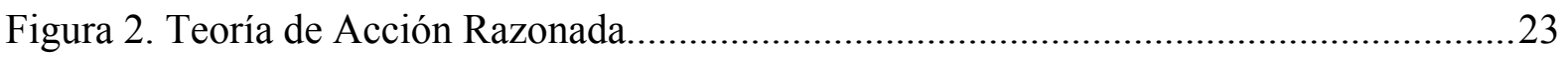

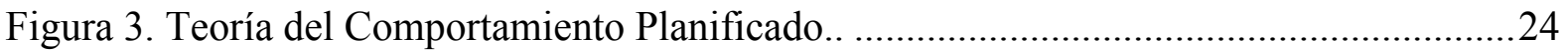

Figura 4. Teoría del Comportamiento Planificado de Ajzen.................................................24

Figura 5. Modelo de Intención de Emprendimiento según Liñán, Urbano y Guerrero...........26

Figura 6. Modelo de Análisis Propuesto........................................................................ 31

Figura 7. Modelo de Análisis Propuesto Ampliado con Hipótesis de Estudio.........................34

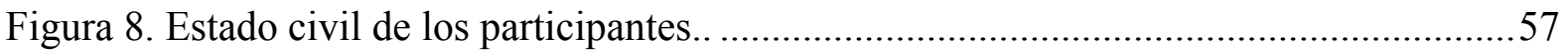

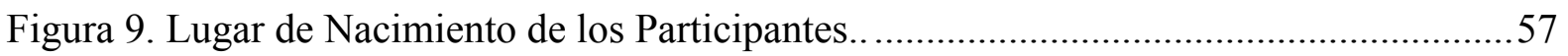

Figura 10. Experiencia en Crear Empresa de los Participantes............................................59

Figura 11. Nivel del Puesto de Trabajo de los Participantes.. ..............................................59

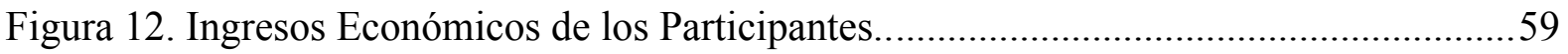

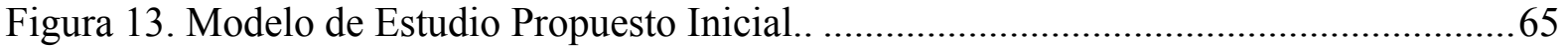

Figura 14. Modelo de Estudio Propuesto Final.. ….................................................................68

Figura 15. Modelo de Estudio Propuesto Final con Hipótesis..............................................69 


\section{Capítulo I: Introducción}

En este capítulo se presentan los antecedentes de la problemática a partir de las principales investigaciones realizadas; asimismo, se definen el problema, las preguntas y los objetivos de la investigación; y, finalmente se explica la justificación del estudio.

\subsection{Antecedentes del Problema}

El emprendimiento es explicado a través del tiempo desde una perspectiva económica y una perspectiva científica. Desde el punto de vista económico, desde inicios del siglo XVIII el emprendimiento ha sido la figura central de la historia económica, Cantillon (1732) describió el emprendimiento como la voluntad de los individuos de desarrollar formas de intermediación que implican el riesgo económico de una nueva empresa. Luego Baptist (1803) definió al emprendedor como un agente económico que une todos los medios de producción. Posteriormente para Schumpeter (1934) los emprendedores son innovadores que buscan destruir el estatus-quo de los productos y servicios existentes para crear nuevos productos y servicios, y en 1964 Drucker señaló que un emprendedor busca el cambio, responde a él y explota sus oportunidades. Para Birch (1987) el emprendimiento y las pequeñas empresas son máquinas de crecimiento por el fenómeno de creación de trabajo, no sólo en países desarrollados. Por su parte Scott y Twomey (1988) afirman que el emprendimiento juega un rol importante en el crecimiento de economías en desarrollo por sus efectos inmediatos en la generación de empleo. Para Baumol $(1993,1996)$ las instituciones adecuadas son un requisito necesario para que tenga lugar una relación positiva entre el emprendimiento y el crecimiento económico. Según Chan y Balam (2011) la generación de emprendedores es de vital importancia para un país debido a sus beneficios en el ámbito económico. En el campo de la investigación científica, el emprendimiento está tomando más relevancia en las ciencias sociales, especialmente en el campo administrativo, ya que dicho constructo es aplicable para cualquier tipo de negocio y en cualquier país, lo cual lo 
hace de interés mundial (Ullah, Farooq, \& Ahmad, 2012). Por lo tanto, la perspectiva económica ha establecido la importancia del emprendimiento en la economía de los países, de modo tal, que se ha convertido en un tema de investigación científica.

El emprendimiento como tema de investigación científica se viene estudiando desde diferentes aspectos. Así, los estudios realizados han buscado relacionarlo con regiones/países similares (Moreno \& Olmos, 2010), economía y/o crecimiento económico (Beugelsdijk \& Smeets, 2008; Laborde \& Veiga, 2010), negocios (Frank, Kessler, \& Fink, 2010; Friar \& Meyer, 2003), educación (García, 2013; Kailer, 2009; Kuehn, 2008) y el constructo intención de emprendimiento, basándose en que las intenciones son las que mejor predicen la conducta planeada (Krueger JR, Reilly, \& Carsrud, 2000). Por lo tanto, la evolución de la literatura científica ha enfocado el emprendimiento desde aspectos que van de la economía hasta la intención de emprendimiento.

La intención de emprendimiento, al ser un proceso planeado, ha logrado conjugar teorías del campo empresarial con teorías de psicología social, siendo la Teoría del Comportamiento Planificado de Ajzen (1991) la más utilizada. La literatura en el campo empresarial referida a intención de emprendimiento se inicia con el Modelo del Evento Empresarial de Shapero (1984), que se basa en el trabajo previo de Shapero y Sokol (1982), luego Bird (1988) contribuye con el Modelo de Implementación de Ideas Empresariales y posteriormente Krueger Jr. y Brazeal (1994) elaboran el Modelo de Potencial Empresarial. Por su parte y casi en paralelo, en el campo de la psicología social, especialmente en lo referido a psicología cognitiva, se desarrollan modelos para predecir el comportamiento, entre los que resaltan el Modelo de Autoeficacia de Bandura (1982) y la Teoría del Comportamiento Planificado de Ajzen (1991), que se basa en la Teoría de Acción Razonada de Ajzen y Fishbein (1980). De todos los modelos y teorías se han encontrado suficiente soporte para el Modelo de Shapero (1984) y Ajzen (1991) (Krueger Jr. \& Brazeal, 1994; Krueger JR et al., 2000); sin embargo, 
el modelo con base cognitiva más usado es el de la Teoría del Comportamiento Planificado de Ajzen (1991) por su eficacia en la predicción del comportamiento humano (Armitage \& Conner, 2001; Kautonen, Van, \& Tornikoski, 2011; Van et al., 2008). En consecuencia, de todas las teorías empresariales y de psicología social, la Teoría del Comportamiento Planificado de Ajzen (1991) es la más utilizada en intención de emprendimiento.

La Teoría del Comportamiento Planificado de Ajzen (1991) se ha aplicado en la mayoría de estudios sobre intención de emprendimiento en estudiantes universitarios, incluso en universitarios de países específicos así como comparaciones regionales entre ellos. Los estudios que se han enfocado en las intenciones de emprendimiento de estudiantes universitarios (Da Fonseca, Aguilar, Laguía, Moriano, \& Salazar, 2016; Douglas \& Shepherd, 2002; Gatewood, Shaver, Powers, \& Gartner, 2002; Gupta, Turban, Wasti, \& Sikdar, 2009; Peterman \& Kennedy, 2003; Van et al., 2008); se han realizado principalmente en: (a) Pakistán (Ullah et al., 2012), (b) Estados Unidos (Carey, Flanagan, \& Palmer, 2010), (c) Chile (Rivera \& Pizarro, 2009), (d) México (Chan \& Balam, 2011; Montiel, Marquez, Arámbula \& Ordoñez, 2012), (e) Bangladesh (Uddin \& Kanti Bose, 2012), (f) Colombia (González \& Rodríguez, 2008), y (g) Croacia (Raguz \& Matic, 2011); y, se han desarrollado comparaciones regionales principalmente en: (a) México, España y Portugal (Sánchez, 2009), (b) España, Italia, Grecia, Portugal, Finlandia, Suecia y Dinamarca (Fernández, Liñán, \& Santos, 2009), y (c) España y Taiwán (Liñán \& Chen, 2009). Como resultado, la Teoría del Comportamiento Planificado de Ajzen (1991) es la teoría más utilizada en estudios sobre intención de emprendimiento en estudiantes universitarios.

Adicionalmente a la Teoría del Comportamiento Planificado de Ajzen (1991) las investigaciones en intención de emprendimiento se han enfocado en características personales y factores contextuales (Liñán, Urbano, \& Guerrero, 2011); sin embargo, con menor poder predictivo que la Teoría del Comportamiento Planificado (Krueger JR et al., 2000). Los 
estudios basados en características personales sólo buscan identificar las similitudes entre la personalidad del individuo y la personalidad del emprendedor (Henry, Hill, \& Leitch, 2005; Ismail et al., 2009; Krueger JR et al., 2000; Nishantha, 2009); mientras que, los estudios basados en la influencia de factores contextuales sólo buscan identificar el impacto de la educación (Gelard, 2011; Ismail et al., 2009; Keat, Selvarajah, \& Meyer, 2011; Nabi \& Holden, 2008; Wu \& Wu, 2008) y el impacto de la familia (Ahmed, Aamir, \& Ijaz, 2011; Segal, Borgia, \& Schoenfeld, 2005). En consecuencia, los estudios que sólo enfocan los factores motivacionales o sólo los factores contextuales no tienen mejor nivel de predicción que la Teoría del Comportamiento Planificado de Ajzen (1991).

No obstante, no todas las preguntas ya tienen una respuesta, se necesitan mayores aportes científicos en la investigación sobre intención de emprendimiento (Krueger, 2007). En relación a las teorías, Ajzen (1991) sostiene que la Teoría del Comportamiento Planificado está, en principio, abierta a la inclusión de predictores adicionales si se puede demostrar que explican una proporción significativa de la variación de la intención después de haber analizado las variables del modelo. Por su parte Krueger (2007) sugiere desarrollar modelos teóricos más integradores y sofisticados; mientras que Fitzsimmons y Douglas (2011) recomiendan la interacción en los modelos de intención de emprendimiento. Respecto a la educación y su influencia sobre las intenciones de emprender, se sugiere investigar cómo la formación desarrolla competencias empresariales en los estudiantes (Martin, McNally, \& Kay, 2013). Respecto a las características personales, Hayton y Cholakova (2012) sugieren mejorar el entendimiento de los supuestos sobre las intenciones. En lo referido a factores contextuales se recomienda estudiar cómo las políticas públicas afectan de manera positiva o negativa la intención de emprender (Liñán, Fernández-Serrano, \& Romero, 2013; Liñán et al., 2011). Finalmente, en cuanto a la relación intención-comportamiento, se sugieren estudios que diseñen modelos que incluyan la implementación de la intención y la influencia 
del compromiso personal en implementar la intención (Fayolle, Basso, \& Tornikoski, 2011). Por lo tanto, es pertinente desarrollar modelos que permitan explicar de manera integral la intención de emprendimiento.

Como resultado de la revisión de la literatura científica se puede afirmar que, de todas las formas en que se ha estudiado el emprendimiento, la intención de emprendimiento es el enfoque más utilizado y la Teoría del Comportamiento Planificado de Ajzen (1991) es el marco teórico con mejores resultados de predicción del comportamiento; siendo los estudiantes universitarios el tipo de población más utilizada en estos estudios.

Adicionalmente, se han realizado estudios sobre intención de emprendimiento enfocados en las características personales y los factores contextuales, sin llegar a resultados satisfactorios dada su limitación en las variables de estudio. Sumado a ello, la literatura sugiere diseñar modelos más integradores, donde se incluyan variables como educación, políticas públicas e implementación de la intención y compromiso.

Hasta aquí se ha presentado el desarrollo del emprendimiento como tema de investigación científica a nivel mundial como se resume en la Figura 1; sin embargo, en paralelo la actividad empresarial mundial y el sector empresarial del país también han avanzado al respecto, ya sea identificando el perfil del emprendedor, los tipos de empresa y actividad económica preferidos por los emprendedores; así como analizando los avances en educación universitaria e investigación científica, tal como se indica a continuación. 


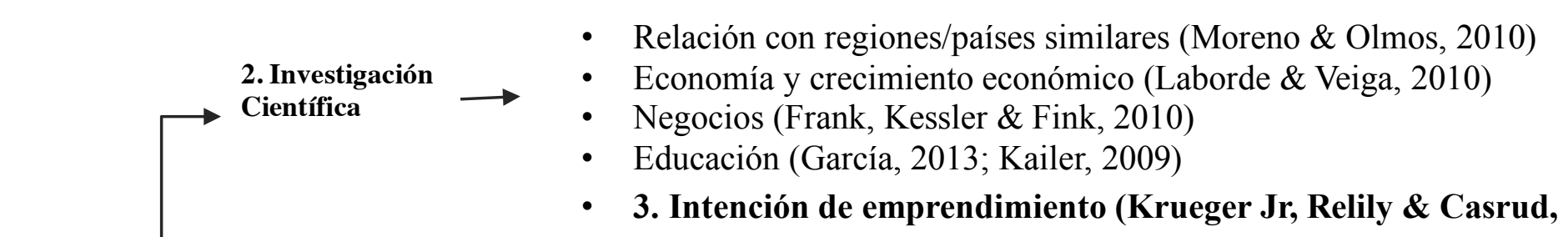

3. Intención de emprendimiento (Krueger Jr, Relily \& Casrud,

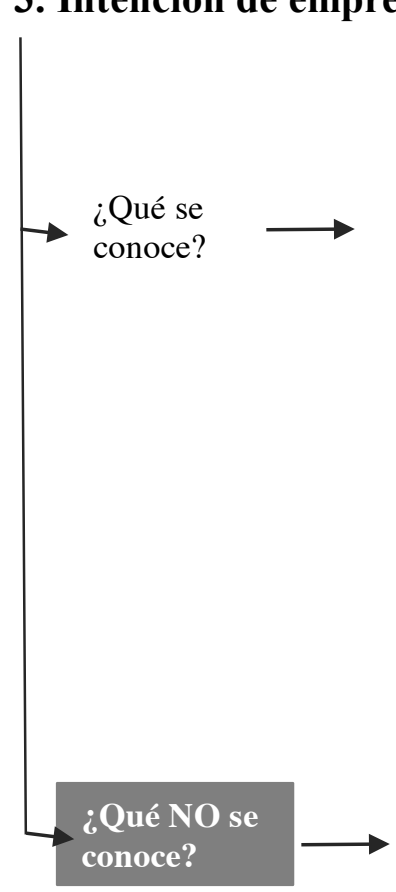

- Teorías del Campo Empresarial y de la Psicología Social (Shapero, 1984; Bird, 1988; Krueger Jr \& Brazeal, 1994)

- Características Personales (Henry, Hill \& Leitch, 2005; Nishantha, 2009)

- Sólo Familia (Ahmed, Aamir \& Ijaz, 2011; Segal, Borgia \& Schoenfeld, 2005)

- Sólo Educación (Gelard, 2011; Wu \& Wu, 2008)

- Teoría del Comportamiento Planificado de Ajzen (1991) en países específicos (Carey, Flanagan \& Palmer, 2010; Chan \& Balam, 2011), comparaciones regionales (Fernández, Liñán \& Santos, 2009; Sánchez, 2009), estudiantes universitarios (Gupta, Turban, Wasti \& Sikdar, 2009)

- Disposición de la Teoría del Comportamiento Planificado de Ajzen (1991) para incluir variables ambientales predictoras

- Disposición del Modelo de Intención de Emprendimiento de Liñán, Urbano y Guerrero (2011) a incluir la variable educación y probar su modelo en diferentes tipos de estudiantes

- Modelos teóricos más integrales (Fitzsimmons \& Douglas, 2011; Krueger, 2007)

- Incluir las variables educación y marco legal (Bae, Qian, Miao, \& Fiet, 2014; Fayolle \& Liñán, 2014; Fernández-Serrano \& Liñán, 2014; Liñán, Jaén, \& Ortega, 2015; Mat, Maat, \& Mohd, 2015) 
Según la organización Funders and Founders (2016), del 2013 al 2020 habrá 5,000 millones de personas sin trabajo y 3,000 millones de personas con trabajo, para un total de 8,000 millones de personas proyectadas en el mundo. Además actualmente una de cada 19 personas es emprendedora, de los cuales el 55\% ya tiene un empleo, el $34 \%$ es niño o anciano y el 11\% corresponde a mujeres que viven fuera de la economía. En paralelo según Bloomberg (2016), la versión estadounidense del Global Entrepreneurship Monitor indica que las mujeres emprendedoras en EE.UU. reportaron necesitar solo la mitad de lo que necesitaban los hombres para iniciar un negocio; y tienen más probabilidad de comenzar un nuevo negocio en el rango etario de 35 a 44 años, mientras que para los hombres es entre 25 y 34 años de edad.

Según la versión peruana del Global Entrepreneurship Monitor, el Perú: (a) es uno de los países más emprendedores de la región y se encuentra entre los primeros cinco con mayor actividad emprendedora dentro del grupo de las economías basadas en eficiencia; (b) en los últimos doce meses, 9 de cada 100 emprendimientos en etapa temprana han desaparecido; este índice de mortandad se encuentra por encima de la mayoría de países de la región; (c) los emprendimientos en etapa temprana son desarrollados en su mayoría (57\%) por jóvenes adultos de entre 18 y 34 años de edad; (d) el 55.6\% de los emprendimientos en etapa temprana es el resultado del aprovechamiento de oportunidades, mientras que el $25.2 \%$ lo es por necesidad; (e) respecto al nivel educativo, no se encuentran diferencias significativas entre los emprendedores en etapa temprana y los establecidos. En ambos grupos alrededor de la tercera parte cuenta con estudios superiores de nivel técnico o universitario. Sin embargo, los varones emprendedores tienden a tener mayor nivel educativo (46\%) que sus pares femeninos (32\%); y (f) la mayoría de la población adulta muestra actitudes positivas hacia el emprendimiento, como la percepción de oportunidades (51\%) y la autopercepción de 
capacidades para emprender (65\%), y supera el promedio de las economías basadas en eficiencia (Serida, Alzamora, Guerrero, Borda y Morales, 2016).

Según el Ministerio de la Producción (2015), en los resultados de su Anuario Estadístico señala que, el $0.5 \%$ de las empresas formales que existen en Perú son grandes empresas y el 99,5\% son consideradas micro, pequeña y mediana empresa (mipymes) cuyo porcentaje de participación dentro del total de empresas tuvo una composición de 95\% para microempresa, 4,3\% para pequeñas empresas y $0,2 \%$ para mediana empresa (ver Tabla 1). Asimismo, durante el período 2007-2015 el número de mipymes ha crecido a un ritmo anual promedio de 7.6\%, lo que guarda relación con el avance de la economía que alcanzó en promedio 5.3\% para el mismo período. El reporte señala que las regiones de Lima (47.4\%), Arequipa (5.7\%), La Libertad (5.2\%), Cusco (4.1\%) y Piura (3.9\%) concentran el 66,3\% del total de mipymes peruanas. Respecto a la preferencia en la actividad económica, los rubros de comercio (44.3\%) y servicios $(41.1 \%)$ son los principales.

Tabla 1

Empresas según Tamaño

\begin{tabular}{lccc}
\hline Estrato empresarial & 2007 & 2015 & $\%$ de participación \\
\hline Microempresa & 893,266 & $1,607,305$ & $95.0 \%$ \\
Pequeña empresa & 42,889 & 72,664 & $4.3 \%$ \\
Mediana empresa & 1,590 & 2,712 & $0.2 \%$ \\
Total Mipymes & 937,745 & $1,682,681$ & $99.5 \%$ \\
Gran empresa & & 8,781 & $0.5 \%$ \\
Total empresas & & $1,691,462$ & $100.0 \%$ \\
\hline
\end{tabular}

Nota. Tomado de Anuario Estadístico Industrial, Mipyme y Comercio Interno 2015 (p. 169), por Ministerio de la Producción, 2015, Lima, Perú: Ministerio de la Producción. Copyright 2015 por Ministerio de la Producción. 
El Comercio (2016c), en el artículo La Radiografía sobre el emprendimiento y la innovación en el Perú realizada para la IX Cumbre PYME APEC 2016, informó que las micro y pequeñas empresas generan empleo para 7.7 millones de trabajadores peruanos $(45 \%$ de la población económicamente activa estimada en 16,396,377 personas); sin embargo, el 83\% de las Mypes son informales. Es decir, contrario a representar un importante motor de crecimiento, empleo y reactivación de la economía peruana, al encontrarse fuera de la legalidad sus trabajadores no cuentan con beneficios sociales como seguro de salud o pensión; los propios empresarios están fuera del sistema financiero y de las cadenas productivas formales; y, el Estado no percibe impuestos por dichos negocios. Entre varias razones, esta situación se explica por la falta de incentivos por parte del Estado ya que se requiere la simplificación de la estructura tributaria empresarial, las tasas impositivas y los procesos de recaudación para que en conjunto faciliten la tributación («Radiografía del emprendimiento y la innovación en el Perú», 2016).

De acuerdo a los resultados del II Censo Nacional Universitario realizado en el año 2010, la oferta universitaria en el Perú se duplicó (ver Tabla 2) especialmente por el incremento de universidades privadas que concentraban el $60.5 \%$ de la población estudiantil. En las 65 universidades privadas que venían funcionando formalmente en el Sistema Universitario Peruano, el 40\% de los alumnos de pre grado estudiaba en la ciudad de Lima, de éstos el 36\% trabajaba, el $92.4 \%$ estudiaba en la modalidad presencial y el $4.5 \%$ en la modalidad semi-presencial (Asamblea Nacional de Rectores e Instituto Nacional de Estadística e Informática, 2010). Posteriormente, según El Comercio (2016a) en su artículo Educación Total - Prepárate (2016), se observa que la tendencia en el incremento de la oferta universitaria se ha mantenido y actualmente en el país existen 142 universidades públicas y privadas, de las cuales 91 son públicas y 51 privadas, y de éstas últimas 47 están ubicadas en Lima (ver Tabla 2). En conjunto las universidades públicas y privadas tuvieron 1’060,078 
alumnos matriculados en el 2014, de los cuales el 69\% $(729,092)$ se matricularon en universidades privadas. Los egresados universitarios en general se distribuyen en $56.6 \%$ mujeres y $43.4 \%$ hombres, mientras que el $53.5 \%$ son egresados de universidades privadas. Del total de egresados que se encuentran laborando el $85.7 \%$ son dependientes, el $9.7 \%$ son independientes y el 3.7\% son empleadores.

Al cierre de esta investigación, la última información estadística publicada en la página web de SUNEDU al 28 de Diciembre del 2016, indica que los estudiantes matriculados en pre-grado para el año 2015 ascienden a 1'312,396, de los cuales el 25\% corresponde a universidades públicas y el 75\% a universidades privadas. Asimismo, se mantiene el total de 142 universidades, de las cuales el 36\% son públicas y el 64\% son privadas (ver Tabla 2) (Superintendencia Nacional de Educación Superior Universitaria - SUNEDU, 2016). Tabla 2

Universidades en Perú según Tipo de Universidad

\begin{tabular}{lccc}
\hline Tipo de Universidad & 1996 & 2010 & $2015-2016$ \\
\hline $\mathrm{N}^{\mathrm{o}}$ de Universidades & 57 & 100 & 142 \\
Universidades Privadas & $51 \%$ & $65 \%$ & $64 \%$ \\
Universidades Públicas & $49 \%$ & $35 \%$ & $36 \%$ \\
\hline
\end{tabular}

Nota. Tomado de II Censo Nacional Universitario 2010: Principales Resultados (p. 456), por Instituto Nacional de Estadística e Informática (INEI), 2011, Lima, Perú: INEI. Copyright 2011 por INEI; Educación Total - Prepárate, por El Comercio, 2016a; “Universidades," por la SUNEDU, 2016, Recuperado de https://www.sunedu.gob.pe/

Si bien es cierto en 1996 se abrió por primera vez en el Perú la modalidad de carreras universitarias para gente que trabaja, es en los últimos 6 años que las universidades privadas han desarrollado y fortalecido esta oferta educativa y actualmente son alrededor de 13 universidades las que ofrecen este tipo de programas, las que en conjunto suman unas 100 
carreras profesionales para los 2’576,000 jóvenes adultos de 21 a 35 años que existen en Lima Metropolitana. La demanda por estos programas se caracteriza por: (a) 25,000 adultos aproximadamente han decidido ingresar a la universidad después de haber sido parte del mundo laboral, (b) las carreras más demandadas están ligadas a las ramas de la Administración y la Ingeniería, (c) dentro de las razones para volver a estudiar se encuentra la posibilidad de poder emprender un negocio propio; y, (d) el 40.2\% de los jóvenes adultos eligen la universidad privada por su prestigio y el $12.8 \%$ la elige porque ofrece la carrera que desean estudiar (E1 Comercio, 2016b).

Según la página web de cada universidad, a la fecha la Universidad Peruana de Ciencias Aplicadas, Universidad Ricardo Palma, Universidad San Ignacio de Loyola, Universidad Alas Peruanas, Universidad Cesar Vallejo, Universidad Tecnológica del Perú, Universidad Norbert Wiener, Universidad Científica del Sur, Universidad Privada del Norte, Universidad Privada Telesup, Universidad Las Américas, Universidad Continental y la Universidad ESAN ofrecen diferentes carreras para este tipo de personas, bajo la modalidad presencial, semi-presencial y virtual; incluso algunas lo hacen al interior del país. De todas éstas universidades, la Universidad Peruana de Ciencias Aplicadas, la Universidad San Ignacio de Loyola y la Universidad Tecnológica del Perú tienen más de tres años de trayectoria y al menos una promoción egresada en éste tipo de programas; lo que les ha permitido ofrecer las carreras de Administración de Banca y Finanzas, Administración de Empresas, Administración de Negocios, Administración de Negocios y Finanzas, Administración de Negocios y Marketing, Administración de Recursos Humanos, Administración y Gerencia del Emprendimiento, Contabilidad, Contabilidad Financiera, Ingeniería Civil, Ingeniería de Redes y Comunicaciones, Ingeniería de Sistemas, Ingeniería de Sistemas e Informática, Ingeniería Empresarial, Ingeniería Empresarial y de Sistemas, Ingeniería Industrial, Marketing, Marketing y Gestión Comercial, Negocios Internacionales. 
Finalmente, considero importante mencionar algunos datos sobre la investigación científica en el país. Estamos entre los países de América Latina que menos invierten por estudiante y menos investigaciones científicas realizan, ya que empleamos el $0.1 \%$ del PBI en investigación, lo que nos ubica como el país de América Latina que menos gasta en este rubro, ya que por ejemplo Colombia se ha propuesto alcanzar el 1\% para el año 2018. Por otro lado, en el 2014 se promulgó la nueva Ley Universitaria 30220 que entre sus reformas más saltantes destacan: (a) la creación de la Superintendencia Nacional de Educación Superior Universitaria (SUNEDU); medida que cuenta con un 61\% de aprobación de la población (Ipsos Perú, 2016); y (b) se establecieron nuevos parámetros para impulsar la investigación al fijar que las universidades deben contar con al menos un $25 \%$ de profesores a tiempo completo con grado de maestría y doctorado (Paredes, 2016). Asimismo, la presidenta del Consejo Nacional de Ciencia, Tecnología e Innovación Tecnológica (CONCYTEC) afirma que en Perú tenemos 1,313 investigadores calificados versus los 20,000 de Chile (La República, 2016).

\subsection{Definición del Problema}

Existe literatura científica acerca de los factores que influyen en la intención de emprendimiento (Ullah et al., 2012), en los cuales la Teoría del Comportamiento Planificado de Ajzen (1991) es la que mejor predice el comportamiento (Armitage \& Conner, 2001; Kautonen et al., 2011; Van et al., 2008), estas investigaciones se han centrado en estudiantes universitarios, ya que serán la próxima fuerza laboral (Fernández et al., 2009). Sin embargo, no existe evidencia empírica sobre los factores que inciden en la intención de emprendimiento de estudiantes universitarios adultos con experiencia laboral ${ }^{1}$ en un país

\footnotetext{
${ }^{1}$ Las universidades que ofrecen estos programas, definen a los estudiantes universitarios adultos con experiencia laboral como hombres y mujeres que se desarrollaron en el campo laboral a base de experiencia y requieren de un título universitario, tienen más de 3 años de
} 
emergente; de aquí que, Ullah et al. (2012) sugieran estudios de emprendimiento en países en vías de desarrollo y Montiel, Marquez, Arambula y Ordoñez (2012) recomienden estudios comparativos entre estudiantes con diferentes ingresos económicos y Liñán et al. (2011) propongan estudios sobre la relación entre la formación universitaria y las intenciones de emprendimiento de los estudiantes, así como la aplicación de su teoría en muestras diversas de estudiantes. Además, el Perú es un país con altos índices de emprendimiento, la oferta y la demanda de carreras universitarias para personas con experiencia laboral se ha incrementado y los universitarios adultos con experiencia laboral son parte de la PEA que contribuye al desarrollo económico, mi tema de investigación es un tema relevante según la realidad peruana presentada en los Antecedentes del estudio.

Por lo tanto, desde el punto de vista de la investigación científica mi problemática es que las variables educación y marco legal no se han estudiado y yo las quiero estudiar; y, desde el punto de vista social estoy trabajando la intención de emprendimiento en universitarios adultos con experiencia laboral por ser un tema relevante para la sociedad y la economía del país; en consecuencia, se identifica la oportunidad de investigar la intención de emprendimiento de universitarios adultos con experiencia laboral en Lima Perú.

experiencia laboral y trabajan como dependientes; son mayores de 20 años de edad y residen en Lima y Callao. 


\subsection{Preguntas de Investigación}

Las preguntas de investigación son:

\section{Pregunta General 1.}

¿Cuáles son los factores motivacionales que inciden en la intención de emprendimiento de universitarios adultos con experiencia laboral?

\section{Preguntas Específicas asociadas a la Pregunta General 1.}

1. ¿Cómo incide la actitud hacia la conducta en la intención de emprendimiento de universitarios adultos con experiencia laboral?

2. ¿Cómo incide el control percibido de la conducta en la intención de emprendimiento de universitarios adultos con experiencia laboral?

Las preguntas específicas sobre la relación entre factores motivacionales son:

3. ¿Cómo incide la norma subjetiva en la actitud hacia la conducta de universitarios adultos con experiencia laboral?

4. ¿Cómo incide la norma subjetiva en el control percibido de la conducta de universitarios adultos con experiencia laboral?

\section{Pregunta General 2.}

¿Cuáles son los factores ambientales que inciden en la intención de emprendimiento de universitarios adultos con experiencia laboral?

\section{Preguntas Específicas asociadas a la Pregunta General 2.}

5. ¿Cómo incide la valoración cercana en la actitud hacia la conducta de universitarios adultos con experiencia laboral?

6. ¿Cómo incide la valoración cercana en la norma subjetiva de universitarios adultos con experiencia laboral?

7. ¿Cómo inciden las instituciones y normas legales en la norma subjetiva de universitarios adultos con experiencia laboral? 
8. ¿Cómo inciden las instituciones y normas legales en el control percibido de la conducta de universitarios adultos con experiencia laboral?

9. ¿Cómo incide la educación emprendedora en la norma subjetiva de universitarios adultos con experiencia laboral?

10. ¿Cómo incide la educación emprendedora en el control percibido de la conducta de universitarios adultos con experiencia laboral?

\subsection{Objetivos de la Investigación}

Los objetivos de la tesis son:

\section{Objetivo General 1.}

Identificar los factores motivacionales que inciden en la intención de emprendimiento de universitarios adultos con experiencia laboral.

\section{Objetivos Específicos asociados al Objetivo General 1.}

1. Identificar la incidencia de la actitud hacia la conducta en la intención de emprendimiento de universitarios adultos con experiencia laboral.

2. Identificar la incidencia del control percibido de la conducta en la intención de emprendimiento de universitarios adultos con experiencia laboral.

Los objetivos específicos sobre la relación entre los factores motivacionales son:

3. Identificar la incidencia de la norma subjetiva en la actitud hacia la conducta de universitarios adultos con experiencia laboral.

4. Identificar la incidencia de la norma subjetiva en el control percibido de la conducta de universitarios adultos con experiencia laboral.

\section{Objetivo General 2.}

Identificar los factores ambientales que inciden en la intención de emprendimiento de universitarios adultos con experiencia laboral. 


\section{Objetivos Específicos asociados al Objetivo General 2.}

5. Identificar la incidencia de la valoración cercana en la actitud hacia la conducta de universitarios adultos con experiencia laboral.

6. Identificar la incidencia de la valoración cercana en la norma subjetiva de universitarios adultos con experiencia laboral.

7. Identificar la incidencia de las instituciones y normas legales en la norma subjetiva de universitarios adultos con experiencia laboral.

8. Identificar la incidencia de las instituciones y normas legales en el control percibido de la conducta de universitarios adultos con experiencia laboral.

9. Identificar la incidencia de la educación emprendedora en la norma subjetiva de universitarios adultos con experiencia laboral.

10. Identificar la incidencia de la educación emprendedora en el control percibido de la conducta de universitarios adultos con experiencia laboral.

\subsection{Justificación}

Los resultados de esta investigación contribuirán a la cultura de emprendimiento en:

\section{Justificación teórica.}

Los resultados del estudio contribuyen a la literatura científica con un nuevo modelo de intención de emprendimiento que integra variables que no han sido analizadas en conjunto en los estudios previos. A la fecha, las investigaciones han utilizado como marco teórico la Teoría del Comportamiento Planificado de Ajzen (1991) o la similitud de los estudiantes con las características del emprendedor o la influencia de la familia o la influencia de los estudios universitarios o el Modelo de Intención de Emprendimiento de Liñán et al. (2011) el cual trata de integrar los factores motivacionales de la Teoría del Comportamiento Planificado de Ajzen (1991) con algunos factores ambientales. La presente investigación toma de la Teoría del Comportamiento Planificado de Ajzen (1991) la clasificación de factores motivacionales 
y del Modelo de Liñán et al. (2011) la clasificación de factores ambientales e integra las dimensiones de educación emprendedora e instituciones y normas legales como parte de la valoración social, con la finalidad de estudiar en conjunto las variables motivacionales y ambientales sobre las cuales los estudios recomiendan un análisis integral para determinar de manera más completa los factores que influyen en la intención de emprendimiento. Por lo tanto, la justificación teórica se sustenta en el nuevo modelo integral que plantea la presente investigación.

El nuevo modelo que se analizará en esta investigación puede ser utilizado para estudios similares y/o para estudios de tipo longitudinal. Dado que el modelo pretende identificar los factores motivacionales y ambientales que influyen en la intención de emprendimiento de universitarios adultos con experiencia laboral, puede también ser utilizado para analizar la intención de emprendimiento de universitarios de pre-grado regular y estudiantes de postgrado. Asimismo, los resultados de esta investigación pueden servir de punto de partida para estudios longitudinales que busquen medir si las intenciones de emprendimiento identificadas en los resultados de este estudio se materializaron en la formación de empresas. Por lo tanto, el modelo de este estudio puede contribuir a estudios posteriores en otros tipos de población y estudios longitudinales sobre la misma población de éste estudio.

\section{Justificación práctica.}

Los resultados del estudio podrían ser de utilidad para los estudiantes universitarios, las universidades y las instituciones públicas y privadas. Por un lado, los resultados sobre los factores motivacionales ayudarían a los estudiantes a conocer cuáles son las percepciones de deseabilidad y factibilidad que influyen en su intención de emprender; de modo que puedan realizar acciones que concretas orientadas a desarrollar una actitud emprendedora positiva; así como, los conocimientos y habilidades para crear una empresa. Por otro lado, los resultados sobre los factores ambientales podrían contribuir a que: (a) Las instituciones 
públicas y privadas realicen reformas legales que faciliten la creación de empresas; así como también, puedan ampliar la cantidad y mejorar la calidad de las instituciones que asesoran y financian la creación de empresas, (b) Las universidades puedan reforzar su malla curricular con cursos orientados a desarrollar capacidades empresariales; apliquen metodologías de enseñanza orientadas al desarrollo de habilidades de negocio; $y$, generen espacios promotores del emprendimiento a través de seminarios y charlas magistrales gratuitas. El rol que desempeñen las instituciones públicas y privadas y las universidades impactarán en la percepción de los estudiantes sobre la facilidad o dificultad de emprender; lo que a su vez impactará sobre la economía del país debido a la importancia del rol emprendedor.

\subsection{Limitaciones}

Esta investigación tuvo limitaciones en el acceso a las universidades debido a sus políticas de confidencialidad, lo que no permitió realizar una muestra probabilística en la UPC ni incluir a otras universidades. Por lo tanto, el estudio se realizó en las universidades USIL, UPC y UTP. En el caso de la USIL y UTP se tuvo acceso a todos los estudiantes y en la UPC fue un acceso limitado. 


\section{Capítulo II: Marco Teórico}

En este capítulo se explica, basado en diferentes autores, la definición conceptual y los modelos más utilizados sobre Intención de Emprendimiento. Posteriormente, se presenta el modelo de análisis propuesto y las hipótesis del estudio, basados en la revisión de la literatura.

\subsection{Definiciones Conceptuales}

El marco teórico se basa en los siguientes conceptos

\section{Emprendimiento.}

Rivera y Pizarro (2009) elaboran una recopilación de las definiciones sobre Emprendimiento de los autores más relevantes en el campo empresarial, las cuales se muestran en la Tabla 3.

Tabla 3

Concepto de Emprendimiento según Rivera y Pizarro (2009)

\begin{tabular}{ll}
\hline \multicolumn{1}{c}{ Autor } & \multicolumn{1}{c}{ Concepto de Emprendimiento } \\
\hline $\begin{array}{l}\text { Real Academia } \\
\text { Española }\end{array}$ & $\begin{array}{l}\text { Acometer y comenzar una obra, un negocio, un empeño, especialmente } \\
\text { si encierran dificultad o peligro y tomar el camino con resolución de } \\
\text { llegar a un punto. }\end{array}$ \\
Vesper, 1990 & $\begin{array}{l}\text { Se emprende a partir de disponer uno o varios de los siguientes ítems: } \\
\text { conocimiento técnico, producto o idea de servicio, contactos } \\
\text { personales, recursos físicos u órdenes de clientes. }\end{array}$ \\
Verin, 1982 & $\begin{array}{l}\text { La palabra emprendimiento se deriva del término francés entrepreneur, } \\
\text { que significa estar listo para tomar decisiones o para iniciar algo. }\end{array}$ \\
\hline
\end{tabular}

Nota. Adaptado de Características Emprendedoras de Egresados de Contador Auditor e Ingeniería en Administración de Empresas, por la Universidad Católica del Maule, 2009, Maule, Chile: Universidad Católica de Maule. Copyright 2009 por Universidad Católica de Maule.

Por su parte Ullah et al. (2012) enfoca el concepto de Emprendimiento como proceso estableciendo que: “Tradicionalmente se conceptualizó al Emprendimiento como el esfuerzo 
de una persona innovadora que logra materializar sus sueños en una empresa próspera (Collins et al, 1964). Mientras que en la actualidad implica un proceso que existe en las empresas de diferentes tamaños dependiente de los individuos. (Burgelman, 1983; Gartner, 1985; Kao, 1989; Miller, 1983; Wortman, 1987).”

Por su parte Gartner, Shaver, Gatewood, y Katz (1994), y a su vez, Kyrö y Carrier (2005) consideran que el Emprendimiento es un proceso que ocurre en el tiempo y que el primer paso en este proceso (a veces largo) es la intención de emprendimiento.

Adicionalmente, la decisión de convertirse en emprendedor es voluntaria y consciente (Krueger JR et al., 2000) por lo que es razonable analizar como se toma ésta decisión. La actividad empresarial puede ser motivada por diferentes aspiraciones personales y motivaciones como innovación, independencia y éxito financiero, las cuales a su vez pueden generar diferentes tipos de emprendedores, quienes formarán empresas para sustituir sus ingresos o para desarrollarlas (Carey et al., 2010). El rol del emprendedor es importante tanto en empresas nuevas como en las ya establecidas (Ullah et al., 2012). Desde una perspectiva dinámica, los emprendedores son agentes de cambio ya que el emprendimiento implica iniciar nuevos negocios, experimentar con nuevas técnicas, nuevas formas de producir, introducir nuevos productos o crear nuevos mercados (Wennekers, Uhlaner, \& Thurik, 2002). Finalmente, de acuerdo a las investigaciones realizadas por la Babson College la educación ayuda a los estudiantes a decidir si tienen el material adecuado para ser empresarios antes de embarcarse en carreras para los cuales pueden ser poco adecuados (Spies, 2011).

Por lo tanto, el término Emprendimiento en este estudio estará referido a que el estudiante crea una empresa de manera formal, con el objetivo de desarrollarla aplicando los conocimientos adquiridos durante su educación universitaria. 


\section{Intención de emprendimiento.}

Las intenciones capturan los factores motivacionales que influyen en el comportamiento ya que son indicadores que cuan fuerte la persona intenta, es decir, cuanto esfuerzo está planeando ejecutar para lograr el comportamiento deseado. Como regla general cuanto más fuerte es la intención, existe más probabilidad de ejecutar el comportamiento (Ajzen, 1991). Posteriormente, el mismo autor define la intención como la disposición de una persona a ejecutar un comportamiento.

Por su parte, Thompson (2009) define la intención de emprendimiento, desde el contexto empresarial, como el reconocimiento que hace una persona sobre la convicción que posee de intentar crear un nuevo negocio y conscientemente planifica realizarlo en algún momento en el futuro. Para (Krueger JR et al., 2000) las intenciones son el mejor predictor de cualquier conducta planeada, incluyendo el emprendimiento; así, el emprendimiento claramente representa una planificación y una intención de ejecutar un comportamiento (Bird, 1988; Katz \& Gartner, 1988).

Para Sánchez (2009), según la teoría del aprendizaje social de Bandura (1977), la mayor parte del comportamiento humano es aprendido mediante la observación de modelos que ejecutan el comportamiento en cuestión, siendo éste uno de los medios más poderosos para transmitir valores, actitudes y patrones de pensamiento y comportamiento (Sánchez, 2006). En el proceso de socialización del individuo, su entorno social le transmite normas, lenguaje, aspiraciones educativas y preferencias de carrera a través del aprendizaje social y el modelado (Bandura, 1977). En este contexto, la socialización emprendedora se refiere a las experiencias que preparan al individuo para elegir la opción de emprender (Dyer, 1994) en un proceso de aprendizaje a través del cual la persona adquiere y se familiariza con el conocimiento y destrezas necesarias para desempeñar el rol emprendedor. Por tanto, la socialización emprendedora es un conjunto de experiencias relacionadas con la realización 
exitosa de las tareas emprendedoras que pueden ser fácilmente establecidas a partir de la interacción con personas que poseen características emprendedoras que sirven como modelos de rol. Siguiendo la teoría de Bandura (1986), tales modelos dirigen la atención del individuo hacia el fenómeno empresarial, le inculcan los conocimientos y habilidades necesarios para crear una nueva empresa y activan, facilitan y proporcionan apoyo al surgimiento de comportamientos emprendedores, los individuos con más posibilidades de observar directamente a emprendedores serán más propensos a convertirse en emprendedores ellos mismos, puesto que experimentarán una mayor interiorización de los conocimientos y destrezas necesarios para crear una empresa y tendrán una percepción más positiva sobre la deseabilidad de convertirse en empresarios (Bygrave \& Miniti, 2000; Minniti \& Bygrave, 1999).

Por lo tanto, el término Intención de Emprendimiento en este estudio estará referido a la mejor forma de predecir si el estudiante se convertirá en Emprendedor.

\subsection{Modelos de Intención de Emprendimiento}

Los estudios de investigación científica sobre intención de emprendimiento han buscado identificar a través de diferentes modelos los factores personales y contextuales que influyen en la intención de emprender. Las teorías más relevantes en el área de emprendimiento son el evento emprendedor de Shapero (1984), la implementación de ideas emprendedoras de Bird (1988) y el modelo del potencial emprendedor de Krueger Jr. y Brazeal (1994); por otro lado, las teorías más utilizadas del área de la psicología social son: la teoría de acción razonada de Ajzen y Fishbein (1980), la teoría de autoeficacia de Bandura (1982) y la Teoría del comportamiento planificado de Ajzen (1991) y el modelo de intención de emprendimiento de Liñán et al. (2011). De todas éstas teorías, la teoría del comportamiento planificado de Ajzen (1991) es la que mejor predice los factores motivacionales que influyen en la intención de emprendimiento (Armitage \& Conner, 2001; Kautonen et al., 2011; Krueger JR et al., 2000); 
y el modelo de intención de emprendimiento de Liñán et al. (2011) es el que integra algunos factores ambientales a la teoría del comportamiento planificado de Ajzen (1991) logrando con ello un modelo más completo, ya que permite identificar los factores motivacionales y ambientales que influyen en la intención de emprendimiento. Es por ello que éstas teorías se explicarán en los siguientes puntos.

\subsubsection{La teoría del comportamiento planificado de Ajzen.}

La teoría del comportamiento planificado es una extensión de la teoría de la acción razonada (Ajzen, 1991), la cual explica la intención a través de las variables la actitud hacia la conducta y la norma subjetiva (ver Figura 2). La teoría del comportamiento planificado busca superar las limitaciones de la teoría de acción razonada en lo concerniente a los comportamientos sobre los cuales las personas tienen control volitivo incompleto (Ajzen, 1991). En tal sentido explica la intención a través de las mismas variables de la teoría de acción razonada y agrega la variable control percibido de la conducta (ver Figura 3).

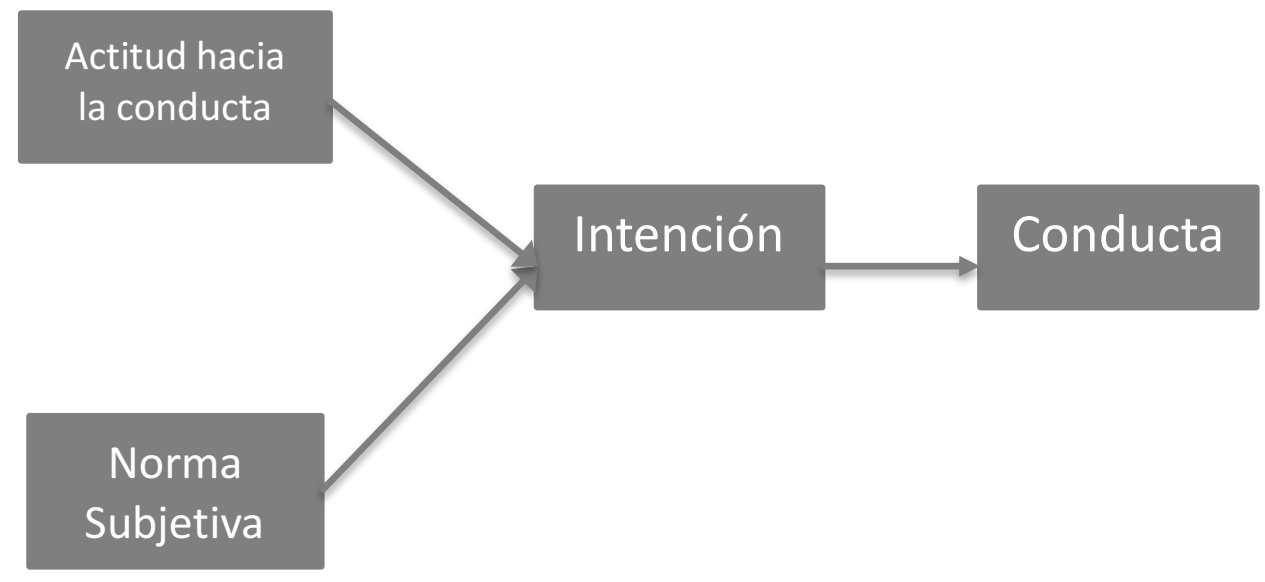

Figura 2. Teoría de acción razonada. Tomado de Understanding Attitudes and Predicting Social Behavior (p. 8), por I. Ajzen \& M. Fishbein, 1980, Englewood Cliffs, NJ: Prentice-Hall. Copyright 1980 por Prentice-Hall.

Según Ajzen (1991), el factor central de la teoría del comportamiento planificado es la intención del individuo en realizar un comportamiento dado, por lo tanto, cuanto más fuerte es la intención se tiene mayor probabilidad de ejecutar el comportamiento. No obstante, para 
que la intención se pueda materializar en un comportamiento es necesario que dicho comportamiento se encuentre bajo control volitivo. Tal como se puede observar en la Figura 4, según la teoría del comportamiento planificado, la intención del individuo está basada en la actitud hacia la conducta, la norma subjetiva y el control percibido de la conducta; así como, en las relaciones de estas variables entre si, con la intención y con el comportamiento.

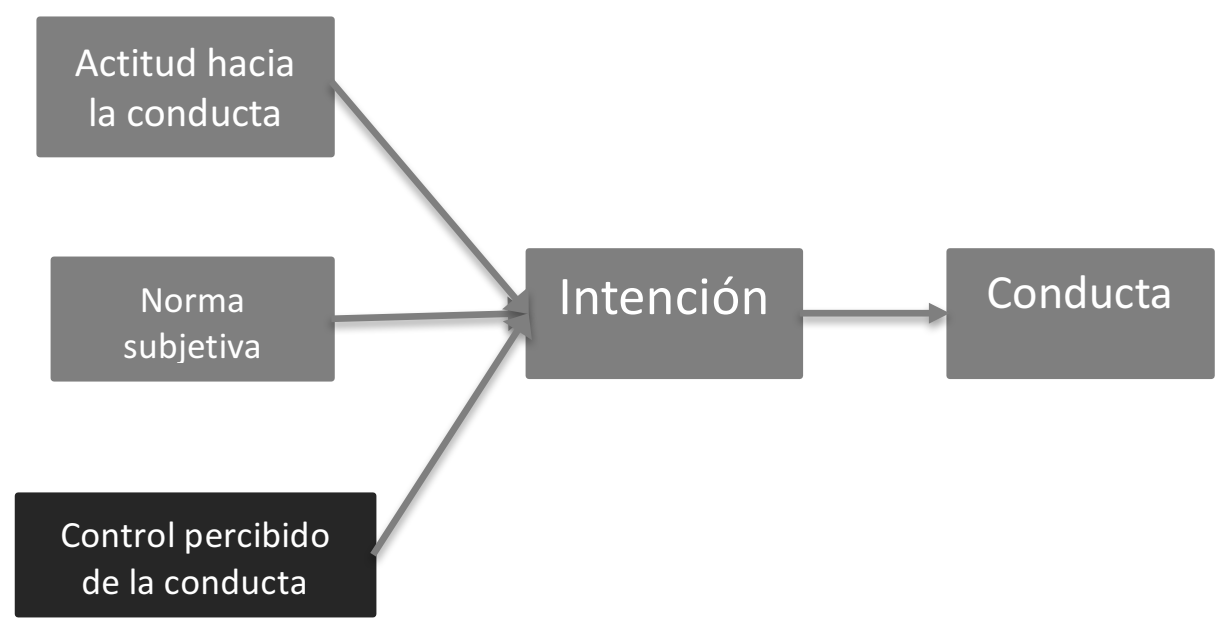

Figura 3. Teoría del comportamiento planificado. Adaptado de "The Theory of Planned Behavior," por I. Ajzen, 1991, Organizational Behavior and Human Decision Process, 50 (2), p. 182. Copyright 1991 por University of Massachusetts at Amherst.

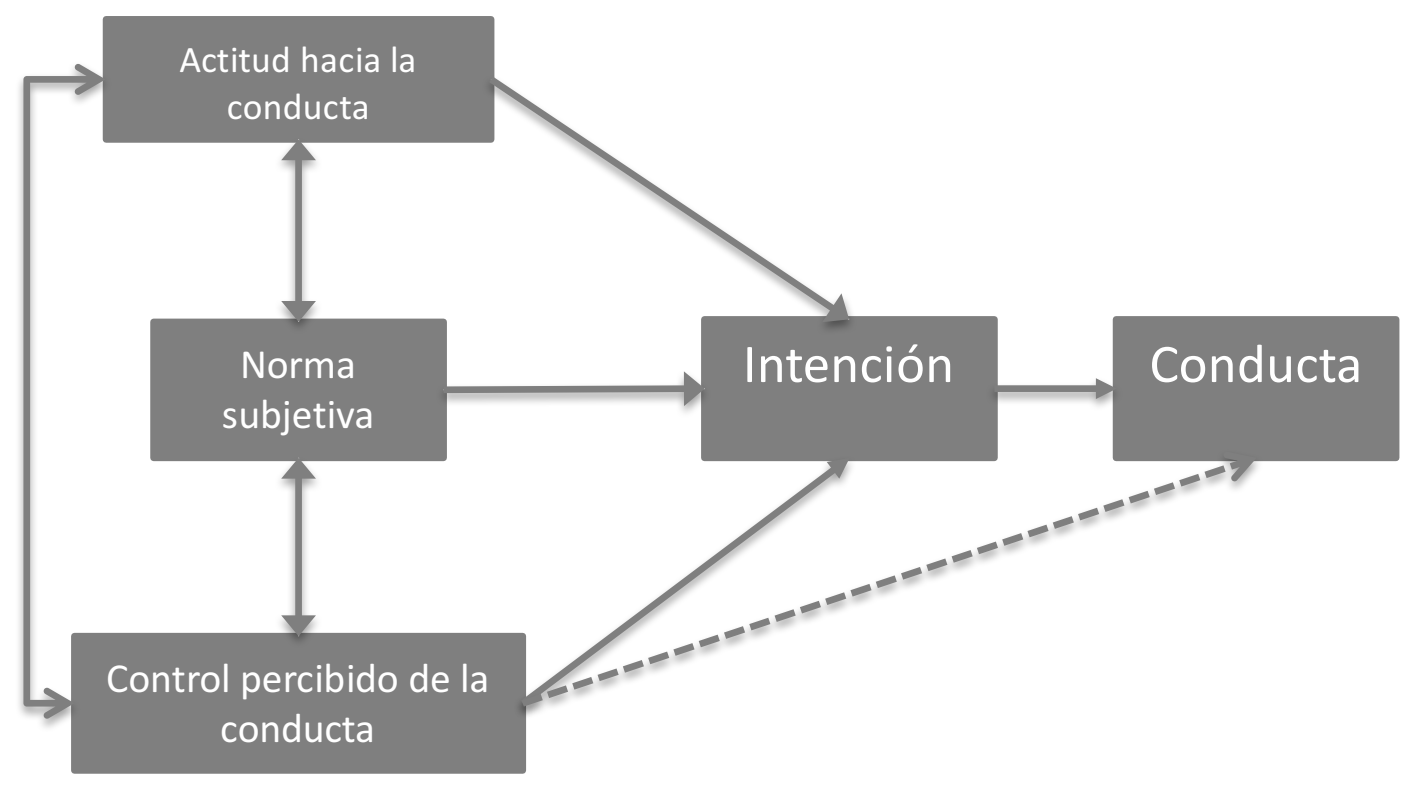

Figura 4. Teoría del comportamiento planificado de Ajzen. Adaptado de "The Theory of Planned Behavior," por I. Ajzen, 1991, Organizational Behavior and Human Decision Process, 50 (2), p. 182. Copyright 1991 por University of Massachusetts at Amherst. 
Según Ajzen (1991) las tres variables de la teoría del comportamiento planificado se pueden definir como: (a) la actitud hacia la conducta es el grado en que una persona tiene una evaluación favorable o desfavorable hacia un comportamiento dado, (b) la norma subjetiva son factores sociales referido a la presión social percibida para ejecutar o no un comportamiento dado, y (c) el control percibido de la conducta es la percepción de facilidad o dificultad en ejecutar un comportamiento y se asume que refleja tanto experiencias pasadas como impedimentos previstos y obstáculos.

La eficacia de la teoría del comportamiento planificado de Ajzen (1991) ha sido analizada a través del tiempo en la literatura del emprendimiento con resultados favorables. Los estudios sugieren que la actitud hacia la conducta, la norma subjetiva y el control percibido de la conducta explican entre el 30\% - 45\% de la variabilidad en las intenciones (Autio, Keeley, Klofsten, Parker, \& Hay, 2001; Kolvereid, 1996; Krueger JR et al., 2000; Liñán \& Chen, 2009; Van et al., 2008). Por su parte, Armitage y Conner (2001) en su estudio de meta análisis sobre investigaciones basados en la teoría del comportamiento planificado de Ajzen (1991) reportan una correlación de .47 entre la intención y el comportamiento. Por lo tanto, las investigaciones han comprobado la eficacia de la teoría del comportamiento planificado de Ajzen (1991), de aquí que se decide utilizar esta teoría como parte del modelo de análisis propuesto en este estudio.

\subsubsection{El modelo de intención de emprendimiento de Liñán, Urbano y Guerrero.}

El modelo de intención de emprendimiento de Liñán et al. (2011) se basa en los factores motivacionales de la teoría del comportamiento planificado de Ajzen (1991), algunas proposiciones de la teoría Institucional económica y algunas influencias de la teoría del Capital social y la adecúa para medir la intención de emprendimiento a través de factores motivacionales y factores ambientales (ver Figura 5), logrando así recoger lo mejor de los estudios mencionados en el acápite antecedentes del planteamiento del problema. 


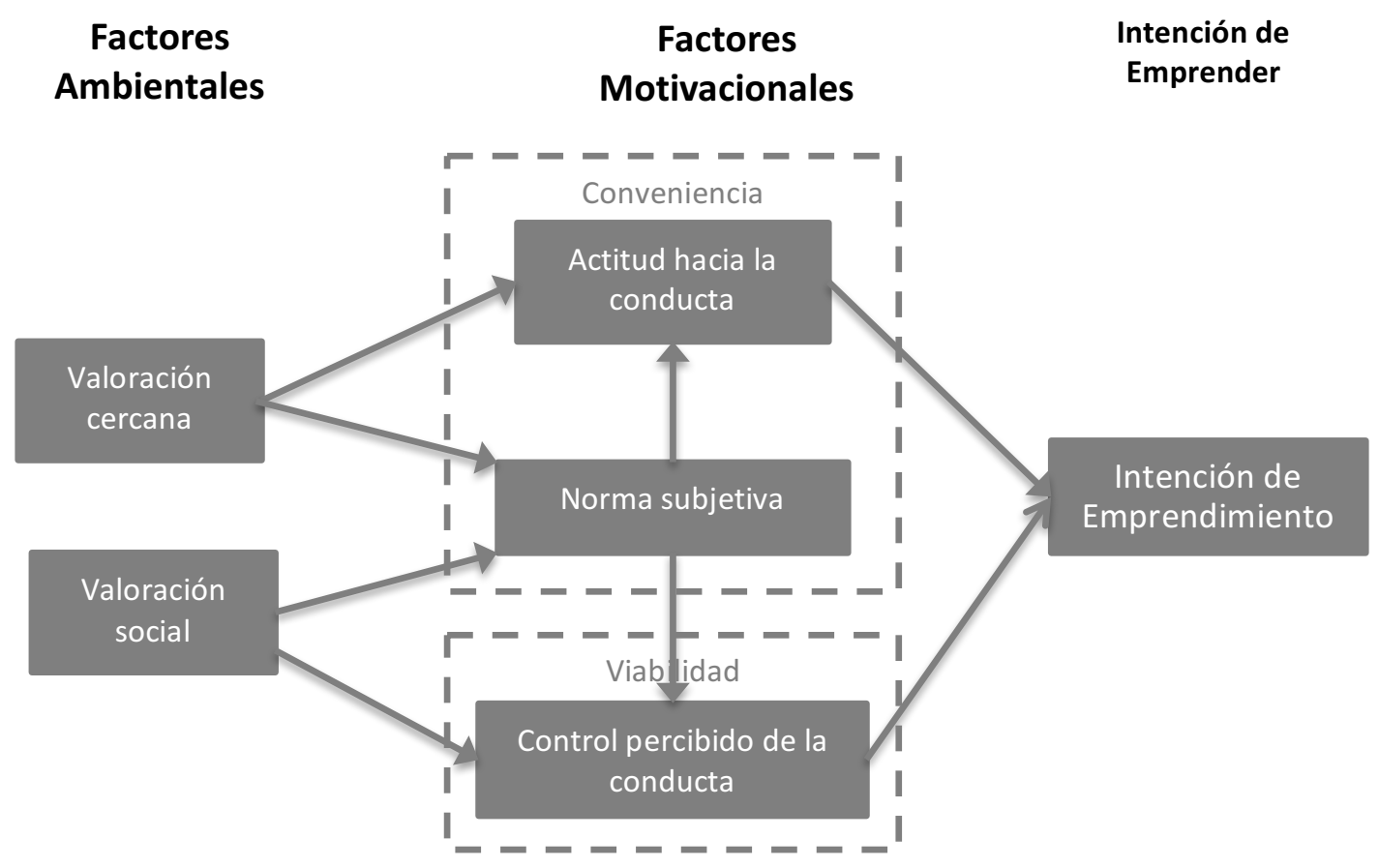

Figura 5. Modelo de intención de emprendimiento según Liñán, Urbano y Guerrero. Adaptado de "Regional Variations in Entrepreneurial Cognitions: Start-up Intentions of University Students in Spain,” por F. Liñán, D. Urbano, y M. Guerrero, 2011, Entrepreneurship \& Regional Development, 23(3-4), p. 193. Copyright 2011 por Universidad de Sevilla y Universidad de Barcelona.

En el modelo de Liñán et al. (2011) las variables que comprenden los factores motivacionales mantienen los conceptos establecidos en la teoría del comportamiento planificado de Ajzen (1991) y son aplicadas a la intención de emprender. En tal sentido, la variable actitud hacia la conducta se refiere a lo atractivo de la conducta propuesta o grado bajo el cual un individuo mantiene una valoración positiva o negativa hacia ser emprendedor (Ajzen, 1991, 2002). La segunda variable es el control percibido de la conducta, esto es, la facilidad o dificultad percibida en ser emprendedor (Ajzen, 1991). Esta variable es importante por su capacidad predictiva, ya que refleja la percepción del individuo si podrá controlar esa conducta (Ajzen, 2002). Respecto a la variable norma subjetiva, estas miden la presión social percibida de la familia, amigos u otras personas cercanas (Ajzen, 1991) para desempeñar una conducta empresarial, ya que estas personas pudieran aprobar o no la decisión de ser emprendedor (Ajzen, 2011). Respecto a las relaciones entre las variables, este modelo no 
contempla la relación bidireccional entre la actitud hacia la conducta y la norma subjetiva, así como, entre la norma subjetiva y el control percibido de la conducta; además tampoco considera la relación directa entre la norma subjetiva y la intención.

Sobre los factores ambientales, según la teoría del aprendizaje social, los factores ambientales tienen una gran influencia sobre procesos cognitivos y de aprendizaje (Bandura, 1997). El enfoque estará en el análisis del rol que juega un factor informal especifico: la valoración del emprendimiento en el medio ambiente del individuo. Estos factores informales institucionales reflejaran las dinámicas sociales del emprendimiento, donde el nivel de actividad de este dentro de una comunidad es una consecuencia no intencional de muchas opciones individuales hacia el emprendimiento (Bygrave \& Miniti, 2000). Este capital social cognitivo (CSC) es derivado de procesos mentales y de sus ideas resultantes, reforzadas por la cultura e ideología, generando valores, actitudes, creencias y confianza (Nahapiet \& Ghoshal, 1998), y no ha recibido mucha atención (Liñán et al., 2011). Al juntar el CSC, basado en fuertes lazos con familia y amigos (valoración cercana), genera diferentes valores, confianza, lenguajes y narrativas compartidas (Liñán et al., 2011). Por otra parte, la valoración social del emprendimiento toma un rol critico en determinar la conducta empresarial (Zahra, Jennings, \& Kuratko, 1999). El sistema de valores de un grupo o sociedad forma el desarrollo de ciertos rasgos y habilidades, modelando las percepciones normativas y de habilidad hacia la actividad empresarial (Thomas \& Mueller, 2000).

La aplicabilidad del modelo de intención de emprendimiento de Liñán et al. (2011), que adiciona las variables valoración cercana y valoración social como factores ambientales que influyen en la intención de emprender, ha sido comprobada en el tiempo por diferentes estudios (Abdullah, F., \& Abu Samah, B., 2014; Fayolle \& Liñán, 2014; Malebana, 2014), de aquí que, se decide utilizar la clasificación de valoración cercana y valoración social que este modelo establece, como parte del modelo de análisis propuesto en este estudio. 


\subsection{Modelo Propuesto.}

\section{Definición de los constructos propuestos en el modelo.}

\section{Educación emprendedora.}

Muchos estudios sobre intención de emprendimiento han analizado la variable educación empresarial y sugieren que tiene una influencia importante por lo que debe ser considerada en los modelos que buscan identificar los factores que influyen en la intención de emprendimiento. De acuerdo a los estudios realizados por la Babson College existe suficiente evidencia para afirmar que la educación influye de manera positiva sobre la intención de convertirse en emprendedores, ya sea al finalizar los estudios o tiempo después (Spies, 2011). Los estudios sugieren que puede existir una importante conexión positiva entre la educación y entrenamiento empresarial con una variedad de activos de capital humano relativos al espíritu empresarial y los resultados de emprendimiento (Kuratko, 2005; Pittaway \& Cope, 2007; Weaver, Dickson, \& Solomon, 2006), por ejemplo, los individuos que han llevado cursos de emprendimiento a nivel universitario tienen mayores intenciones de crear una empresa que aquellos que no lo llevaron (Galloway \& Brown, 2002), o los individuos que han tenido entrenamiento o educación en emprendimiento son más propensos a crear una empresa que aquellos que no lo tuvieron (Kolvereid \& Moen, 1997), o también podrían tener más éxito en la identificación de oportunidades que aquellos que no recibieron educación y/o entrenamiento en emprendimiento (DeTienne \& Chandler, 2004). Adicionalmente, los mismos autores del modelo de intención de emprendimiento sugieren incluir la variable educación para identificar la relación entre la cultura universitaria y las intenciones de emprendimiento de los estudiantes universitarios (Liñán et al., 2011). Por lo tanto, investigadores en emprendimiento, educadores y profesionales son algunos de los interesados en identificar la influencia de la variable educación como un factor ambiental que en conjunto con otras variables ambientales y motivacionales influye en las intenciones de 
emprendimiento de estudiantes universitarios, de aquí que, esta variable es considerada en el modelo de análisis propuesto en éste estudio.

\section{Instituciones y normas legales.}

Muchos estudios sobre intención de emprendimiento sugieren que las condiciones económicas, socio-políticas y legales de cada país influyen en la percepción de las personas sobre la facilidad o dificultad de emprender. Según Sánchez (2009) las tasas de creación de nuevas empresas varían significativamente entre diferentes países, o incluso entre diferentes regiones dentro de una misma nación, es por ello que a menudo se argumenta que ciertas partes del mundo son más emprendedoras que otras. El mismo autor también sugiere que la relación entre la actividad emprendedora de un país y su infraestructura económica no es siempre positiva y lineal, de modo que las diferencias pueden persistir a pesar de que las circunstancias políticas y económicas de distintos países sean similares. Adicionalmente, Bygrave y Miniti (2000) así como Minniti y Bygrave (1999) argumentan la existencia de interdependencia entre la decisión de emprender a nivel individual y la cantidad de actividad emprendedora local; sostienen que la existencia de altas tasas de creación de nuevas empresas en una determinada región favorece la concentración emprendedora en dicho territorio, lo que se convierte en un importante factor capaz de influir sobre la decisión de otros individuos de convertirse en emprendedores. Así, según los autores, las tasas de actividad emprendedora registradas en una región en un determinado periodo de tiempo se convierten en predictivas de las tasas de actividad emprendedora futuras, en interdependencia con otros factores económicos y políticos. Por lo tanto, investigadores en emprendimiento, estado y funcionarios públicos y privados son algunos de los interesados en identificar la influencia de las políticas públicas como un factor ambiental que en conjunto con otras variables ambientales y motivacionales influye en las intenciones de emprendimiento de estudiantes 
universitarios, de aquí que, esta variable es considerada en el modelo de análisis propuesto en éste estudio.

\section{Modelo Propuesto.}

Como resultado de todo el análisis teórico previo, se propone para el desarrollo de este estudio un modelo de análisis teórico o particular para identificar los factores que influyen en la intención de emprendimiento de universitarios adultos con experiencia laboral. Este modelo toma como base los factores motivacionales establecidos en la teoría del comportamiento planificado de Ajzen (1991) a través de la actitud hacia la conducta, la norma subjetiva y el control percibido de la conducta, y mantiene las relaciones entre variables establecidas por esta teoría; adicionalmente, toma como base los factores ambientales establecidos en el modelo de intención de emprendimiento de Liñán et al. (2011), a través de la valoración cercana y la valoración social. Sobre este último constructo, el modelo de análisis propone considerar las dimensiones educación emprendedora e instituciones y normas legales como parte de la valoración social (ver Figura 6).

Para este estudio la dimensión educación emprendedora comprende: (a) los cursos que reciben los estudiantes universitarios con experiencia laboral a lo largo de los años de estudio, específicamente sobre aquellos referidos a desarrollar conocimientos y competencias emprendedoras; (b) la metodología de enseñanza en lo referido a guiarlos hacia el emprendimiento; (c) las actividades complementarias que realizan las universidades para fomentar el emprendimiento; y (d) la cultura de emprendimiento de la universidad (Bae, Qian, Miao, \& Fiet, 2014; DeTienne \& Chandler, 2004; Fayolle \& Liñán, 2014; Galloway \& Brown, 2002; Kuratko, 2005; Liñán, 2004;Malebana, 2014; Mat, Maat, \& Mohd, 2015; Nabi, Walmsley, Liñán, Akhtar, \& Neame, 2016; Nabi, Liñán, Krueger, Fayolle, \& Walmsley, 2016; Pittaway \& Cope, 2007; Weaver et al., 2006; Yusoff, Zainol, \& Ibrahim, 2015). 
Para este estudio la dimensión instituciones y normas legales comprende: (a) el acceso a instituciones de asesoría y financiamiento para la creación de empresas, (b) un marco legal favorable hacia el emprendimiento, y (c) la experiencia de contacto con instituciones que promueven el emprendimiento ( Abdullah \& Samah, 2013; Bygrave \& Miniti, 2000;

Cumplido \& Liñán, 2006; Fayolle \& Liñán, 2014; Fernández-Serrano \& Liñán, 2014; Lee, Wong, Foo, \& Leung, 2011; Liñán, Jaén, \& Ortega, 2015; Liñán \& Santos, 2007; Liñán et al., 2009; Shinnar, Giacomin, \& Janssen, 2012).

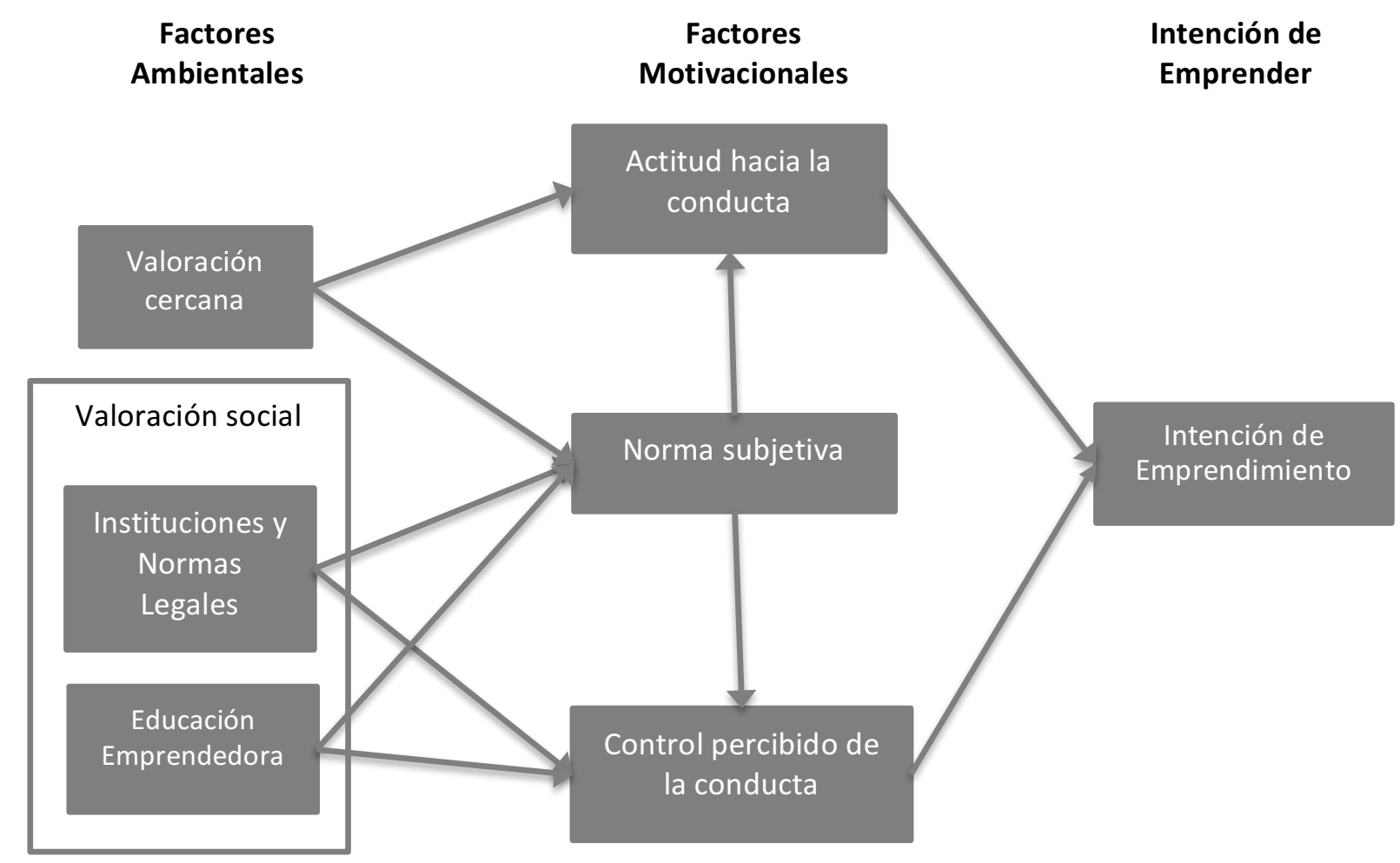

Figura 6. Modelo de análisis teórico o particular propuesto. Adaptado de la Teoría del Comportamiento Planificado de Ajzen (1991) y el Modelo de Intención de Emprendimiento de Liñán, Urbano y Guerrero (2011).

Finalmente, luego de la revisión bibliográfica la construcción de los constructos del Modelo de Análisis Teórico o Particular propuesto se resume en la Tabla 4. 
Intención de Emprendimiento

Intención de Emprendimiento
Certeza y Grado de esfuerzo

Grado de esfuerzo
El individuo reconoce con certeza que tiene la intención de establecer un nuevo negocio y ha previsto conscientemente hacerlo en algún momento en el futuro.

La escalera empresarial distingue entre diferentes grados de esfuerzo que el individuo ha invertido en el proceso de creación de una empresa.

No son simplemente preguntas de "si o no"; sino que también, una cuestión de rangos de "muy poco" a "muy alto".

(Ajzen, 1991; Armitage \& Conner, 2001; Autio, Keeley, Klofsten, Parker, \& Hay, 2001; Kautonen et al., 2011; Kolvereid, 1996; Krueger Jr et al., 2000; Liñán, 2004; Liñán \& Chen, 2009; Van Gelderen et al., 2008)

¿Qué tan probab inicie un negocic

Grado de valoración positiva o negativa de convertirse en un emprendedor. Incluye Valoración emocional aspectos emocionales (me gustaría, es atractivo) y racionales (tiene ventajas). Se espera que la intención de emprender de un estudiante esté asociada positivamente con las creencias de comportamiento sobre esta intención de emprender.

Actitud hacia la conducta (AHC) - Creencias de comportamiento

Valoración racional

Hipótesis ejemplo: La intención de emprender tiene una relación positiva con la creencia de comportamiento del estudiante.

(Ajzen, 1991; Armitage \& Conner, 2001; Autio, Keeley, Klofsten, Parker, \& Hay, 2001 Kautonen et al., 2011; Kolvereid, 1996; Krueger Jr et al., 2000; Liñán, 2004; Liñán \& Chen, 2009; Van Gelderen et al., 2008)
¿ Abrir un negoc es atractivo par
Aprobación de personas cercanas

Normas subjetivas (NS) - Creencias normativas

Factores Motivacionales Importancia de la
aprobación
Facilidad / Dificultad

Control percibido de la conducta (CPB) - Creencias de control
Capital social:

Valoración cercana (VC)
Control / Sentir que se puede
Mide la percepción de presión social que se tiene para ejecutar o no un comportamiento emprendedor. Específicamente está referido a la percepción de que "personas cercanas" aprueben la decisión de convertirse en emprendedor.

Ser empresario es probable que esté influenciado por las opiniones y valores de las personas cercanas.

Se espera una asociación entre las intenciones de los estudiantes para poner en marcha un negocio y las percepciones acerca de las actitudes de los individuos, grupos y redes, tales como la familia, amigos, compañeros y otras personas importantes.

Hipótesis ejemplo: La intención de emprender tiene una relación positiva con la creencia normativa del estudiante.

(Ajzen, 1991; Armitage \& Conner, 2001; Autio, Keeley, Klofsten, Parker, \& Hay, 2001; Kautonen et al., 2011; Kolvereid, 1996; Krueger Jr et al., 2000; Liñán, 2004; Liñán \& Chen, 2009; Van Gelderen et al., 2008)

Percepción de facilidad o dificultad de convertirse en emprendedor.

Aplicada al contexto de la creación de empresas, son el grado en que una persona siente que puede controlar el éxito de poner en marcha un nuevo negocio. Este factor es similar a Bandura (1986) el concepto de auto-eficacia (Krueger et al., 2000). De acuerdo con este punto de vista, nuestras intenciones se ven afectados no sólo por el deseo de iniciar un negocio, sino también por el hecho de que sentimos que podemos iniciar un negocio. Al igual que la auto-eficacia, este factor es, en parte, influenciada por nuestras experiencias pasadas, que influyen en la facilidad o dificultad percibida de tener éxito en iniciar una nueva empresa.

Un emprendedor potencial puede estar ansioso de empezar un negocio nuevo porque siente que tiene la visión de negocio y los fondos necesarios. Por el contrario la intención de emprender puede ser baja para una persona que tiene mucha experiencia pero carece de la percepción de tiempo necesario para hacer exitoso un nuevo negocio.

Hipótesis ejemplo: La intención de emprender tiene una relación positiva con la creencia de control.

(Ajzen, 1991; Armitage \& Conner, 2001; Autio, Keeley, Klofsten, Parker, \& Hay, 2001; Kautonen et al., 2011; Kolvereid, 1996; Krueger Jr et al., 2000; Liñán, 2004; Liñán \& Chen, 2009; Van Gelderen et al., 2008)
¿Si inicia un $\mathrm{n}$ propio, contarí respaldo de las que más le im (familiares, ami Y ¿Qué importar para Ud. lo que ellos?
¿Ud. Cree que puede desarrol habilidade conocimientos $\mathrm{n}$ para iniciar un 1 con éxito
Mide la influencia positiva o negativa que ejercen la familia, los amigos y compañeros sobre: a) sus creencias emocionales y racionales sobre emprender, y b) sus creencias referidas al respaldo que le puede proporcionar su propio entorno. También mide la influencia positiva o negativa sobre el conocimiento que pueda tener el estudiante sobre casos de emprendimiento en su entorno cercano.

(Ajzen, 1991; Liñán, 2004; Liñán \& Chen, 2009; Liñán, Urbano \& Guerrero, 2011)
¿La valoraciór ambiente cer favorece la act emprended 


\subsection{Hipótesis de Investigación}

Las hipótesis específicas de la tesis se aprecian en la Figura 7 y son las siguientes:

\section{Hipótesis General 1.}

Los factores motivacionales tienen un impacto positivo en la intención de emprendimiento de universitarios adultos con experiencia laboral.

\section{Hipótesis Específicas asociadas a la Hipótesis General 1.}

H1a. La actitud hacia la conducta tiene un impacto positivo en la intención de emprendimiento de universitarios adultos con experiencia laboral.

H1b. El control percibido de la conducta tiene un impacto positivo en la intención de emprendimiento de universitarios adultos con experiencia laboral.

H2a. La norma subjetiva tiene un impacto positivo en la actitud hacia la conducta de universitarios adultos con experiencia laboral.

H2b. La norma subjetiva tiene un impacto positivo en el control percibido de la conducta de universitarios adultos con experiencia laboral.

\section{Hipótesis General 2.}

Los factores ambientales tienen un impacto positivo en la intención de emprendimiento de universitarios adultos con experiencia laboral.

\section{Hipótesis Específicas asociadas a la Hipótesis General 2.}

H3a. La valoración cercana tiene un impacto positivo en la actitud hacia la conducta de universitarios adultos con experiencia laboral.

H3b. La valoración cercana tiene un impacto positivo en la norma subjetiva de universitarios adultos con experiencia laboral.

H3c. Las instituciones y normas legales tienen un impacto positivo en la norma subjetiva de universitarios adultos con experiencia laboral. 
H3d. Las instituciones y normas legales tienen un impacto positivo en el control percibido de la conducta de universitarios adultos con experiencia laboral.

H3e. La educación emprendedora tiene un impacto positivo en la norma subjetiva de universitarios adultos con experiencia laboral.

H3f. La educación emprendedora tiene un impacto positivo en el control percibido de la conducta de universitarios adultos con experiencia laboral.

Factores

Ambientales
Factores

Motivacionales

\section{Actitud hacia la}

conducta

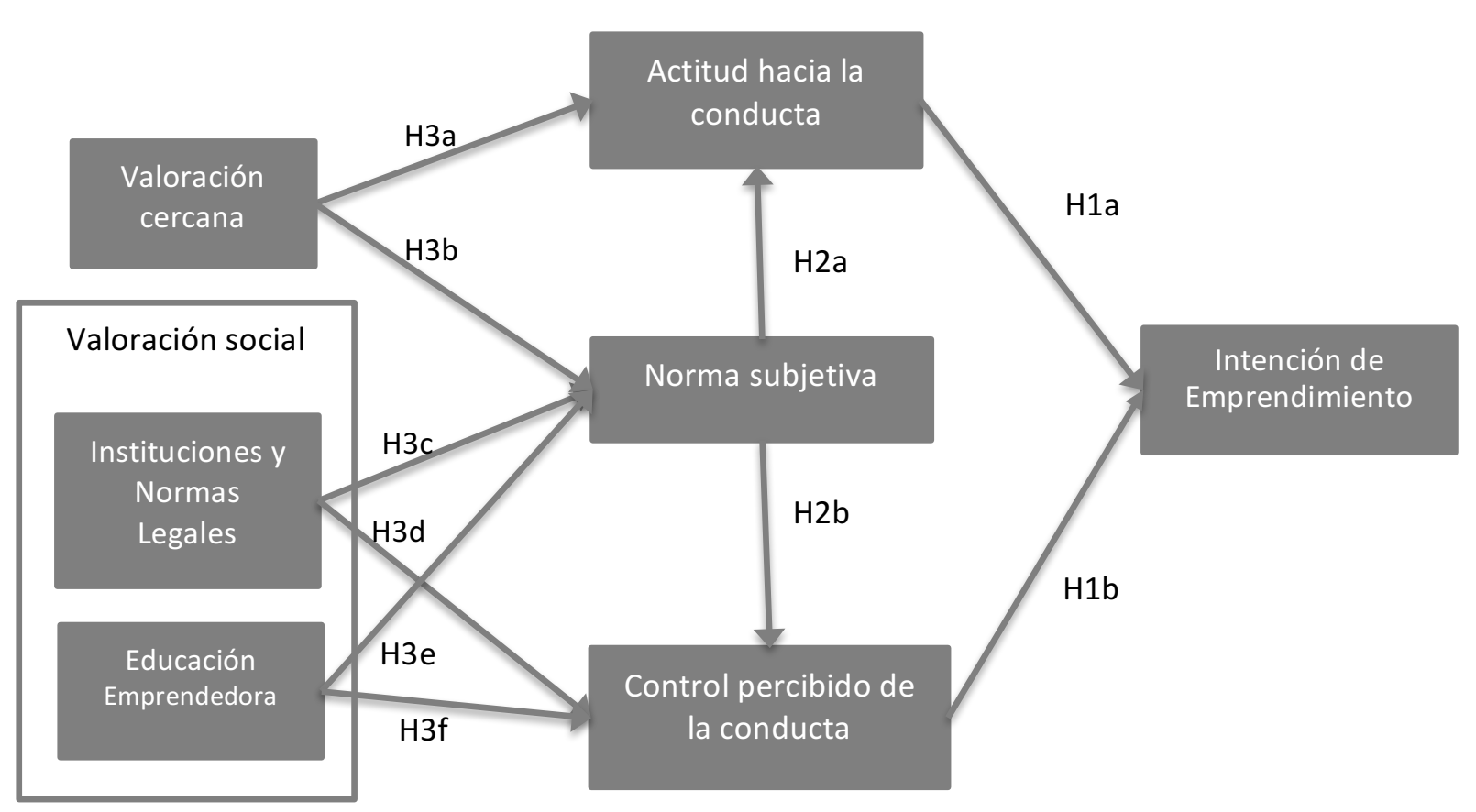

Intención de Emprender

Figura 7. Modelo de análisis teórico o particular propuesto con las hipótesis de estudio. Adaptado de la Teoría del Comportamiento Planificado de Ajzen (1991) y el Modelo de Intención de Emprendimiento de Liñán, Urbano y Guerrero (2011). 


\section{Capítulo III: Método de Investigación}

En este capítulo se aborda el método seguido en la investigación, para lo cual se presenta la naturaleza y el diseño del estudio, el proceso de muestreo y la recolección de datos. Finalmente se desarrolla el procesamiento y análisis de datos donde se explica los métodos estadísticos utilizados.

\subsection{Naturaleza de la Investigación}

La investigación se desarrolló bajo el paradigma post-positivista con un enfoque cuantitativo para tratar de identificar factores relacionados entre sí. En este sentido, el propósito fue causal explicativo (Liñán et al., 2011) ya que buscó explicar la relación entre los factores motivacionales y ambientales con la intención de emprendimiento de estudiantes adultos de las universidades privadas de Lima Perú.

Durante la investigación se utilizó la lógica deductiva, es decir, de lo general a lo específico (Nunnally, 1978). La investigación fue aplicada ya que además de generar conocimiento como tal, la investigación se orientó principalmente a proporcionar un modelo integrador que permitió identificar los factores que inciden en la intención de emprendimiento, cuyo resultado puede ser utilizado por los estudiantes universitarios con experiencia laboral para mejorar sus estrategias de emprendimiento; así como, a las universidades y entidades públicas y privadas para desarrollar políticas de emprendimiento en sus respectivos ámbitos de influencia.

\subsection{Diseño de Investigación}

Se diseñó e implementó una investigación no experimental cuantitativa (Chandler \& Lyon, 2001) porque: (a) no se manipularon variables, (b) la literatura sugiere que es apropiada para métodos de análisis estadísticos, y (c) este tipo de diseño de investigación ha sido utilizado para explicar los factores que inciden en la intención de emprendimiento de estudiantes de institutos, universidades y maestrías de diferentes carreras (Ahmed et al., 
2011; Gelard, 2011; Keat et al., 2011; Krueger JR et al., 2000; Ismail et al., 2009; Liñán et al., 2011; Lu, Wang, \& Millington, 2010; Nabi \& Holden, 2008; Nishantha, 2009; Segal et al., 2005; Tong, Tong, \& Loy, 2011).

El horizonte de análisis fue transversal, ya que los datos se obtuvieron en un momento único del tiempo. La técnica utilizada para recolectar los datos fue la encuesta, la cual tuvo como objetivo obtener información primaria para identificar los factores que inciden en la intención de emprendimiento.

\subsection{Proceso de Muestreo}

\subsubsection{Población.}

La población de la investigación estuvo conformada por los estudiantes adultos con experiencia laboral que cursaban el último año de estudios, es decir, se encontraban estudiando entre el séptimo y décimo ciclo, en la modalidad presencial, semi presencial y virtual, de todas las carreras de las facultades de Administración e Ingeniería, en los Programas de Carrera para Personas con Experiencia Laboral (CPEL) de la Universidad San Ignacio de Loyola (USIL), Profesionalización para Ejecutivos (PPE) de la Universidad Tecnológica del Perú (UTP); y, Especialización Profesional para Ejecutivos (EPE) de la Universidad Privada de Ciencias Aplicadas (UPC), las cuales tienen más de tres años de trayectoria y al menos una promoción egresada en este tipo de programas. Los estudiantes universitarios son hombres y mujeres que se desarrollaron en el campo laboral a base de experiencia y requieren de un título universitario, tienen más de 3 años de experiencia laboral y trabajan como dependientes; son mayores de 20 años de edad y residen en Lima y Callao.

Criterio de exclusión: La población no comprende a los estudiantes que sean propietarios de empresas.

En ese sentido, la población que cumplió con los criterios de segmentación ascendió a 4,429 alumnos matriculados en el último ciclo académico 2016, que va de setiembre a 
diciembre del 2016 (ver Tabla 5) según reportes internos de personal que trabaja en dichas instituciones, ya que no existen registros públicos disponibles de la cantidad de universitarios en programas para personas con experiencia laboral en cada una de las universidades elegidas.

Tabla 5

Cantidad de Alumnos Matriculados en el Último Ciclo Académico 2016

\begin{tabular}{ccccc}
\hline & USIL & UTP & UPC & Total \\
\hline Total Población & 1,257 & 70 & 3,102 & 4,429 \\
\hline
\end{tabular}

Nota. Adaptado de Reportes Internos del Personal Administrativo de las Universidades, 2016, Lima, Perú.

\subsubsection{Tamaño de muestra.}

El objetivo en esta fase fue obtener un tamaño de muestra representativo en cantidad, por lo que no se calculó el tamaño de la muestra ya que en las universidades USIL y UTP se tenía acceso a toda la población de estudio y se procedió a medir a todos los elementos de la población, es decir, se realizó un censo para recopilar información de carácter primario a los 1327 estudiantes universitarios (ver Tabla 6). Para el caso de la UPC se utilizó el método no probabilístico porque no se tenía acceso a la población de estudio; en ese sentido, el tamaño de la muestra estuvo conformado por aquellos alumnos a los que se pudo tener acceso y estaban dispuestos a participar de la investigación. Cabe señalar que, como en esta investigación se ha trabajado con análisis factorial y según Hair, Ringle, y Sarstedt, (2011) se requiere al menos 5 casos por variable observada, el tamaño mínimo de muestra para esta investigación sería de 135, valor que es superado ampliamente por el tamaño de muestra utilizado. Finalmente, para asegurar la calidad de la muestra, se consideró como criterios de inclusión sólo a los estudiantes que cumplían con las características de la población. 


\subsubsection{Selección de los elementos de la muestra.}

Para el caso de las universidades USIL y UTP no hubo selección de elementos de la muestra porque el objetivo era que todos los alumnos que cumplieran con los criterios de inclusión participaran en la investigación; mientras que en la UPC la selección fue por conveniencia, ya que se aplicó a los alumnos a quienes se tuvo acceso y quisieron participar del estudio. Como resultado de esta selección se obtuvo 871 participantes distribuidos de la siguiente manera: 686 participantes en la USIL y 20 para la UTP con un margen de error del $3 \%$; y 165 para la UPC, tal como se resume en la Tabla 6.

Tabla 6

Tamaño de Muestra y Cantidad de Participantes

Tamaño de Muestra Inicial Participantes

\begin{tabular}{lcc}
\hline Universidad San Ignacio de Loyola - USIL & 1257 & 686 \\
Universidad Tecnológica del Perú - UTP & 70 & 20 \\
Universidad Peruana de Ciencias Aplicadas - UPC & & 165 \\
Total & 1,327 & 871 \\
\hline
\end{tabular}

Nota. Adaptado de Reportes Internos del Personal Administrativo de las Universidades, 2016, Lima, Perú.

Finalmente, cabe señalar que en esta investigación no se ha cometido ninguno de los errores no muestrales señalado por Malhotra (2008) respecto a la definición de la población y selección de la muestra. El tratamiento de los otros tipos de errores no muestrales se señalan en el procesamiento de datos. 


\subsection{Recolección de Datos}

\subsubsection{Diseño del cuestionario.}

De acuerdo al enfoque cuantitativo se utilizó como instrumento inicial un cuestionario estructurado con preguntas cerradas denominado Cuestionario de Intención de Emprendimiento para Universitarios Adultos con Experiencia Laboral, el cual estuvo basado en: (a) el instrumento Entrepreneurial Intention Questionnaire (EIQ) versión 3 de Liñán et al., (2011) (ver Apéndice A); (b) la literatura teórica y empírica existente sobre la aplicación de la teoría del comportamiento planificado de Ajzen (1991) (Armitage \& Conner, 2001; Autio et al., 2001; Kautonen et al., 2011; Kolvereid, 1996; Krueger JR et al., 2000; Liñán, 2004; Liñán \& Chen, 2009; Van et al., 2008); y (c) las variables estudiadas para medir los constructos instituciones y normas legales y educación emprendedora (Abdullah \& Samah, 2013; Bae et al., 2014; Bygrave \& Miniti, 2000; Cumplido \& Liñán, 2006; DeTienne \& Chandler, 2004; Fayolle \& Liñán, 2014; Fernández-Serrano \& Liñán, 2014; Galloway \& Brown, 2002; Kuratko, 2005; Lee et al., 2011; Liñán, 2004; Liñan \& Santos, 2007; Liñán et al., 2015; Liñán et al., 2009; Malebana, 2014; Mat et al., 2015; Nabi, Walmsley, et al., 2016; Nabi, Liñán, et al., 2016; Pittaway \& Cope, 2007; Shinnar et al., 2012; Weaver et al., 2006; Yusoff et al., 2015).

La construcción del instrumento inicial se basó en la revisión de la literatura y el marco teórico y fue realizada por la autora quien tiene 9 años de experiencia laboral docente y el nivel avanzado del idioma inglés. El proceso tuvo las siguientes fases: La primera fase denominada adecuación consistió en: (a) la traducción del EIQ del idioma inglés al idioma español, (b) la conversión de los 9 ítems inversos en positivos cambiando la redacción de negaciones por afirmaciones, (c) la mejora en la redacción de los 7 ítems que fueron observados en el estudio donde se publica el instrumento, (d) se agregan las sub dimensiones para todas las dimensiones de estudio y en consecuencia se ubican los ítems de acuerdo a las 
sub dimensiones; y, (e) se buscó evitar la generalidad de las afirmaciones y alinearlas en el contexto de la cultura peruana y en estudiantes adultos con experiencia laboral.

Posteriormente, se ejecuta la segunda fase denominada ampliación que consistió en: (a) eliminar 9 ítems porque existe redundancia entre ellos, por ejemplo: el ítem A9 luego del cambio de redacción a ítem positivo declaraba Estoy seguro que crearé mi propia empresa mientras que el ítem A13 indicaba Estoy decidido a crear mi propia empresa, en esencia ambos ítems afirmaban lo mismo por lo que se decidió eliminar el ítem A9; (b) agregar 8 ítems en los factores motivacionales, de acuerdo a la operacionalización conceptual de cada constructo; (c) agregar un ítem referido a esposo(a) e hijos en el factor ambiental valoración cercana de acuerdo a las características demográficas de la población de estudio; (d) eliminar la sub dimensión cultura país de la dimensión valoración social ya que no es parte del presente estudio y corresponde al constructo sobre el cual se realizarán los aportes de la investigación; (e) agregar 4 ítems para las instituciones y normas legales y 5 ítems para la educación emprendedora, que son las sub dimensiones que se proponen en el modelo de estudio (ver Figura 6); y (f) se mejora la redacción de algunos ítems como último paso en esta fase de ampliación. Todos los pasos realizados en la fase de adecuación y ampliación se resumen en el Apéndice B.

Como resultado de estas dos fases, el instrumento inicial contó con 44 preguntas y estuvo dividido en dos partes, la primera parte tenía 31 afirmaciones enfocadas en medir: (a) la Intención de Emprendimiento a través de afirmaciones referidas a emprender un negocio propio, (b) los Factores Motivacionales con afirmaciones sobre la actitud hacia la conducta, la norma subjetiva y el control percibido de la conducta, y (c) los factores ambientales con afirmaciones acerca de la valoración cercana, las instituciones y normas legales y la educación emprendedora (Ajzen, 1991; Liñán et al., 2011). Para medir la incidencia de los Factores Motivacionales y Factores Ambientales sobre la Intención de Emprendimiento se 
diseñaron afirmaciones de escala ordinal basados en la escala de Likert para que el estudiante indique su nivel de acuerdo o desacuerdo hacia las afirmaciones, ya que este tipo de escalas es más confiable (Nunnally, 1978). La puntuación va desde un punto (1) hasta cinco (5) puntos, donde (1) es totalmente en desacuerdo, (2) en desacuerdo, (3) neutral, (4) de acuerdo, (5) totalmente de acuerdo, ya que este es el tipo de respuesta más usado en investigaciones similares (Chen, Greene, \& Crick, 1998; Zhao, Seibert \& Hills, 2005). La segunda parte del cuestionario inicial tenía 13 preguntas que correspondían a las variables de control con preguntas cerradas sobre información demográfica, socio económica y laboral relevantes a personas adultas con experiencia laboral con la finalidad de que puedan elegir la alternativa que corresponde a sus datos. La distribución de las afirmaciones y preguntas del cuestionario inicial se resumen en las Tablas 7 y 8 .

Tabla 7

Cantidad de Afirmaciones para las Variables de Estudio

\begin{tabular}{llcc}
\hline \multicolumn{1}{c}{ Constructo } & \multicolumn{1}{c}{ Dimensión } & Sub Dimensión & Total Ítems \\
\hline Intención de Emprendimiento & Intención de Emprendimiento & 4 \\
Factores Motivacionales & Actitud hacia la Conducta & 4 \\
& Control Percibido de la Conducta & 4 \\
& Normas Subjetivas & 6 & 4 \\
Factores Ambientales & Valoración Cercana & & 4 \\
& & Instituciones y Normas Legales & 4 \\
Total & Ealoración Social & & 5 \\
\hline
\end{tabular}

Nota. Adaptado de la Teoría del Comportamiento Planificado de Ajzen (1991) y el Modelo de Intención de Emprendimiento de Liñán, Urbano y Guerrero (2011). 
Tabla 8

Cantidad de Preguntas para las Variables de Control

Variables de Control

Estudios

Demográficos

Laborales

Estudios y trabajo de los padres y la pareja

Total
Total Preguntas

3

5

3

2

13

Nota. Adaptado de la Teoría del Comportamiento Planificado de Ajzen (1991) y el Modelo de Intención de Emprendimiento de Liñán, Urbano y Guerrero (2011).

\subsubsection{Validez del contenido - Juicio de expertos.}

Para la validación del contenido del instrumento inicial se siguieron los pasos establecidos por de Arquer (1995). El primer paso consistió en preparar las instrucciones para los jueces: para lo cual se definieron como objetivos de la validez del contenido del cuestionario el evaluar la adaptación cultural de los ítems y validar los nuevos indicadores del modelo propuesto. Luego se elaboró una hoja de instrucciones que indicaba a través de un cuadro el significado de marcar Si o No para las categorías Claridad, Contexto, Relevancia y Coherencia del ítem. Adicionalmente, se colocó un ejemplo de cómo realizar la calificación para estas categorías y para la Suficiencia del constructo a medir.

El segundo paso se enfocó en diseñar una plantilla para recoger las respuestas de los jueces: para lo cual se diseñó una plantilla para los 7 constructos en estudio que constaba de 3 partes: La primera parte estaba referida a la calificación de los ítems y se indicaba el constructo, la definición, el objetivo y la sub dimensión a medir por cada indicador propuesto; seguido de las 4 categorías y una columna de observaciones. La segunda parte estaba referida a la suficiencia del constructo a medir, mostrando una escala del 1 al 4 que iba 
de menor a mayor nivel de suficiencia. Finalmente, la tercera parte comprendía un casillero a llenar si el constructo tenía un nivel moderado de suficiencia.

El tercer paso se enfocó en seleccionar a los expertos: para lo cual se utilizó los criterios de selección recomendados por Skjong y Wentworth (2000), que establecen que los jueces deben tener: (a) experiencia en la realización de juicios, (b) reputación en la comunidad, (c) disponibilidad y motivación para participar, (d) imparcialidad, y (e) adaptabilidad. Para cumplir con los criterios (a) y (b) primero se recurrió al Centro de Investigación y Desarrollo de Tecnología de la USIL quienes recomendaron a cuatro posibles revisores, de los cuales dos accedieron inicialmente y finalmente sólo uno pudo participar. Luego se recurrió al Centro de Emprendimiento de la USIL quienes recomendaron a uno de los revisores que accedió y participó. Cabe mencionar que los criterios (c) y (e) fueron los que limitaron y a su vez permitieron que este primer grupo de expertos participara en el estudio. Continuando con la identificación de jueces, en función al criterio (d) se decidió agregar el criterio de diversidad de opiniones, buscando jueces con amplia experiencia en el tema de investigación (que son conocidos en los artículos académicos como practitioners) y trayectoria académica, ya que pueden ser más inmunes a la presión de caer en la creencia de un campo de estudio de un experto (Fischhoff, Slovic, \& Lichtenstein, 1983). Tal como se muestra en la Tabla 9, se alcanzó un total de 5 jueces dispuestos a validar el contenido del instrumento inicial, lo que se considera una cantidad adecuada ya que no existe una cantidad fija y el rango oscila entre 3 y 6 jueces (de Arquer, 1995). 
Tabla 9

Relación de Expertos para la Validez de Contenido

\begin{tabular}{|c|c|c|c|c|}
\hline $\mathrm{N}^{\mathrm{o}}$ & Juez & Cargo & Universidad & País \\
\hline 1 & Mag. Jorge Mesa & $\begin{array}{l}\text { Coordinador Programa Empresarismo } \\
\text { - Centro para la Innovación, } \\
\text { Consultoría y Empresarismo - CICE }\end{array}$ & EAFIT & Colombia \\
\hline 2 & Doctor (c) Pablo Colmenarejo & Profesor Asociado & UNED & España \\
\hline 3 & Mag. Eduardo Canales & Sub Director del Programa CPEL & USIL & Perú \\
\hline 4 & Doctor (c) Decio Rubio & $\begin{array}{l}\text { Director Académico - Centro de } \\
\text { Emprendimiento }\end{array}$ & USIL & Perú \\
\hline 5 & Doctor (c) Ricardo Guadalupe & Profesor Asociado & UNALM & Perú \\
\hline
\end{tabular}

El cuarto paso consistió en recoger los juicios de los expertos: para lo cual se les envió una carta de solicitud firmada por la autora, una hoja con los objetivos de la Validez del Contenido del Cuestionario, las instrucciones de llenado y las plantillas para los 7 constructos del estudio. En algunos casos el envío y la recepción de la documentación fue por correo electrónico y en otros de manera física, todos debidamente firmados por el experto evaluador. Algunas de las revisiones se realizaron de manera presencial, lo que permitió brindar un contexto más detallado de la investigación y fomentó la discusión sobre la suficiencia de los constructos medidos. Como evidencia del resultado de éste paso se adjunta sólo uno de los resultados en el Apéndice $\mathrm{C}$, debido a la extensión del documento.

El quinto paso y final, se enfocó en calcular la concordancia entre los expertos: para lo cual se utilizó el coeficiente de validez V de Aiken porque puede ser calculado sobre las valoraciones de un conjunto de jueces con relación a un ítem o como las valoraciones de un 
juez respecto a un grupo de ítems. Asimismo las valoraciones asignadas pueden ser dicotómicas (recibir valores de 0 o 1) o politómicas (recibir valores de 0 a 5) (Escurra, 1988). En este caso se calculará para respuestas dicotómicas y el análisis de 1 ítem por un grupo de jueces, para los 31 ítems de los 7 constructos medidos (ver Tabla 10) utilizando la siguiente fórmula:

$$
V=\frac{S}{(n(c-1))}
$$

\section{Donde:}

$\mathrm{S}=$ Sumatoria de $\mathrm{S}_{\mathrm{i}}$

$\mathrm{S}_{\mathrm{i}}=$ Valor asignado por el juez i

$\mathrm{n}=5$ (número de jueces)

$\mathrm{c}=2$ (número de valores de la escala de valoración)

De acuerdo a la Tabla 10 que muestra los resultados del coeficiente de validez $\mathrm{V}$ de Aiken, las 4 categorías referidas a Claridad, Contexto, Relevancia y Coherencia obtuvieron valores mayores a .70. A nivel de dimensión todas las dimensiones obtuvieron valores mayores a .70 en las categorías Claridad, Contexto, Relevancia y Coherencia. Por su parte, a nivel de ítems todos obtuvieron valores superiores a .70 excepto los ítems P2, P5 y P12 para la categoría Coherencia y P2 para la categoría Claridad con un valor de .40. Con estos resultados, se puede afirmar que todos los ítems mayores a .70 demuestran que existe concordancia entre los expertos respecto a la idoneidad del ítem como parte del constructo que están midiendo (Escurra, 1988), por lo que se mantienen sin cambios en el instrumento. Para el caso de los ítems P2 y P5, P12 se decide mantenerlos en el instrumento porque no pasan el umbral sólo en 2 y 1 categoría respectivamente de las 4 categorías evaluadas y porque corresponden a la construcción del constructo que se basa en el marco teórico; en ese sentido, se decidió esperar a los resultados del análisis estadístico de la prueba piloto para 
decidir su tratamiento. Finalmente, los resultados obtenidos en su conjunto permitieron afirmar que como resultado de la validación de contenido a través del juicio de expertos se confirma que los reactivos utilizados en el instrumento son idóneos para este tipo de estudios.

Tabla 10

Coeficiente de Validez V de Aiken

Categorías

Dimensión

Claridad Contexto Relevancia Coherencia

\begin{tabular}{lcccc}
\hline Intención de Emprendimiento & 0.95 & 1.00 & 1.00 & 1.00 \\
Actitud Hacia la Conducta & 0.85 & 1.00 & 1.00 & 0.85 \\
Normas Subjetivas & 0.80 & 0.87 & 0.80 & 0.80 \\
Control Percibido de la Conducta & 0.90 & 1.00 & 1.00 & 0.90 \\
Valoración Cercana & 0.80 & 1.00 & 0.90 & 0.70 \\
Instituciones y Normas Legales & 1.00 & 1.00 & 0.95 & 1.00 \\
Educación Emprendedora & 0.92 & 1.00 & 0.96 & 0.96 \\
Total & 0.89 & 0.98 & 0.94 & 0.89 \\
\hline
\end{tabular}

\subsubsection{Prueba piloto.}

El objetivo general de la prueba piloto fue obtener información que ayude a mejorar la fiabilidad y validez del instrumento mejorado en el paso anterior, validar el modelo propuesto; e, identificar problemas de redacción e instrucciones. La prueba piloto se realizó del 16 al 20 de junio del 2016, con 91 estudiantes universitarios del último año de estudios de las carreras de administración, marketing, negocios internacionales, ingeniería de sistemas, contabilidad, e ingeniería industrial de la USIL, de los cuales, se eliminaron 2 casos por 
superar el 10\% de ítems perdidos, quedando 89 casos válidos para el análisis estadístico. Tal como se muestra en la Tabla 11, del total de estudiantes que participaron en la prueba piloto, el $51.7 \%$ son hombres, el $49.4 \%$ tiene entre 31 y 40 años de edad, el 58.4\% estudia la carrera de administración y el $87.4 \%$ estudia entre el noveno y décimo ciclo de estudios. Estos datos son similares a las características de la población en estudio, por lo que se puede considerar que la cantidad de participantes en la prueba piloto fue representativa para continuar con el análisis estadístico.

Para el cumplimiento del primer objetivo, el primer paso fue verificar que los ítems tuvieran una correlación significativa, para lo cual se utilizó el coeficiente de correlación de Pearson, obteniendo resultados por encima de .500 para 6 de las 7 dimensiones de estudio. Sólo en la dimensión Norma Subjetiva se observó que los ítems P4, P11, P18 y P25 mostraban un bajo nivel de correlación; sumado a ello, en el juicio de expertos el Juez 3 recomendó eliminar estos ítems por ser redundantes con los otros ítems del constructo, lo que hizo que se eliminarán del análisis. Luego, se realizó el análisis estadístico que se muestra en la Tabla 12, donde el instrumento obtuvo un coeficiente Alfa de Cronbach entre .730 y .870, rango de valores que permitieron afirmar que se había alcanzado una buena relación entre los ítems y todos cargaban en el factor correspondiente. Como resultado de la prueba KaiserMeyer-Olkin obtuvo los valores de .819 y .791 para los factores motivacionales y ambientales respectivamente. Adicionalmente, la varianza total explicada estuvo en el rango del $56.33 \%$ al $78.43 \%$, lo que en conjunto permite afirmar que los ítems corresponden a su constructo. Si bien es cierto el instrumento debía mejorarse y probarse, estos resultados sugieren que el cuestionario Intención de Emprendimiento para Universitarios Adultos con Experiencia Laboral cumple con los requerimientos de fiabilidad y validez exigidos para una estudio de investigación doctoral. 
Para el segundo objetivo, se realizó un análisis estadístico básico para comprobar la idoneidad del modelo, donde se obtuvo que: (a) los datos no se distribuyen normalmente según la prueba de Kolmogorov-Smirnova; y, (b) según el método de extracción para factorizar los ejes, se observó que el ítem P29 de la dimensión Norma Subjetiva tenía un bajo nivel de comunalidad; sin embargo, se decidió mantenerlo para la siguiente prueba.

Para el tercer objetivo referido a identificar problemas de redacción en los ítems que no estén claros, estén mal redactados, o sean demasiado complejos, se mejoró la redacción del ítem P29 agrupando a los elementos de la familia en el término entorno familiar y para el ítem P31 se mejoró la redacción separando en ítems independientes los términos grupo de amigos y entorno profesional, con la finalidad de mejorar los coeficientes de la dimensión Normas Subjetivas. Luego, para la dimensión Valoración Cercana se decidió cambiar los 4 ítems por 3 nuevos ítems.

Finalmente, se mejora la redacción del ítem P15 incrementando la certeza de la afirmación. Por otro lado, se identificó que en la sección Variables de Control, las preguntas sobre el nivel educativo y el trabajo de los padres y esposo(a) eran instrucciones difíciles de comprender y seguir, por lo que se mejoró el orden de las preguntas y el diseño de la tabla de opciones de respuesta. El instrumento final, como resultado de la prueba piloto se presenta en el Apéndice D. 
Tabla 11

Prueba Piloto - Características Generales

Características Generales

$\mathrm{N}$

$\%$

Género

Femenino

43

48,3

Masculino

46

51,7

Edad

$\begin{array}{lcc}<30 \text { años } & 29 & 32,6 \\ 31-40 \text { años } & 44 & 49,4 \\ 41-50 \text { años } & 10 & 11,2 \\ >50 \text { años } & 6 & 6,7\end{array}$

\section{Carrera}

$\begin{array}{lcc}\text { Administración } & 52 & 58,4 \\ \text { Marketing } & 12 & 13,5 \\ \text { Negocios Internacionales } & 8 & 9,0 \\ \text { Ingeniería de Sistemas } & 6 & 0,0 \\ \text { Contabilidad } & 10 & 6,7 \\ \text { Ingeniería Industrial } & & 11,2 \\ \text { de Estudios } & 11 & 12,6 \\ \text { 7mo - 8vo } & 76 & 87,4 \\ \text { 9no - 10mo } & \end{array}$

Nota. Prueba Piloto - Características Generales. Datos obtenidos de la prueba piloto del estudio. 2016. 
Tabla 12

Prueba Piloto - Fiabilidad y Validez

\begin{tabular}{llccc}
\hline \multirow{2}{*}{ Constructo } & \multicolumn{1}{c}{ Factor } & Fiabilidad & \multicolumn{2}{c}{ Validez } \\
\cline { 3 - 5 } & & $\alpha$ Cronbach & KMO & $\begin{array}{c}\text { Varianza Total } \\
\text { Explicada \% }\end{array}$ \\
\hline Intención de Emprendimiento & Intención de Emprendimiento & .800 & & \\
Factores Motivacionales & Actitud hacia la Conducta & .856 & .819 & 78.43 \\
& Norma Subjetiva & .848 & & \\
& Control Percibido de la Conducta & .870 & & \\
& & & & \\
Factores Ambientales & Valoración Cercana & .855 & .791 & 56.33 \\
& Valoración Social & .730 & & \\
\hline
\end{tabular}

Nota. Prueba Piloto - Fiabilidad y Validez. Datos obtenidos de la prueba piloto del estudio. 2016.

Adicionalmente, la prueba piloto permitió estimar que el tiempo de duración en el llenado del cuestionario ascendía a 12 minutos en promedio y el tiempo requerido para la explicación previa al llenado alcanzaba los 7 minutos aproximadamente. La autora realizó personalmente la aplicación de los cuestionarios cuidando además la ética del proceso.

\subsubsection{Aplicación del instrumento.}

La aplicación del instrumento final se llevó a cabo mediante la modalidad de encuestas a los estudiantes universitarios que cumplían con los criterios de inclusión de la muestra en las Universidades USIL, UTP y UPC. Para el caso de la USIL, la toma de datos las realizó la autora en las instalaciones de la universidad, específicamente en el salón de clases de los alumnos, en la semanas de prácticas calificadas del 23 de Noviembre al 01 de Diciembre del 2016, utilizando parte de la hora académica otorgada por el profesor del curso de aproximadamente 15 minutos para crear el Rapport idóneo, el silencio y la atención total de los encuestados, la explicación de los objetivos de la investigación, las instrucciones de llenado, la entrega de los cuestionarios, la respuesta a los interrogantes planteadas por los 
estudiantes universitarios y el recojo de los cuestionarios. La participación fue voluntaria y se obtuvo un ratio de respuesta del $55 \%$ debido a la inasistencia a clases.

Para el caso del UTP donde las clases son virtuales, la toma de datos se realizó a través de dos correos electrónicos enviado por la Directora de las Carreras para Gente que Trabaja a cada uno de los estudiantes que conformaba la población de estudio, durante la semana de evaluaciones del 26 al 30 de Noviembre, donde les indicaba la importancia de la investigación y los alentaba a participar llenando la encuesta web a través del enlace de Google Forms adjunto en el mensaje. La participación fue voluntaria y se obtuvo un ratio de respuesta del 29\% debido a que no aceptaron participar del estudio.

En la UPC la aplicación de los cuestionarios para obtener los datos se realizó en las instalaciones de la universidad, específicamente en el salón de clases de los alumnos, en la semana de prácticas calificadas del 29 de Noviembre al 02 de Diciembre del 2016, utilizando parte de la hora académica otorgada por el profesor del curso, quien a su vez impartió las instrucciones de llenado y los objetivos de la investigación. La participación fue voluntaria y se limitó a aquellos salones a los que se pudo tener acceso.

\subsection{Procesamiento y Análisis de Datos}

Una vez aplicados los 871 cuestionarios, se llevó a cabo las fases de procesamiento y análisis de datos que explico a continuación:

\subsubsection{Procesamiento.}

Se verificó la validez de las respuestas antes de ser consideradas en el análisis, este proceso de limpieza de datos consistió en:

- Eliminar los casos no válidos. Se eliminaron 25 casos por estar incompletos ya que se llenó sólo una cara de la encuesta o marcaron pocas respuestas o porque casi todas las respuestas marcadas son iguales. 
- Identificar los valores perdidos. Se verificó a través de la tabla de distribución de frecuencias las preguntas que estaban en blanco para revisar si fue un error de digitación o no había sido respondida. Se corrigieron algunos errores de digitación y se confirmaron algunas respuestas vacías.

- Identificar los valores fuera de rango. Se verificó a través de la tabla de distribución de frecuencias, donde se había ingresado una respuesta que no estaba considerada dentro de la lista de opciones y se corrigió el error de digitación.

- Eliminar los casos pertenecientes a dueños de empresas. Se eliminaron 53 casos en cumplimiento de este criterio de exclusión de la muestra.

- Eliminar casos que contengan más del 10\% de ítems perdidos por caso, es decir, casos que tengan de 2 a más preguntas sin responder. Se eliminaron 9 casos en los cuales la cantidad de preguntas no contestadas superaba el ratio.

Como resultado del proceso de limpieza de datos, se eliminó el 9.99\% del total de casos y se quedaron 784 casos válidos para el estudio. El cuestionario en esencia fue anónimo, pero se tenía una pregunta con los datos de contacto si es que el estudiante deseaba participar en estudios posteriores. La identidad de los participantes que registraron sus datos de contacto y sus respuestas se trabajaron de manera confidencial, en tal sentido, sus nombres y sus respuestas fueron codificados para proteger su identidad. Para el registro y tabulación de los datos recogidos se utilizó el software SPSS Statistics ${ }^{\circledR}$ versión 21, con el cual se realizó la siguiente etapa de análisis de datos.

\subsubsection{Análisis de datos.}

Para analizar los datos se desarrollaron tres etapas: (a) Análisis descriptivo para las características de los participantes, (b) Análisis factorial exploratorio para validar el instrumento, y (c) Ecuaciones estructurales para la validez empírica del modelo. Para la primera etapa denominada Análisis descriptivo para las características de los participantes, se 
utilizó la estadística descriptiva a través del método tabular para elaborar presentaciones resumidas con los parámetros y estadísticos referidos a medidas de resumen que determinen el perfil del estudiante universitario a través de tablas simples, tablas de contingencia y tablas apiladas. Asimismo, se utilizó el método gráfico con la finalidad de dar una impresión visual de fácil comprensión utilizando gráficos circulares. El software utilizado en esta etapa fue el SPSS Statistics ${ }^{\circledR}$ versión 21 y Microsoft Excel ${ }^{\circledR}$ para Mac versión 15.13.3.

Con respecto a la segunda etapa, denominada Análisis factorial exploratorio para validar el instrumento, se realizó un análisis factorial exploratorio muy utilizado en este tipo de estudios (Klein, Astrachan, \& Smyrnios, 2005; Liñán \& Chen, 2009; Liñán et al., 2011; Moriano, Palací, \& Morales, 2006) que estuvo conformado por las siguientes dos fases: La primera fase consistió en analizar la fiabilidad y validez del test. Para la fiabilidad se calculó el coeficiente Alfa de Cronbach con la finalidad de medir para cada ítem la consistencia y estabilidad de la puntuación en la escala de Likert utilizada (Chandler \& Lyon, 2001); el objetivo fue lograr que las dimensiones del estudio sean individualmente mayor a .700, que es el valor establecido para trabajos de investigación, considerando inclusive valores desde .600 ya que se trata de un nuevo instrumento de medición (Kavadia, 2013), para poder afirmar que el instrumento tenía una consistencia interna aceptable. En lo referente a la validez del test, se buscó que todos los ítems concuerden con la construcción del constructo para que los ítems sean relevantes y representativos para el constructo que están midiendo (Chandler \& Lyon, 2001), por ello se realizaron dos pruebas, la prueba Kaiser-Meyer-Olkin (KMO) para comprobar que todos los resultados sean mayor a .500 y la prueba de esfericidad de Barlett para comprobar un alto nivel de significancia $(\mathrm{p}<.001)$, los que en conjunto permitirán afirmar que el análisis factorial es una técnica apropiada. Por su parte, en la segunda fase se utilizó el método de extracción para factorizar los ejes que es la prueba no paramétrica más utilizada en este tipo de estudios para medir la validez del modelo cuando 
los datos no tienen una distribución normal (Liñán \& Chen, 2009; Liñán et al., 2011), donde se esperaba que todos los valores estadísticos resultantes de la carga factorial y de las comunalidades debían ser mayores al 50\%. El Software usado en esta etapa fue el SPSS Statistics ${ }^{\circledR}$ versión 21 .

En cuanto a la tercera y última etapa denominada Ecuaciones Estructurales para la validez empírica del modelo, se decidió validar el modelo de análisis propuesto en esta investigación haciendo uso de las ecuaciones estructurales con la técnica de mínimos cuadrados parciales (PLS-SEM), ya que se cumplen los siguientes supuestos: (a) se utiliza para medir modelos complejos de relación causa - efecto donde se tienen muchos constructos y muchos indicadores (Hair et al., 2011; Marcoulides \& Saunders, 2006), como el modelo de análisis propuesto en este estudio; (b) no necesita que la muestra tenga distribución normal (Fornell \& Bookstein, 1982; Hwang, Malhotra, Kim, Tomiuk, \& Hong, 2010), lo cual se comprobará al presentar los resultados; (c) se pueden utilizar constructos con pocos ítems (Hair et al., 2011); (d) la investigación es una extensión de una teoría existente (Hair et al., 2011); y (e) se busca evitar el sesgo por tamaño de muestras grandes (Leyva \& Olague, 2014). Sumado a ello, los estudios base en los que se fundamenta esta investigación utilizaron PLS-SEM (Liñán \& Chen, 2009; Liñán et al., 2011) y la aplicabilidad de PLS-SEM se ha incrementado y fortalecido en las ciencias sociales y la literatura académica (Gefen, Straub, \& Boudreau, 2000; Leyva \& Olague, 2014; Liñán \& Chen, 2009; Liñán et al., 2011; Shook, Ketchen, Hult, \& Kacmar, 2004). Luego, en esta investigación se utilizó con el software SmartPLS ${ }^{\circledR}$ versión 3.2.4 (Gefen, Straub, \& Boudreau, 2000; Leyva \& Olague, 2014).

Posteriormente, debido a que la técnica de mínimos cuadrados parciales estima sus propias cargas factoriales, se debió analizar nuevamente la fiabilidad del constructo y la validez de convergencia (Burnkrant \& Page, 1982; Shook et al., 2004). Para la fiabilidad, primero se comprobó la fiabilidad de composición, verificando que todos los ítems en cada 
constructo presenten cargas por encima de .600 ya que se trata de un nuevo instrumento de medición (Roldán \& Leal, 2003); luego, se comprobó la fiabilidad del constructo a través del Alfa de Cronbach verificando que todas las dimensiones superen el umbral de .700 (Nunally, 1978). Para la validez de convergencia se analizó que todos los ítems de cada constructo estén relacionados entre sí, es decir, que alcancen los mayores valores positivos dentro de sus propios constructos. que la varianza extraída media supere el umbral de .500 lo que permitirá afirmar que la correlación de coeficientes es positiva y estadísticamente significativa, con todos estos resultados se confirmó que los ítems muestran una relación suficientemente alta con sus propios constructos. Adicionalmente, se verificó que la Varianza Extraída Promedio (AVE) supere el umbral de .500. Finalmente, se validaron las hipótesis planteadas en este estudio a través de los coeficientes de trayectoria significativos en el modelo final, teniendo como regla de decisión que los coeficientes de trayectoria positivos confirman las hipótesis planteadas.

En lo referido al tratamiento de las consideraciones éticas, se respetó la dignidad y la decisión voluntaria de participar de los estudiantes universitarios, los cuales fueron libres de abandonar y/o participar de la sesión en el momento que lo deseaban y realizar las preguntas cuando lo consideraron necesario. Los cuestionarios fueron anónimos para garantizar la confidencialidad y privacidad de los participantes; y en caso decidieran participar de futuras investigaciones podían llenar sus datos de contacto.

Finalmente se elaboró la Matriz de Consistencia del estudio, la cual sintetiza la información presentada hasta aquí (ver Apéndice E). 


\section{Capítulo IV: Análisis y Discusión de Resultados}

En este capítulo se presentan los resultados obtenidos en el estudio acompañados de la discusión respectiva, los cuales se analizaron según los parámetros establecidos en el análisis de datos.

\subsection{Análisis Descriptivo para las Características de los Participantes}

En este punto se realiza una descripción de los principales rasgos socio demográficos y económicos que caracterizan a la población de estudio, lo que permitió verificar que los participantes cumplían con los criterios establecidos en el proceso de muestreo. Como se observa en la Tabla 13, del total de estudiantes que participaron el 78.4\% son de la USIL y el 65.6\% se encuentra en el último año de estudios entre el noveno y décimo ciclo. Por su parte, cada universidad considera diferentes nombres para las carreras que ofrecen en sus programas para adultos, por ello se clasificaron las carreras en cinco grupos, donde la carrera Administración comprende las carreras de Administración y Gerencia del Emprendimiento, Administración de Empresas, Administración de Negocios, entre otras; y de manera análoga para los cuatro grupos restantes; lo que dio como resultado que el $32 \%$ estudia una carrera de ingeniería y el resto una carrera de negocios. Por otro lado, la participación en cuanto al género fue equitativa ya que el $49.5 \%$ fueron mujeres y el $50.5 \%$ hombres. Finalmente, en lo referido a la edad, el 46\% es menor de 30 años, mientras que el $42.9 \%$ tiene entre 31 y 40 años de edad.

Con respecto al estado civil de los participantes, la mayoría son solteros seguido de los casados y divorciados con una participación del 70\%, 27\% y 26.8\% respectivamente, tal como se observa en la Figura 8 . En lo referente al lugar de nacimiento el $82 \%$ se concentra en Lima y el $18 \%$ en provincias, tal como lo indica la Figura 9. Adicionalmente, el $32 \%$ de los participantes afirmó que tenía experiencia previa en crear una empresa (ver Figura 10). 
Adicionalmente, una de las características de la población de estudio es que son personas que trabajan, por lo que se les preguntó acerca de sus puestos de trabajo donde se desempeñan como trabajadores dependientes, y los resultados mostraron que el $48 \%$ de los participantes labora como Gerente, Jefe, Supervisor o Coordinador teniendo personal a cargo (ver Figura 11). Luego sobre sus ingresos, el 53\% de los participantes percibe un ingreso menor a S/. 3,500, seguido por el 35.7\% que tiene ingresos entre S/. 3,501 y S/. 6,500 mensuales (ver Figura 12).

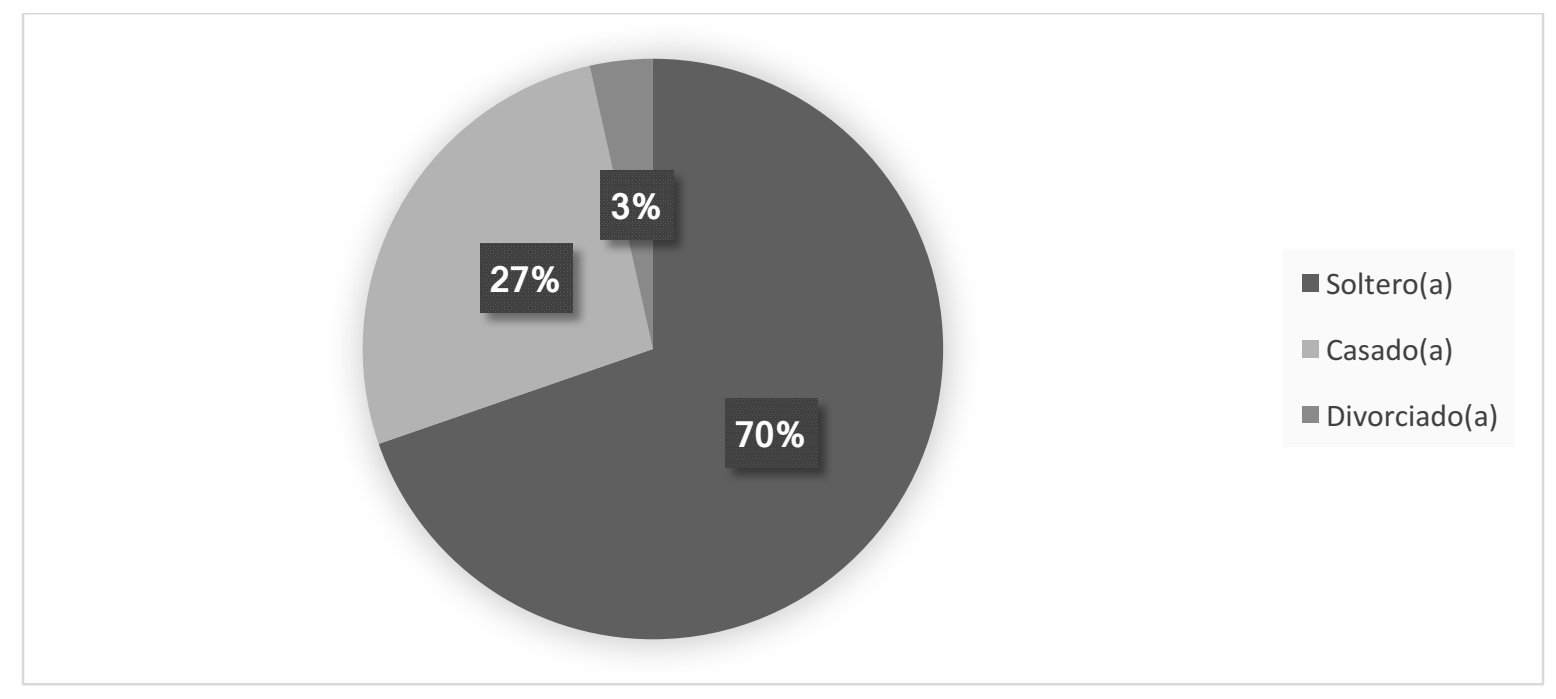

Figura 8. Estado civil de los participantes. Datos obtenidos en el estudio 2016.

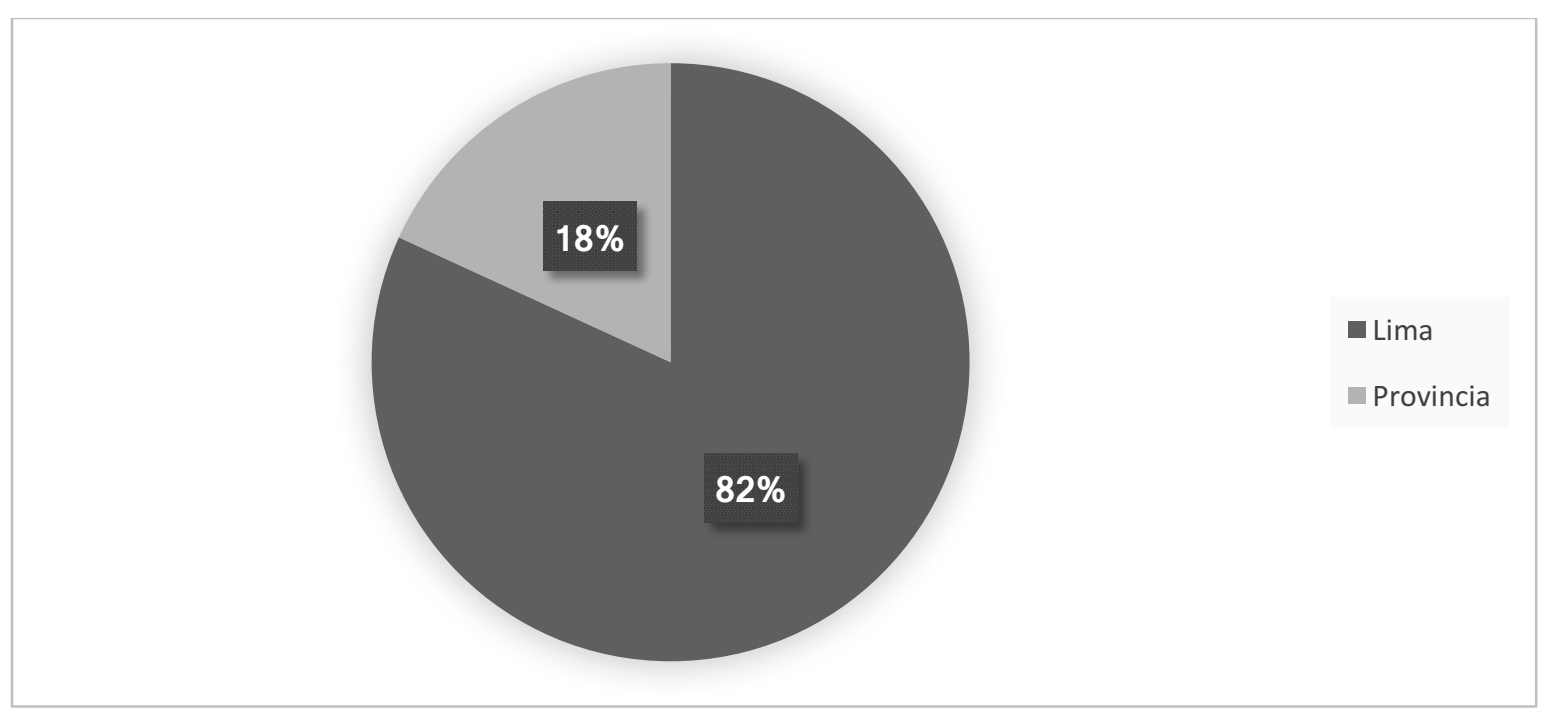

Figura 9. Lugar de Nacimiento de los Participantes. Datos obtenidos en el estudio 2016. 
Tabla 13

Características de los Participantes

Características Generales

$\mathrm{N}$

$\%$

Universidad

$\begin{array}{lcc}\text { USIL } & 615 & 78,4 \\ \text { UPC } & 150 & 19,1 \\ \text { UTP } & 19 & 2,4\end{array}$

Carrera

Administración

302

38,5

Contabilidad

39

5,0

Ingenierías

251

32,0

Marketing

88

11,2

Negocios Internacionales

104

13,3

Ciclo de Estudios

$$
\begin{aligned}
& 7 \mathrm{mo}-8 \mathrm{vo} \\
& 9 \mathrm{no}-10 \mathrm{mo}
\end{aligned}
$$

513

65,6

Género

Femenino

Masculino

Edad

$$
<30 \text { años }
$$$$
31 \text { - } 40 \text { años }
$$$$
41 \text { - } 50 \text { años }
$$$$
>50 \text { años }
$$

385

393

50,5

49,5

46,0

42,9

68

8,7

19

Nota. Características de los Participantes. Datos obtenidos en el estudio. 2016. 


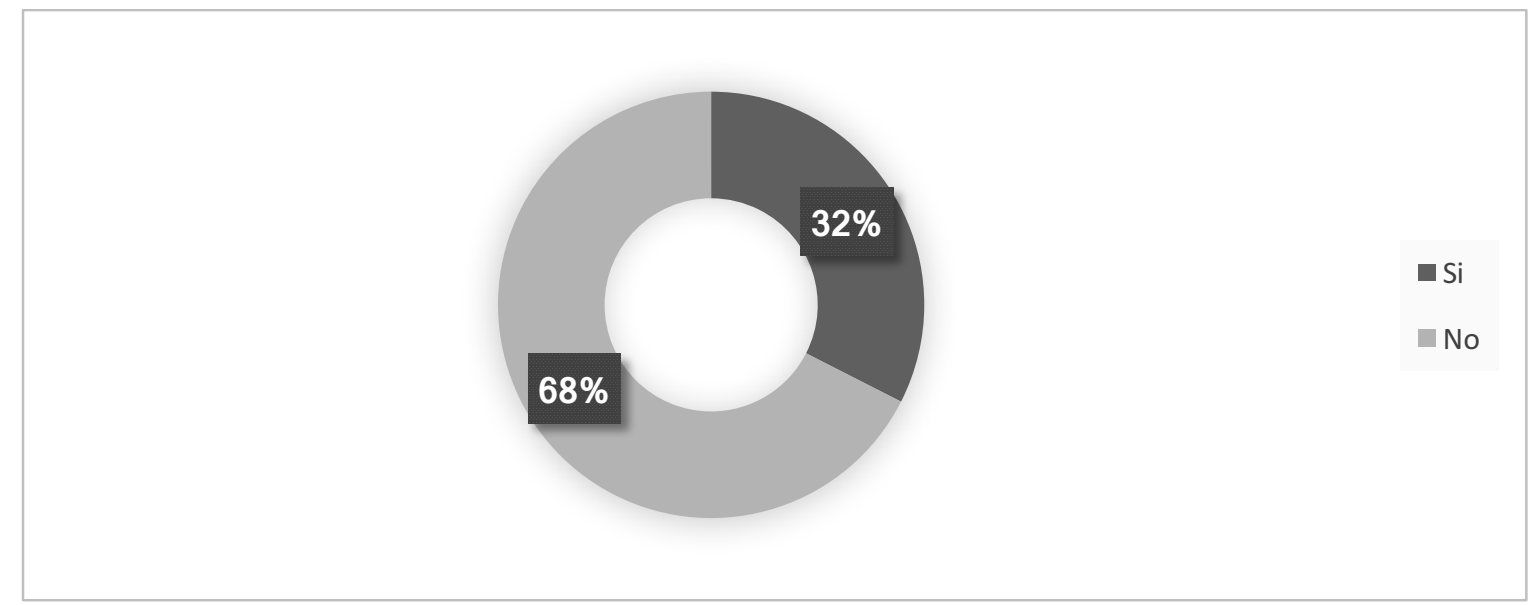

Figura 10. Experiencia en Crear Empresa de los Participantes. Datos obtenidos en el estudio. 2016.

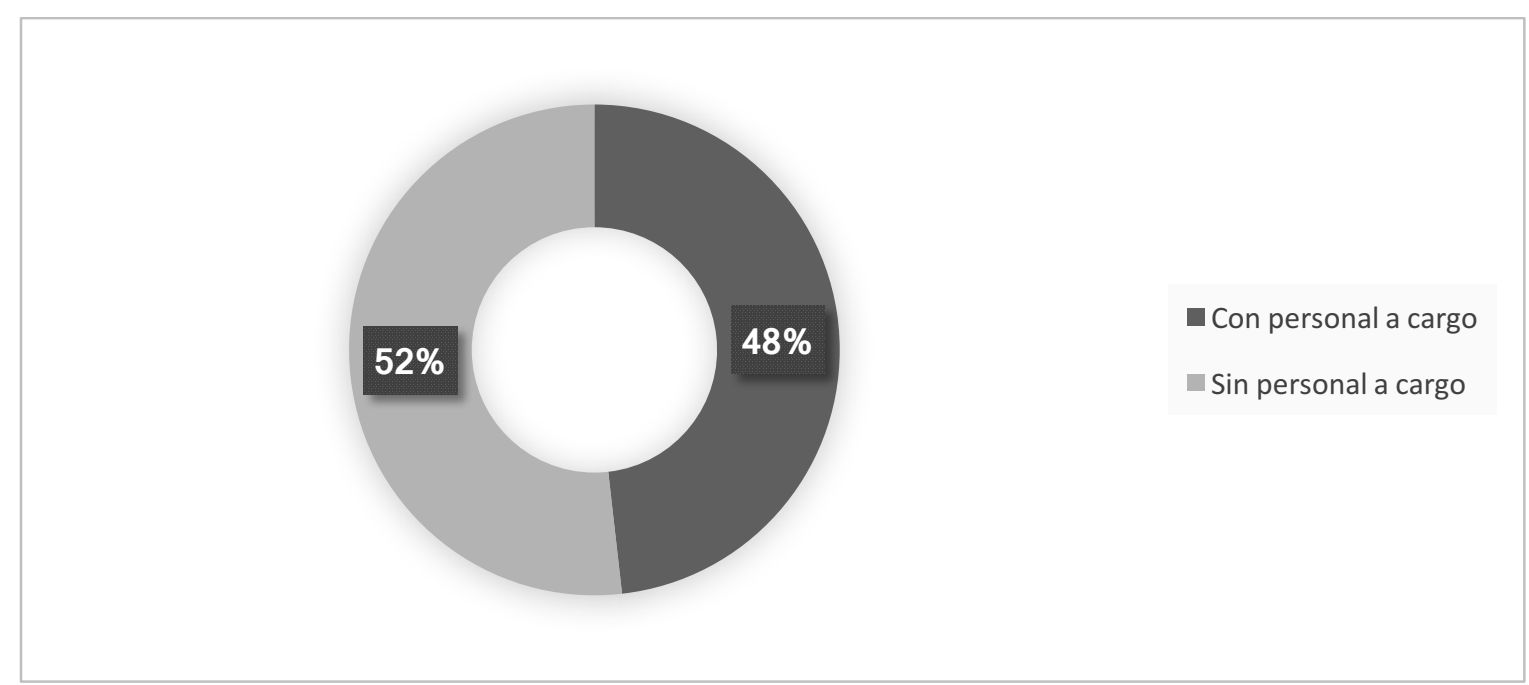

Figura 11. Nivel del Puesto de Trabajo de los Participantes. Datos obtenidos en el estudio. 2016.

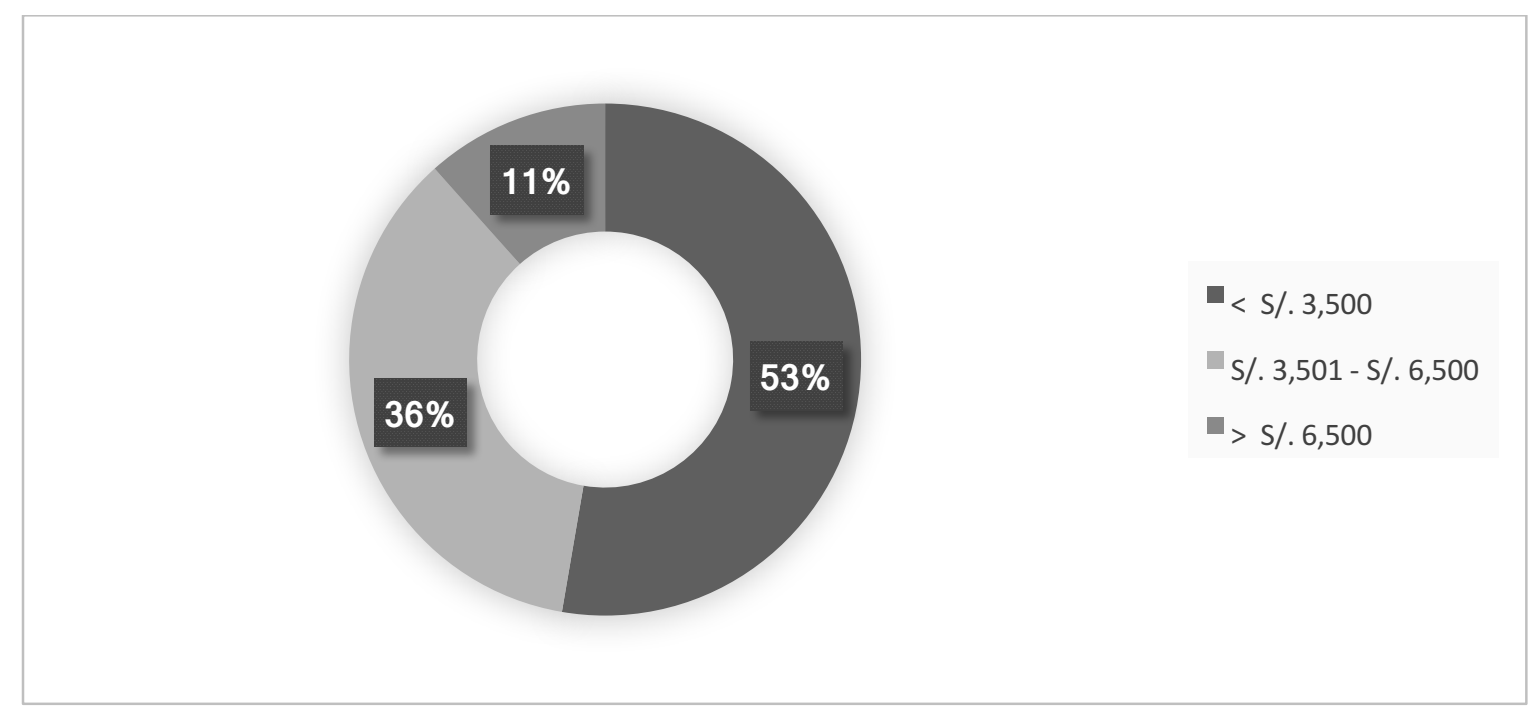

Figura 12. Ingresos Económicos de los Participantes. Datos obtenidos en el estudio. 2016. 


\subsection{Análisis Factorial Exploratorio para Validar el Instrumento}

El análisis factorial exploratorio para validar el instrumento Intención de Emprendimiento de Universitarios Adultos con Experiencia Laboral tuvo las siguientes dos etapas: Como primera etapa se analizaron todas las afirmaciones referidas a los factores motivacionales, los factores ambientales y la intención de emprendimiento, obteniendo los siguientes resultados: Para la fiabilidad del instrumento se obtuvo un coeficiente Alfa de Cronbach entre .660 y .849 tal como se muestra en la Tabla 14, rango de valores que permiten afirmar que las escalas desarrolladas teóricamente son fiables, es decir, se alcanzó una buena relación entre los ítems porque todos cargaron en el factor al que corresponden; no obstante a nivel de indicadores, se encontró que en la dimensión Norma Subjetiva los ítems P9 y P16 y en la dimensión Instituciones y Normas Legales los ítems P4, P11 y P18 son los que menos aportan con valores de $.536, .526, .572, .561$ y .571 respectivamente; debido a ello, se verificó que no aportaran a otros factores y como Kavadia (2013) establece que para instrumentos nuevos se puede considerar inclusive valores por encima de $.600 \mathrm{y}$ al encontrarse estos valores muy cerca del umbral, se decidió mantenerlos y esperar los resultados de la validación empírica del modelo. Por otro lado, como se observa en la Tabla 14, para la validez del instrumento se obtuvo como resultado de la prueba Kaiser-MeyerOlkin (KMO) valores entre .635 y .840 que son superiores al umbral de .500 (Chandler \& Lyon, 2001) y la prueba de esfericidad de Barlett fue altamente significativa $(\mathrm{p}<.001)$; resultados que en conjunto sugieren que el análisis factorial es la técnica apropiada a utilizar. Por lo tanto, se pudo afirmar que el cuestionario Intención de Emprendimiento para Universitarios Adultos con Experiencia Laboral cumplió con los requerimientos de fiabilidad y validez exigidos para un estudio de investigación doctoral. 
Tabla 14

Fiabilidad y Validez del Instrumento

\begin{tabular}{llcc}
\hline \multirow{2}{*}{ Constructo } & \multicolumn{1}{c}{ Dimensión } & Fiabilidad & Validez \\
\cline { 3 - 4 } & & $\alpha$ Cronbach & KMO \\
\hline Intención de Emprendimiento & Intención de Emprendimiento & .782 & .770 \\
& Actitud hacia la Conducta & .746 & .750 \\
& Norma Subjetiva & .692 & .635 \\
& Control Percibido de la Conducta & .789 & .771 \\
& & .787 & .698 \\
Factores Ambientales & Valoración Cercana & .660 & .708 \\
& Instituciones y Normas Legales & .849 & .840 \\
\hline
\end{tabular}

Nota. Fiabilidad y Validez del Instrumento. Datos obtenidos en el estudio 2016.

Para la segunda etapa, se ejecutó el método de extracción para factorizar los ejes con el objetivo de confirmar que los ítems cargan en el factor esperado, obteniendo los siguientes resultados: Para los Factores Ambientales, la Tabla 15 muestra que todos los ítems cargan en el factor esperado; luego, revisando las comunalidades de la extracción se observó que las variables mejor explicadas son las que pertenecen a la Dimensión Valoración Cercana ya que son capaces de reproducir entre el $65 \%$ y $72 \%$ de su variabilidad original, mientras que, el ítem P25 mostró un bajo nivel de comunalidad con los otros ítems del factor Instituciones y Normas Legales, lo que hizo que se revisara la carga factorial y como ésta superaba el umbral se decidió mantenerlos en el estudio; además, la varianza total explicada fue de $61.49 \%$. Por otro lado, la Tabla 16 muestra que para los Factores Motivacionales todos los ítems cargan en el factor esperado; luego, revisando las comunalidades de la extracción se observó que las variables mejor explicadas son las que pertenecen a la Dimensión Intención de Emprendimiento ya que son capaces de reproducir entre el $67 \%$ y $78 \%$ de su variabilidad 
original, mientras que, los ítems P26 y P2 mostraron niveles ligeramente bajos de comunalidad con los otros ítems del factor al que pertenecen, lo que hizo que se revisara la carga factorial y como ésta superaba el umbral se decidió mantenerlos en el estudio; además, la varianza total explicada fue de $61.46 \%$. Por lo tanto, se puede afirmar que el modelo planteado en el estudio cumplió la validez de convergencia a través de la factorización de ejes.

Tabla 15

Matriz de Configuración Factorial Rotado y Comunalidad de los Factores Ambientales

\begin{tabular}{|c|c|c|c|c|}
\hline & & Factores & & Comunalidad \\
\hline Ítems & Valoración Cercana & $\begin{array}{l}\text { Instituciones y } \\
\text { Normas Legales }\end{array}$ & $\begin{array}{c}\text { Educación } \\
\text { Emprendedora }\end{array}$ & Extracción \\
\hline P6 & .790 & & & .651 \\
\hline P13 & .823 & & & .713 \\
\hline $\mathrm{P} 20$ & .825 & & & .719 \\
\hline P4 & & .785 & & .617 \\
\hline P11 & & .756 & & .609 \\
\hline P18 & & .681 & & .519 \\
\hline $\mathrm{P} 25$ & & .506 & & .348 \\
\hline $\mathrm{P} 1$ & & & .740 & .556 \\
\hline P8 & & & .634 & .505 \\
\hline P15 & & & .811 & .728 \\
\hline $\mathrm{P} 22$ & & & .795 & .691 \\
\hline P27 & & & .826 & .723 \\
\hline
\end{tabular}

Nota. Datos obtenidos en estudio 2016

Método de extracción: análisis de componentes principales.

Método de rotación: Varimax con normalización Kaiser.

a. La rotación ha convergido en 5 iteraciones. 
Tabla 16

Matriz de Configuración Factorial Rotado y Comunalidad de los Factores Motivacionales

\begin{tabular}{|c|c|c|c|c|c|}
\hline \multirow[b]{2}{*}{ Ítems } & \multicolumn{4}{|c|}{ Factores } & \multirow{2}{*}{$\begin{array}{r}\text { Comunalidad } \\
\text { Extracción }\end{array}$} \\
\hline & $\begin{array}{c}\text { Intención de } \\
\text { Emprendimiento }\end{array}$ & $\begin{array}{c}\text { Actitud hacia la } \\
\text { Conducta }\end{array}$ & $\begin{array}{c}\text { Norma } \\
\text { Subjetiva }\end{array}$ & $\begin{array}{c}\text { Control } \\
\text { Percibido de la } \\
\text { Conducta }\end{array}$ & \\
\hline P3 & .822 & & & & .775 \\
\hline P10 & .686 & & & & .666 \\
\hline P17 & .708 & & & & .731 \\
\hline $\mathrm{P} 24$ & .778 & & & & .719 \\
\hline P5 & & .675 & & & .527 \\
\hline P12 & & .770 & & & .663 \\
\hline P19 & & .750 & & & .605 \\
\hline P26 & & .663 & & & .486 \\
\hline $\mathrm{P} 2$ & & & .652 & & .460 \\
\hline P9 & & & .848 & & .720 \\
\hline P16 & & & .818 & & .690 \\
\hline P7 & & & & .783 & .667 \\
\hline P14 & & & & 699 & .567 \\
\hline $\mathrm{P} 21$ & & & & .680 & .684 \\
\hline P23 & & & & .789 & .690 \\
\hline
\end{tabular}

Nota. Datos obtenidos en estudio 2016

Método de extracción: análisis de componentes principales.

Método de rotación: Varimax con normalización Kaiser.

a. La rotación ha convergido en 5 iteraciones.

Para todos los resultados obtenidos en las dos etapas del análisis factorial exploratorio se utilizó el software SPSS Statistics ${ }^{\circledR}$ versión 21. 


\subsection{Ecuaciones Estructurales para la Validez Empírica del Modelo}

Con el objetivo de elegir la técnica estadística más adecuada para validar el modelo y teniendo en cuenta el cumplimiento de los otros supuestos establecidos en el análisis de datos, se procedió con la comprobación del supuesto de normalidad con la prueba de Kolmogorov-Smirnova, obteniendo como resultado que las distribuciones de los datos no correspondían a una distribución normal tal como se observa en la Tabla 17, donde el valor Sig. no es mayor a 0.05 para todas las dimensiones en estudio.

Tabla 17

Prueba de Normalidad

\begin{tabular}{lcccccc}
\cline { 2 - 7 } & \multicolumn{3}{c}{ Kolmogorov-Smirnova } & \multicolumn{3}{c}{ Shapiro-Wilk } \\
\hline Dimensión & Estadístico & $\mathrm{gl}$ & $\mathrm{Sig}$. & Estadístico & $\mathrm{gl}$ & Sig. \\
\hline Intención de Emprendimiento & .108 & 784 & .000 & .933 & 784 & .000 \\
Actitud Hacia la Conducta & .116 & 784 & .000 & .934 & 784 & .000 \\
Norma Subjetiva & .127 & 784 & .000 & .970 & 784 & .000 \\
Control Percibido de la Conducta & .110 & 784 & .000 & .959 & 784 & .000 \\
Valoración Cercana & .134 & 784 & .000 & .952 & 784 & .000 \\
Instituciones y Normas Legales & .120 & 784 & .000 & .973 & 784 & .000 \\
Educación Emprendedora & .124 & 784 & .000 & .961 & 784 & .000 \\
\hline
\end{tabular}

Nota. Prueba de Normalidad. Datos obtenidos en el estudio 2016.

a. Corrección de significación de Lilliefors

Para las ecuaciones estructurales se utilizó la técnica de mínimos cuadrados parciales, la cual se aplicó al modelo de estudio propuesto inicial que se presenta en la Figura 13, donde los ítems para cada constructo han sido definidos como sugirió el análisis de factores en el acápite anterior. Esta figura es la forma como el software SmartPLS ${ }^{\circledR}$ versión 3.2.4 representa gráficamente al modelo de análisis propuesto diseñado de manera conceptual en la Figura 6, donde se aprecian las siete variables latentes del estudio y los indicadores que las medirán. 


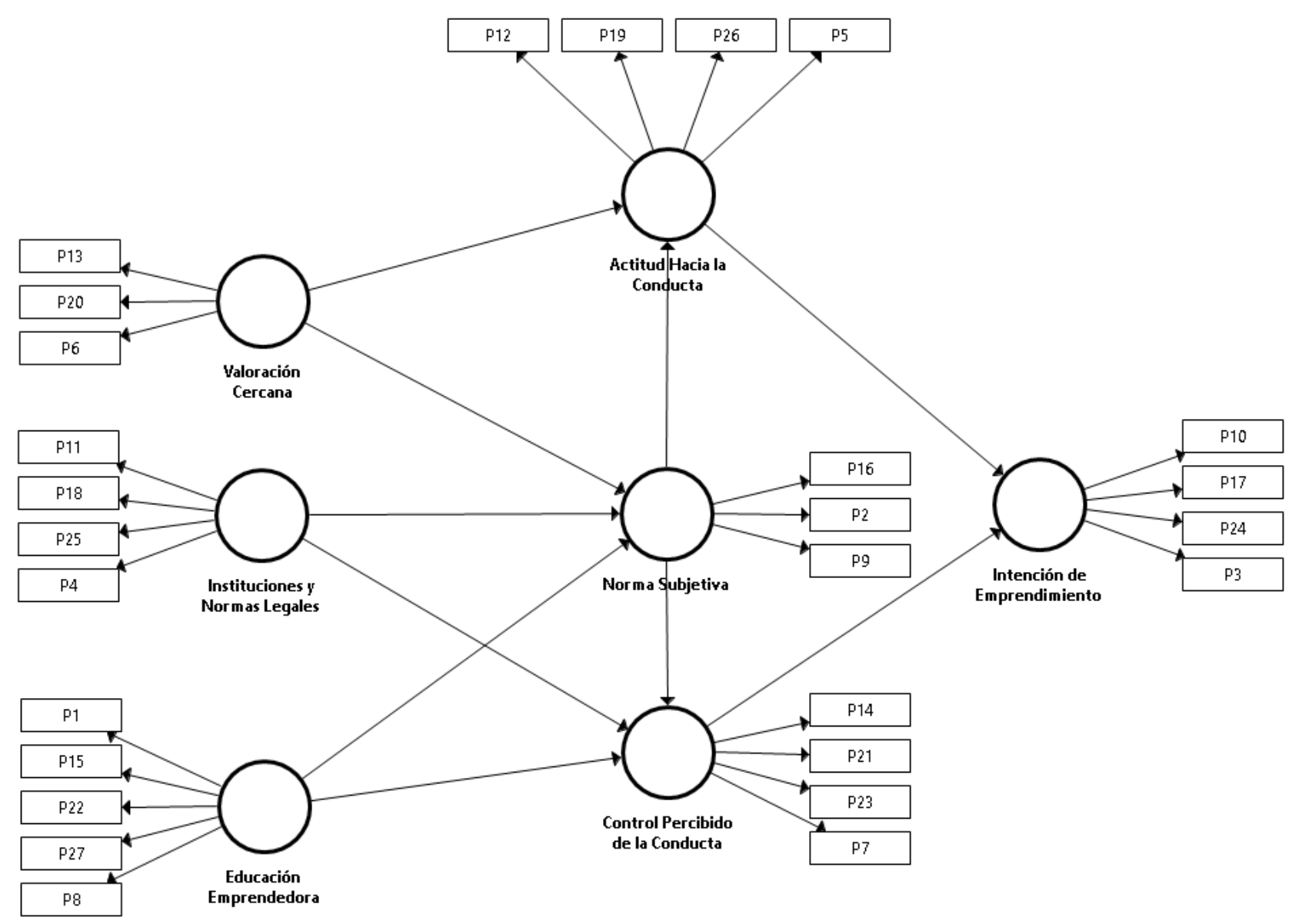

Figura 13. Modelo de Estudio Propuesto Inicial.

Como resultado de ejecutar la regresión de mínimos cuadrados parciales se observó que el ítem P1 de la dimensión Educación Emprendedora, el ítem P2 de la dimensión Norma Subjetiva y los ítems P4 y P25 de la dimensión Instituciones y Normas Legales tenían problemas de fiabilidad de composición ya que presentaban cargas por debajo de 0.707 o incluso por debajo de .600 para nuevos instrumentos de medición (Roldán \& Leal, 2003), por lo que se decidió eliminarlos. Luego se volvió a correr el análisis y se obtuvo los siguientes resultados esquematizados en la Tabla 18: La fiabilidad del constructo se analizó a través del Alfa de Cronbach y la Correlación del ítem al total (Nunnally, 1978), donde todos los valores Alfa de Cronbach obtenidos fueron superiores a .700 (entre .724 y .928) y todas las correlaciones del ítem al total fueron positivas y superiores a .600 (entre .686 y .975) para 
todas las dimensiones de estudio en ambos casos; por lo tanto, todos los constructos propuestos pueden considerarse suficientemente fiables, ya que miden la información para la cual fueron diseñados. Por otro lado, el análisis de validez convergente muestra si los elementos que integran cada constructo están realmente relacionados y en efecto el Coeficiente de correlación alcanzó valores estadísticos positivos entre .269 y .876; por lo tanto, los ítems mostraron una relación suficientemente alta con sus propios constructos. Además, para la Varianza Extraída Promedio (AVE) todas las dimensiones alcanzan valores en el rango de .643 a .824 que son superiores al umbral de .500 , lo que permitió afirmar que los ítems explican más del 50\% de la varianza de sus respectivas dimensiones de estudio. De manera complementaria, los resultados también se presentan en la Figura 14, la cual muestra los coeficientes de trayectoria significativos en los valores sobre las líneas que conectan las variables latentes; así como las correlaciones del ítem al total en los valores asociados a cada ítem.

Para la validación de las hipótesis se utilizó la Figura 15, la que a diferencia de la Figura 14 no muestra los ítems de cada constructo y agrega las hipótesis asociadas a los coeficientes de trayectoria significativos, cuyos valores se usaron para analizar las hipótesis planteadas en esta investigación. Por su parte, la discusión se centró en validar el modelo de estudio propuesto que toma como base la Teoría del Comportamiento Planificado de Ajzen (1991) para los factores motivacionales y la Teoría de Liñán et al. (2011) para los factores ambientales, al cual se agregó las dimensiones de Instituciones y Normas Legales y Educación Emprendedora. 
Tabla 18

Análisis de Fiabilidad y Validez Convergente del Modelo de Estudio Propuesto

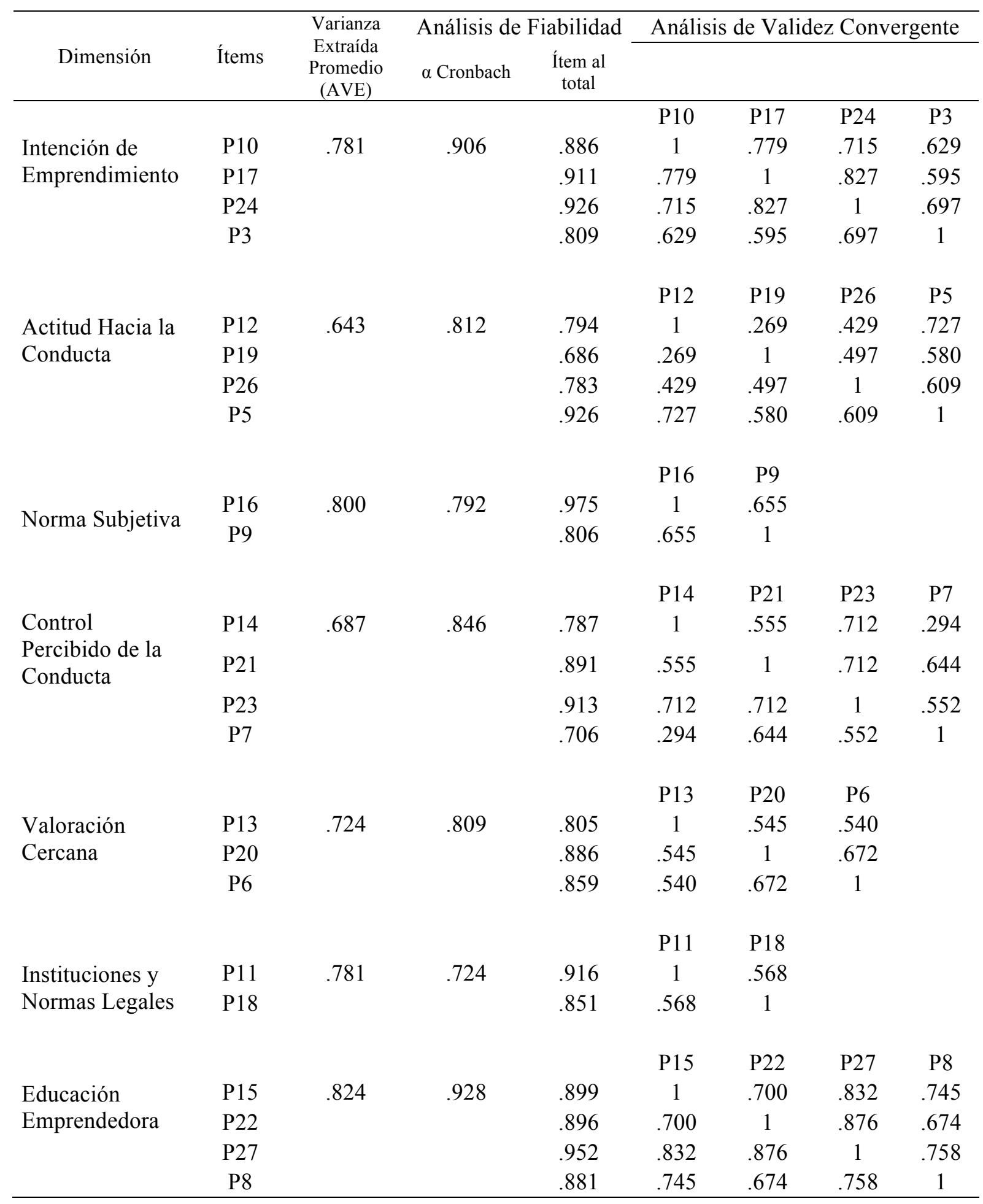

Nota. Datos obtenidos en el estudio 2016. 


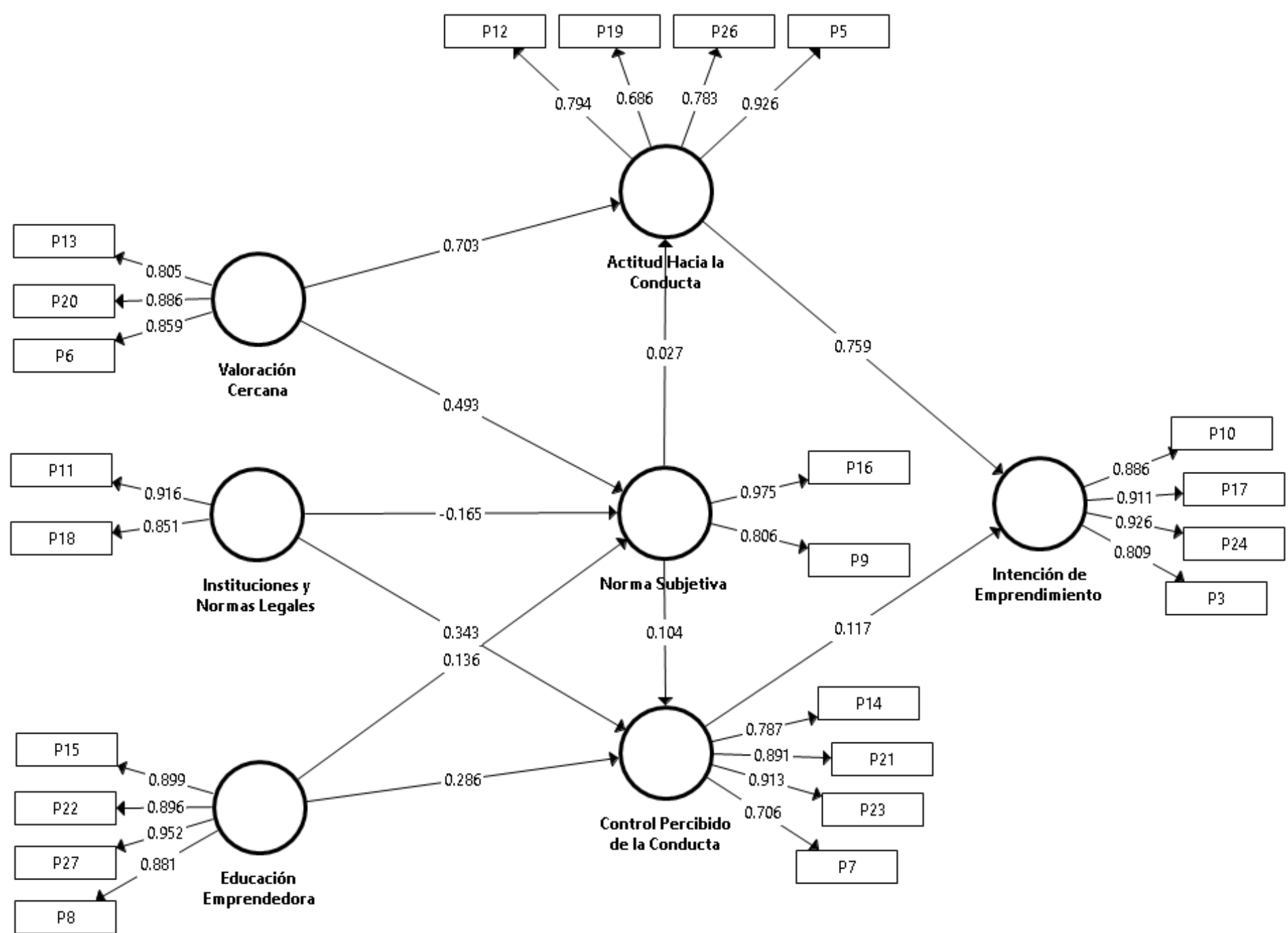

Figura 14. Modelo de Estudio Propuesto. Datos obtenidos en el estudio 2016. 


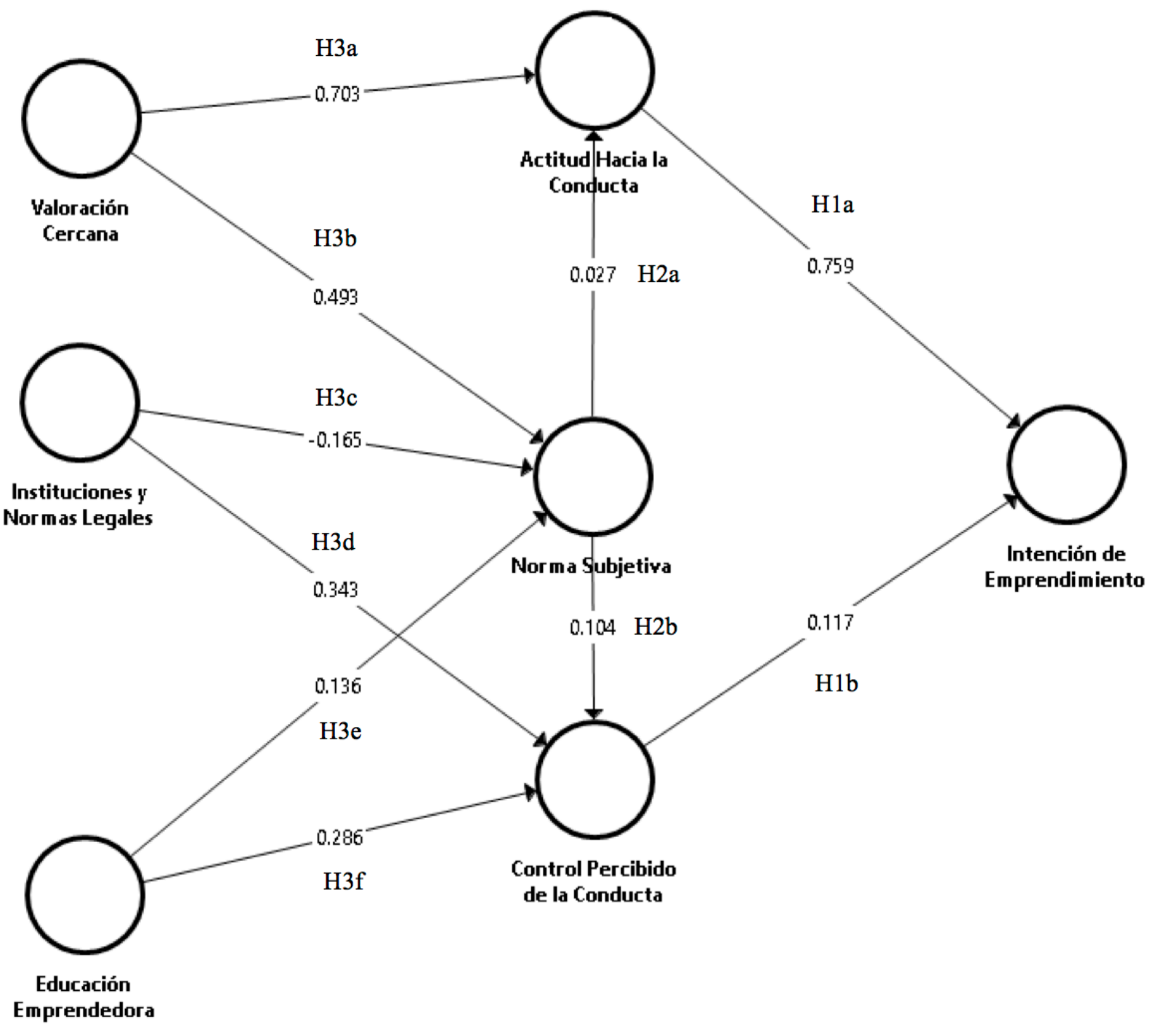

Figura 15. Modelo de Estudio Propuesto con Hipótesis. Datos obtenidos en el estudio 2016. 


\section{Con respecto a la validación de las hipótesis sobre la Teoría del Comportamiento}

\section{Planificado de Ajzen (1991):}

1. Se comprobó la Teoría del Comportamiento Planificado de Ajzen (1991), es decir, se confirmaron las hipótesis H1a, H1b, H2a y H2b las cuales establecen que existe un impacto positivo de la Actitud hacia la Conducta y el Control Percibido de la Conducta hacia la Intención de Emprendimiento (.759 y .117 para las hipótesis H1a y H1b); así como también, existe un impacto positivo de la Norma Subjetiva hacia la Actitud hacia la Conducta y el Control Percibido de la Conducta (.027 y .104 para las hipótesis $\mathrm{H} 2 \mathrm{a}$ y H2b). Por consiguiente, se confirma que el proceso cognitivo en la intención de emprender sería formado en base a los antecedentes motivacionales de los estudiantes (Ajzen, 1991; Liñán \& Chen, 2009; Liñán et al., 2011).

2. La Norma Subjetiva tiene mayor impacto sobre el Control Percibido de la Conducta que sobre la Actitud hacia la Conducta (.104 vs .027), resultados que difieren de los estudios previos de Liñán y Chen (2009) y Liñán et al. (2011) donde la Norma Subjetiva tiene mayor impacto sobre la Actitud hacia la Conducta, ya sea influenciado por la Valoración Cercana y/o por la Valoración Social. Esta última relación coincide con los resultados de esta investigación, ya que los tres factores que explican la Norma Subjetiva ejercen un impacto sobre ella (.493, -.165 y .136). Por su parte, la diferencia de resultados podría estar influenciada en que si bien es cierto la Norma Subjetiva mide la presión percibida por el entorno cercano y social para crear una empresa; y a su vez, contribuye a la intención de emprendimiento de forma indirecta a través de su influencia sobre la Actitud hacia la Conducta y el Control Percibido de la Conducta (Ajzen, 1991); su contribución se ve afectada cuando se trata de personas que tienen la percepción de que ellas mismas controlan su vida (Ajzen, 2002; Armitage \& Conner, 2001), lo que concuerda con los hallazgos de la 
versión peruana del Global Entrepreneurship Monitor que sostiene que la mayoría de la población adulta del país muestra actitudes positivas hacia el emprendimiento a través de la autopercepción de capacidades para emprender. En ese sentido, para los estudiantes es más importante su percepción de facilidad o dificultad para emprender (.104) que su actitud emprendedora (.027).

3. De los dos factores que explican la Intención de Emprendimiento, la Actitud hacia la Conducta tiene un mayor impacto positivo para los estudiantes (.759 vs .117), lo que concuerda con los resultados encontrados en estudios previos (Liñán \& Chen, 2009; Liñán et al., 2011). En consecuencia, los estudiantes perciben una actitud emprendedora positiva en mayor medida de lo que perciben la facilidad de crear una empresa.

En lo referido a la validación de las hipótesis sobre la Teoría de Liñán et al. (2011) y las dimensiones propuestas en el modelo de estudio:

1. Se comprobó la Teoría de Liñán et al. (2011), es decir, se confirmó que la Valoración Cercana y la Valoración Social como factores ambientales tienen impacto sobre los factores motivacionales de Ajzen (1991). Por tanto, se confirman las hipótesis H3a y H3b las cuales establecen que la Valoración Cercana tiene un impacto positivo sobre la Actitud hacia la Conducta y la Norma Subjetiva (.703 y .493 respectivamente), tal como se asumió en el marco teórico. El impacto positivo de la Valoración Cercana es mayor sobre la Actitud hacia la Conducta que sobre la Norma Subjetiva (.703 vs .493), lo que concuerda con los resultados encontrados en el estudio que se toma como base de Liñán et al. (2011). De manera que, los estudiantes perciben el apoyo de su entorno familiar, grupo de amigos y entorno laboral, lo que contribuye a que desarrollen una actitud emprendedora positiva. 
2. Las hipótesis sobre el impacto de las Instituciones y Normas Legales se confirman parcialmente. La hipótesis $\mathrm{H} 3 \mathrm{c}$ se rechaza ya que las Instituciones y Normas Legales no tienen un impacto positivo sobre la Norma Subjetiva, es decir, los estudiantes tienden a percibir poco soporte de las instituciones que brindan financiamiento para la creación de empresas; así como poco apoyo por parte del marco legal vigente en el país para fomentar la creación de empresas (-.165). Por otro lado, se confirma la hipótesis H3d la cual establece que las Instituciones y Normas Legales tienen un impacto positivo sobre el Control Percibido de la Conducta (.343), tal como se asumió en el marco teórico. El impacto positivo de las Instituciones y Normas Legales sobre el Control Percibido de la Conducta es mayor al impacto negativo que ejerce sobre la Norma Subjetiva (.343 vs .165). Si bien es cierto Liñán et al. (2011) no evaluaron esta dimensión per se, en la dimensión Cultura País que utilizaron para medir el constructo Valoración Social encontraron efectos positivos tanto hacia la Norma Subjetiva como hacia el Control Percibido de la Conducta, por lo que es probable que los siguientes dos aspectos hayan influenciado los resultados: (a) debido a que el tamaño de la muestra es grande esto pudo influenciar para mostrar la relación negativa y positiva en este estudio (Liñán et al., 2011) y/o (b) debido a que se utilizaron nuevos reactivos en esta dimensión esto pudo influenciar para medir mejor el constructo y mostrar la relación negativa y positiva en este estudio (Liñán \& Chen, 2009). A su vez, estos resultados concuerdan con los antecedentes y el marco teórico de esta investigación, donde Moreno, Zacarías y Olmos (2010) sostienen que los países Latinoamericanos son emprendedores por la necesidad económica de buscar otras opciones para completar sus necesidades de consumo y Sánchez (2009) establece que la relación entre la actividad emprendedora de un país y su infraestructura política - económica no es siempre positiva y lineal. En suma, los 
estudiantes perciben poco apoyo por parte de las Instituciones y Normas Legales del país, lo cual disminuye su percepción de facilidad para crear una empresa e incrementa su percepción de necesidad para desarrollar habilidades y conocimientos necesarios para iniciar un negocio.

La dimensión Instituciones y Normas Legales es la primera de las 2 dimensiones que se proponen en este estudio con la finalidad de construir un modelo completo sobre la Valoración Social como factor ambiental; y, con los resultados obtenidos se confirma su incidencia tanto positiva como negativa, lo cual responde a las interrogantes planteadas en los estudios previos (Fayolle \& Liñán, 2014; Liñán et al., 2013; Liñán et al., 2011).

3. Se confirma las hipótesis H3e y H3f las cuales establecen que la Educación Emprendedora tiene un impacto positivo sobre la Norma Subjetiva y el Control Percibido de la Conducta (.136 y .286), tal como se asumió en el marco teórico. El impacto positivo de la Educación Emprendedora es mayor sobre el Control Percibido de la Conducta que sobre la Norma Subjetiva (.286 vs .136). Esta dimensión no fue analizada por Liñán et al. (2011) pero sí fue recomendada por ellos para futuros análisis. En resumen, los estudiantes incrementan su percepción de facilidad para crear una empresa y reducen su percepción de necesidad para desarrollar habilidades y conocimientos necesarios para iniciar un negocio a través del aporte positivo que perciben al estudiar una carrera universitaria; ya que su formación académica contribuye a desarrollar su intención de emprendimiento por medio de los cursos de la malla curricular, la metodología de enseñanza, la cultura y las actividades complementarias sobre emprendimiento.

La dimensión Educación Emprendedora es la segunda de las 2 dimensiones que se proponen en el presente estudio con la finalidad de construir un modelo completo 
sobre la Valoración Social como factor ambiental; y, con los resultados obtenidos se confirma su incidencia, lo cual responde a las interrogantes planteadas en los estudios previos (Fayolle \& Liñán, 2014; Liñán et al., 2011; Nabi, Liñán, et al., 2016).

En cuanto al Modelo de Análisis Propuesto. El modelo explicó el 69\% de la varianza en la Intención de Emprendimiento basado en los tres Factores Motivacionales de Ajzen (1991), los cuales se ven influenciados por los Factores Ambientales de Liñán et al. (2011). Estos resultados fueron altamente satisfactorios en comparación al estudio que se tomó como base de Liñán et al. (2011) el cual explicó el 53.5\%. En consecuencia, se cumplen los objetivos de la investigación, ya que se logra identificar los Factores Motivacionales y los Factores Ambientales que inciden en la Intención de Emprendimiento de Universitarios Adultos con Experiencia Laboral. Finalmente, cabe mencionar que no se encontraron relaciones no hipotetizadas. 


\section{Capítulo V: Conclusiones y Recomendaciones}

A continuación se presentan las conclusiones y recomendaciones de la investigación:

\subsection{Conclusiones.}

La participación de los estudiantes de las universidades USIL, UTP y UPC expresan las siguientes conclusiones para el estudio:

\section{Con respecto al modelo de análisis propuesto:}

1. Se identificaron los tres factores motivacionales que inciden en la intención de emprendimiento de universitarios adultos con experiencia laboral, los cuales son la Actitud hacia la Conducta, la Norma Subjetiva y el Control Percibido de la Conducta, al confirmarse las hipótesis H1a, H1b, H2a y H2b.

2. Se identificaron los tres factores ambientales que inciden en la intención de emprendimiento de universitario adultos con experiencia laboral, los cuales son la Valoración Cercana, la Educación Emprendedora y las Instituciones y Normas Legales, al confirmarse las hipótesis H3a, H3b, H3d, H3e y H3f; observándose que las Instituciones y Normas Legales tienen una incidencia negativa sobre la intención de emprendimiento de universitarios adultos con experiencia laboral ya que se rechaza la hipótesis $\mathrm{H} 3 \mathrm{c}$, lo cual refleja la percepción negativa que tienen los estudiantes sobre el apoyo recibido por parte de las Instituciones y Normas Legales.

3. El modelo de análisis propuesto plantea a los constructos Educación Emprendedora e Instituciones y Normas Legales como factores ambientales que inciden en la intención de emprendimiento de universitarios adultos con experiencia laboral; y los resultados obtenidos identifican que la Educación Emprendedora ejerce una incidencia positiva sobre la Norma Subjetiva y el Control Percibido de la Conducta; mientras que, las Instituciones y Normas Legales ejercen una incidencia negativa sobre la Norma Subjetiva y una incidencia positiva sobre el Control Percibido de la 
Conducta. Estos resultados constituyen el aporte de esta tesis, ya que permiten identificar que las universidades e instituciones públicas y privadas juegan un rol importante en el desarrollo de la Intención de Emprendimiento de Universitarios Adultos con Experiencia Laboral.

4. Se confirmó la Teoría del Comportamiento Planificado de Ajzen (1991), la cual establece que los Factores Motivacionales inciden en la Intención y cualquier otra variable tendrá un efecto indirecto. Sumado a ello y en concordancia, se confirmó la Teoría de Liñán et al. (2011) la cual establece que los Factores Ambientales referidos a la Valoración Cercana y la Valoración Social inciden en la Teoría del Comportamiento Planificado de Ajzen (1991).

\section{En lo que respecta al instrumento:}

1. El instrumento Intención de Emprendimiento de Universitarios Adultos con Experiencia Laboral cumplió con los requerimientos de fiabilidad y validez exigidos para un estudio de investigación doctoral.

2. Algunos ítems fueron eliminados como resultado del análisis de fiabilidad. En particular el ítem P2 de la dimensión Norma Subjetiva y los ítems P4 y P25 de la dimensión Instituciones y Normas Legales fueron eliminados, lo que disminuyó la cantidad de indicadores que contribuyen a medir dichas dimensiones.

A modo de síntesis, las percepciones referidas al entorno cercano, el marco legalinstitucional y la educación emprendedora tienen una incidencia en los factores motivacionales de atractivo y factibilidad que determinan la intención de emprender de los universitarios adultos con experiencia laboral de todas las carreras de las universidades USIL, UTP y UPC. 


\subsection{Recomendaciones.}

A continuación se presentan las recomendaciones del estudio, teniendo en cuenta los resultados obtenidos, las limitaciones de la investigación y las futuras líneas de investigación:

\section{Con respecto al modelo de análisis propuesto:}

1. Debido a que el aporte de esta tesis, comprueba que la Educación Emprendedora y las Instituciones y Normas Legales inciden en la Intención de Emprendimiento de Universitarios Adultos con Experiencia Laboral, se requiere que las universidades e instituciones públicas y privadas, una vez que tomen conocimiento de estos resultados, continúen desarrollando acciones que favorezcan el emprendimiento en sus respectivos ámbitos de influencia, ya que así transmitirán un mensaje positivo de su valoración hacia el desarrollo de la intención de emprendimiento.

\section{En lo referido a las características de los participantes:}

1. Debido a que esta investigación tuvo limitaciones en el acceso a las universidades, se recomienda que la Escuela de Post Grado de la USIL desarrolle acuerdos institucionales que faciliten la obtención de datos primarios en los diferentes campos de investigación doctoral; por ejemplo, se podría firmar un acuerdo con el Consejo Nacional de Ciencia, Tecnología e Innovación Tecnológica (CONCYTEC) para que respalde la investigación del doctorando frente a otras universidades y se facilite el acceso a ellas; lo cual estaría alineado con la misión institucional de CONCYTEC enmarcada en promover y gestionar acciones para generar y transferir conocimiento científico y tecnologías a favor del desarrollo social y económico del país; y, con sus objetivos de mejorar la calidad de gasto a través de facilidades para la investigación, innovación y transferencia tecnológica (CONCYTEC, 2015).

2. Como consecuencia del punto anterior, se hace necesario realizar futuras investigaciones en diferentes universidades con la finalidad de validar el modelo de 
análisis propuesto y poder así ampliar los resultados obtenidos. Asimismo, se sugiere replicar la investigación en estudiantes de post grado de maestrías porque presentan características similares con la población analizada, ya que también son adultos con experiencia laboral.

\section{En lo que respecta al instrumento:}

1. Debido a que el ítem P2 de la dimensión Norma Subjetiva y los ítems P4 y P25 de la dimensión Instituciones y Normas Legales fueron eliminados se recomienda revisarlos y probablemente mejorarlos. En paralelo, para los ítems restantes en estas dimensiones se recomienda revisarlos y probablemente agregar algunos ítems que contribuyan a medir mejor el constructo. En suma, se recomienda mejorar el instrumento Intención de Emprendimiento de Universitarios Adultos con Experiencia Laboral, específicamente en los ítems correspondientes a las dimensiones de Norma Subjetiva e Instituciones y Normas Legales.

2. Si posterior a la revisión de los ítems correspondientes a las dimensiones de Norma Subjetiva e Instituciones y Normas Legales se decide agregar nuevos ítems, se recomienda que éstos no sean inversos, ya que incrementan la dificultad en el correcto llenado del cuestionario y no garantizan la eliminación del sesgo en las respuestas (Liñán \& Chen, 2009; Liñán et al., 2011).

\section{Acerca de las futuras líneas de investigación:}

1. Para los investigadores relacionados al tema, se recomienda como futuras líneas de investigación profundizar en la incidencia de los factores ambientales sobre los factores motivacionales, específicamente en lo referido a la dimensión Instituciones y Normas Legales; ya sea que utilicen el modelo de análisis propuesto en este estudio o decidan ampliarlo. 
2. Finalmente, es mi propósito como investigadora, continuar y profundizar en temas relacionados al emprendimiento, en ese sentido, esta tesis será el punto de partida para realizar futuras investigaciones sobre el tema. 


\section{Referencias}

Abdullah, F. A., \& Samah, B. A. (2013). Factors influencing inclination toward agriculture entrepreneurship among students in agriculture learning institute. Asian Social Science, 10(2), 273-278. doi.org/10.5539/ass.v10n2p273

Ahmed, I., A. M., \& Ijaz, H. A. (2011). External factors and entrepreneurial career intentions: Moderating role of personality traits. International Journal of Academic Research, 3(5), $262-267$.

Ajzen, I. (1991). The theory of planned behaviour. Organizational Behavior and Human Decision Processes, 50, 179-211.

Ajzen, I. (2002). Perceived behavioral control, self-efficacy, locus of control, and the theory of planned behavior1. Journal of Applied Social Psychology, 32(4), 665-683. doi.org/10.1111/j.1559-1816.2002.tb00236.x

Ajzen, I. (2011). The theory of planned behaviour: Reactions and reflections. Psychology \& Health, 26(9), 1113-1127. doi.org/10.1080/08870446.2011.613995

Ajzen, I., \& Fishbein, M. (1980). Understanding attitudes and predicting social behavior. n. Recuperado de https://www.researchgate.net/publication/304534338_Understanding_Attitudes_and_Pre dicting_Social_Behavior

Armitage, C. J., \& Conner, M. (2001). Efficacy of the theory of planned behaviour: A metaanalytic review. British Journal of Social Psychology, 40(4), 471.

Autio, E., Keeley, R. H., Klofsten, M., Parker, G. G. C., \& Hay, M. (2001). Entrepreneurial intent among students in Scandinavia and in the USA. Enterprise \& Innovation Management Studies, 2(2), 145-160. doi.org/10.1080/14632440110094632 
Bae, T. J., Qian, S., Miao, C., \& Fiet, J. O. (2014). The relationship between entrepreneurship education and entrepreneurial intentions: A meta-analytic review. Entrepreneurship Theory and Practice, 38(2), 217-254. doi.org/10.1111/etap.12095

Baker, R., Brick, J. M., Bates, N. A., Battaglia, M., Couper, M. P., Dever, J. A., ... Tourangeau, R. (2013). Summary report of the AAPOR task force on non-probability sampling. Journal of Survey Statistics and Methodology, 1(2), 90-143. doi.org/10.1093/jssam/smt008

Bandura, A. (1997). Self-efficacy: The exercise of control. Recuperado de https://www.researchgate.net/publication/229068345_SelfEfficacy_The_Exercise_of_Control

Bandura, A. (1982). Self-efficacy mechanism in human agency. American Psychologist, 37(2), 122-147. doi.org/10.1037/0003-066X.37.2.122

Baptist, J. (1803). Traité d'economie politique. Recuperado de http://classiques.uqac.ca/classiques/say_jean_baptiste/traite_eco_pol/Traite_eco_pol_Liv re_1.doc

Baumol, W. J. (1993). Formal entrepreneurship theory in economics: Existence and bounds. Journal of Business Venturing, 8(3), 197-210. doi.org/10.1016/0883-9026(93)90027-3

Baumol, W. J. (1996). Entrepreneurship: Productive, unproductive and destructive. The Journal of Political Economy, 98, 893-921.

Beugelsdijk, S., \& Smeets, R. (2008). Entrepreneurial culture and economic growth: Revisiting McClelland's thesis. American Journal of Economics \& Sociology, 67(5), 915-939. doi:10.1111/j.1536-7150.2008.00602.x

Birch, D. L. (1987). Job creation in America: How our sallest companies put the most people to work. Free Press. 
Bird, B. J. (1988). Implementing entrepreneurial ideas: The case for intention. The Academy of Management Review, 13(3), 442-453.

Bloomberg (2016, agosto 1). Las mujeres solo necesitan la mitad que los hombres para emprender. El Comercio.

Burnkrant, R. E., \& Page, T. J. (1982). An examination of the convergent, discriminant, and predictive validity of Fishbein's behavioral intention model. Journal of Marketing Research, 19(4), 550. doi.org/10.2307/3151726

Bygrave, W., \& Miniti, M. (2000). The social dynamics of entrepreneurship. Entrepreneurship Theory and Practice, 24(3), 25-36.

Cantillon, R. (1732). Essay on the nature of commerce. Recuperado de https://www.researchgate.net/publication/228247396_Essay_on_the_Nature_of_Commer ce_in_General_Essai_Sur_La_Nature_Du_Commerce_En_General

Carey, T. A., Flanagan, D. J., \& Palmer, T. B. (2010). An examination of university student entrepreneurial intentions by type of venture. Journal of Developmental Entrepreneurship, 15(4), 503-517.

Chan, M., \& Balam, J. (2011). Comparación del nivel de emprendimiento de los alumnos de dos universidades tecnológicas. Global Conference on Business \& Finance Proceedings, $6(2), 1261-1272$.

Chandler, G. N., \& Lyon, D. W. (2001). Issues of research design and construct measurement in entrepreneurship research: The past decade. Entrepreneurship: Theory \& Practice, 25(4), 101.

Chen, C. C., Greene, P. G., \& Crick, A. (1998). Does entrepreneurial self-efficacy distinguish entrepreneurs from managers? Journal of Business Venturing, 13(4), 295-316. doi.org/10.1016/S0883-9026(97)00029-3 
CONCYTEC (2015). Memoria de la gestión institucional 2015 (Memoria Anual).

Recuperado de https://portal.concytec.gob.pe/index.php/publicaciones/memoriainstitucional/item/221-memoria-institucional-2015

Cumplido, F. J. S., \& Liñán, F. (2006). La influencia del capital social sobre los empresarios potenciales. Estudios de Economía Aplicada, 24(2), 459-490.

Da Fonseca, B. M, Aguiar, D., Laguía, A., Moriano, J. A., \& Salazar, V. J. (2016).

Entrepreneurial intention among university students: Adaptation and validation of a scale (QIE). Avaliação Psicológica, 15(2), 187-196. doi: 10.15689/ap.2016.1502.07

De Arquer, M. I. (1995). Fiabilidad humana: Métodos de cuantificación, Juicio de Expertos.

Recuperado de

http://www.insht.es/InshtWeb/Contenidos/Documentacion/FichasTecnicas/NTP/Ficheros /401a500/ntp_401.pdf

DeTienne, D. R., \& Chandler, G. N. (2004). Opportunity identification and its role in the entrepreneurial classroom: A pedagogical approach and empirical test. Academy of Management Learning \& Education, 3(3), 242-257.

doi.org/10.5465/AMLE.2004.14242103

Douglas, E. J., \& Shepherd, D. A. (2002). Self-employment as a career choice: Attitudes, entrepreneurial intentions, and utility maximization. Entrepreneurship: Theory \& Practice, 26(3), 81-90.

Drucker, P. F. (1964). Managing for Results. New York: Harper Business.

El Comercio (2016a, Octubre 17). Educación total - prepárate. El Comercio.

El Comercio (2016b, Noviembre 7). Educación total: Para Ejecutivos. El Comercio.

El Comercio (2016c, Noviembre 7). Radiografía del emprendimiento y la innovación en el Perú. El Comercio. 
Escurra, L. M. (1988). Cuantificación de la validez de contenido por criterio de jueces. Recuperado de http://www.revistas.pucp.edu.pe/index.php/psicologia/article/viewFile/4555/4534

Fayolle, A., Basso, O., \& Tornikoski, E. (2011). Entrepreneurial commitment and new venture creation: A conceptual exploration. Handbook of Research on New Venture Creation, 160-182. doi.org/10.4337/9780857933065

Fayolle, A., \& Liñán, F. (2014). The future of research on entrepreneurial intentions. Journal of Business Research, 67(5), 663-666. doi.org/10.1016/j.jbusres.2013.11.024

Fernandez, J., Liñán, F., \& Santos, F. J. (2009). Cognitive aspects of potential entrepreneurs in southern and northern Europe: An analysis using GEM-Data. Revista de Economia Mundial, (23), 151-178.

Fernández-Serrano, J., \& Liñán, F. (2014). Culture and entrepreneurship: The case of Latin America. Innovar, 24(1Spe), 169-180. doi.org/10.15446/innovar.v24n1spe.47616

Fischhoff, B., Slovic, P., \& Lichtenstein, S. (1983). The public vs. the experts: Perceived vs. actual disagreements about risks of nuclear power. En V. T. Covello, W. G. Flamm, J. V. Rodricks, \& R. G. Tardiff (Eds.), The analysis of actual versus perceived risks (pp. 235249). Boston, MA: Springer US.

Fitzsimmons, J. R., \& Douglas, E. J. (2011). Interaction between feasibility and desirability in the formation of entrepreneurial intentions. Journal of Business Venturing, 26(4), 431440. doi.org/10.1016/j.jbusvent.2010.01.001

Fornell, C., \& Bookstein, F. L. (1982). Two etructural equation models: LISREL and PLS applied to consumer exit-voice theory. Journal of Marketing Research, 19(4), 440. doi.org/10.2307/3151718 
Frank, H., Kessler, A., \& Fink, M. (2010). Entrepreneurial orientation and business performance - A replication study. Schmalenbach Business Review (SBR), 62(2), 175198.

Friar, J. H., \& Meyer, M. H. (2003). Entrepreneurship and start-ups in the Boston region: Factors differentiating high-growth ventures from micro-ventures. Small Business Economics, 21(2), 145-152.

Funders and Founders (2016, noviembre 7). Mil millones de emprendedores en el 2023. Gestión, p. 14.

Galloway, L., \& Brown, W. (2002). Entrepreneurship education at university: a driver in the creation of high growth firms? Education + Training, 44(8/9), 398-405. doi.org/10.1108/00400910210449231

García, D. (2013). Aportaciones para el análisis de la cultura empresarial en la universidad Mexicana. Recuperado de http://search.ebscohost.com/login.aspx?direct=true\&db=zbh\&AN=91024885\&lang=es\& site $=$ ehost-live

Gartner, W. B., Shaver, K. G., Gatewood, E., \& Katz, J. A. (1994). Finding the entrepreneur in entrepreneurship. Entrepreneurship Theory and Practice, 18, 5-5.

Gatewood, E. J., Shaver, K. G., Powers, J. B., \& Gartner, W. B. (2002). Entrepreneurial expectancy, task effort, and performance. Entrepreneurship Theory and Practice, 27(2), 187-206. doi.org/10.1111/1540-8520.00011

Gefen, D., Straub, D., \& Boudreau, M.-C. (2000). Structural equation modeling and regression: Guidelines for research practice. Communications of the Association for Information Systems, 4(1), 7. 
Gelard, P. (2011). Impact of some contextual factors on entrepreneurial intention of university students. African Journal of Business Management, 5(26). doi.org/10.5897/AJBM10.891

González, J., \& Rodríguez, M. (2008). Diagnóstico y valoración del nivel de desarrollo del espíritu empresarial (Entrepreneurship) de los estudiantes de la facultad seccional Sogamoso de la UPTC. (Spanish). Pensamiento \& Gestión, 24, 225-255.

Grajeda, V. (2016, noviembre 24). Perú entre los países que menos invierte en I+D. La República. Recuperado de http://cdn7.larepublica.pe/impresa/economia/824552-peruentre-los-paises-que-menos-invierte-en-id

Gupta, V. K., Turban, D. B., Wasti, S. A., \& Sikdar, A. (2009). The role of gender stereotypes in perceptions of entrepreneurs and intentions to become an entrepreneur. Entrepreneurship: Theory \& Practice, 33(2), 397-417. doi.org/10.1111/j.1540$6520.2009 .00296 . x$

Hair, J. F., Ringle, C. M., \& Sarstedt, M. (2011). PLS-SEM: Indeed a silver bullet. The Journal of Marketing Theory and Practice, 19(2), 139-152. doi.org/10.2753/MTP10696679190202

Hayton, J. C., \& Cholakova, M. (2012). The role of affect in the creation and intentional pursuit of entrepreneurial ideas. Entrepreneurship Theory and Practice, 36(1), 41-68. doi.org/10.1111/j.1540-6520.2011.00458.x

Henry, C., Hill, F., \& Leitch, C. (2005). Entrepreneurship education and training: can entrepreneurship be taught? Part I. Education + Training, 47(2), 98-111. doi.org/10.1108/00400910510586524

Hwang, H., Malhotra, N. K., Kim, Y., Tomiuk, M. A., \& Hong, S. (2010). A comparative study on parameter recovery of three approaches to structural equation modeling. Journal of Marketing Research, 47(4), 699-712. 
Instituto Nacional de Estadística e Informática (2011). II Censo nacional universitario 2010: Principales resultados. Lima, Perú: Instituto Nacional de Estadística e Informática. Ipsos Perú (2016, diciembre 11). Encuesta nacional urbana. El Comercio.

Ismail, M., Khalid, S. A., Othman, M., Jusoff, H. K., Rahman, N. A., Kassim, K. M., \& Zain, R. S. (2009). Entrepreneurial Intention among Malaysian Undergraduates. International Journal of Business and Management, 4(10). doi.org/10.5539/ijbm.v4n10p54

González, J., \& Rodríguez, T. (2008). Diagnóstico y valoración del nivel de desarrollo del espíritu empresarial (Entrepreneurship) de los estudiantes de la facultad seccional Sogamoso de la UPTC. (Spanish). Pensamiento \& Gestión, (24), 225-255.

Kailer, N. (2009). Entrepreneurship education: Empirical findings and proposals for the design of entrepreneurship education education concepts at universities in Germanspeaking countries. Journal of Enterprising Culture, 17(2), 201-231.

Katz, J., \& Gartner, W. B. (1988). Properties of emerging organizations. The Academy of Management Review, 13(3), 429. doi.org/10.2307/258090

Kautonen, T., Van, M., \& Tornikoski, E. T. (2011). Predicting entrepreneurial behaviour: A test of the theory of planned behaviour. Applied Economics, 45(6), 697-707. doi.org/10.1080/00036846.2011.610750

Kavadia, N. (2013). Coefficient alpha interpret with caution. 9(4), 687-696. doi.org/10.5964/ejop.v9i4.653

Keat, O. Y., Selvarajah, C., \& Meyer, D. (2011). Inclination towards entrepreneurship among university students: An empirical study of Malaysian university students. International Journal of Business and Social Science, 2(4), 206-220.

Klein, S. B., Astrachan, J. H., \& Smyrnios, K. X. (2005). The F-PEC scale of family influence: Construction, validation, and further implication for theory. Entrepreneurship Theory and Practice, 29(3), 321-339. doi.org/10.1111/j.1540-6520.2005.00086.x 
Kolvereid, L. (1996). Prediction of employment status choice intentions. Entrepreneurship: Theory \& Practice, 21(1), 47-57.

Kolvereid, L., \& Moen, Ø. (1997). Entrepreneurship among business graduates: does a major in entrepreneurship make a difference? Journal of European Industrial Training, 21(4), 154-160. doi.org/10.1108/03090599710171404

Krueger Jr., N. F., \& Brazeal, D. V. (1994). Entrepreneurial potential and potential entrepreneurs. Entrepreneurship: Theory \& Practice, 18(3), 91-104.

Krueger JR, N. F., Reilly, M. D., \& Carsrud, A. L. (2000). Competing models of entrepreneurial intentions. Journal of Business Venturing, 15(5-6), 411-432. doi.org/10.1016/S0883-9026(98)00033-0

Krueger, N. F. (2007). What lies beneath? The experiential essence of entrepreneurial thinking. Entrepreneurship Theory and Practice, 31(1), 123-138. doi.org/10.1111/j.1540-6520.2007.00166.x

Kuehn, K. W. (2008). Entrepreneurial intentions research: Implications for entrepreneurship education. Journal of Entrepreneurship Education, 11, 87-98.

Kuratko, D. F. (2005). The emergence of entrepreneurship education: Development, trends, and challenges. Entrepreneurship Theory and Practice, 29(5), 577-598. doi.org/10.1111/j.1540-6520.2005.00099.x

Kyrö, P., \& Carrier, C. (2005). Entrepreneurial learning in universities: Bridges across borders. En University of Tampere - Faculty of Education, The dynamics of learning entrepreneurship in a cross-cultural university context (pp. 68-102). Tampere, Finlandia: Saarijärven Offset.

Laborde, M. N., \& Veiga, L. (2010). Emprendimiento y desarrollo económico. Revista de Antiguos Alumnos del IEEM, 13(4), 84-85. 
Lee, L., Wong, P. K., Foo, M. D., \& Leung, A. (2011). Entrepreneurial intentions: The influence of organizational and individual factors. Journal of Business Venturing, 26(1), 124-136. doi.org/10.1016/j.jbusvent.2009.04.003

Leyva, O., \& Olague, J. T. (2014). Modelo de ecuaciones estructurales por el método de mínimos cuadrados parciales (Partial Least Squares-PLS). Recuperado de http://eprints.uanl.mx/8583/

Liñán, F. (2004). Intention-based models of entrepreneurship education. Piccolla Impresa/Small Business, 3(1), 11-35.

Liñán, F., \& Chen, Y.-W. (2009). Development and cross-cultural application of a specific instrument to measure entrepreneurial intentions. Entrepreneurship: Theory \& Practice, 33(3), 593-617. doi.org/10.1111/j.1540-6520.2009.00318.x

Liñán, F., \& Santos, F. J. (2007). Does social capitalaffect entrepreneurial intentions? International Advances in Economic Research, 13(4), 443-453.

Liñán, F., Fernández-Serrano, J., \& Romero, I. (2013). Necessity and opportunity entrepreneurship: The mediating effect of culture. Revista de Economía Mundial, 33, 2147.

Liñán, F., Jaén, I., \& Ortega, F. J. (2015). Entrepreneurship, regional development and culture (pp. 53-73). Berlin, Alemania: Springer International Publishing.

Liñán, F., Moriano, J. A., Romero, I., Rueda, S., Tejada, P., \& Fernández, J. (2009). Vie project: Cultural values and socioeconomic factors as determinants of entrepreneurial intentions. Recuperado de http://www.academia.edu/download/5299653/vieproject202009.pdf

Liñán, F., Urbano, D., \& Guerrero, M. (2011). Regional variations in entrepreneurial cognitions: Start-up intentions of university students in Spain. Entrepreneurship \& Regional Development, 23(3/4), 187-215. doi.org/10.1080/08985620903233929 
Lu, W., Wang, W., \& Millington, J. K. (2010). Comparison of entrepreneurial intention among college students in the USA and China. International Journal of Pluralism and Economics Education, 1(4), 327. doi.org/10.1504/IJPEE.2010.037974

Malebana, M. (2014). The effect of knowledge of entrepreneurial support on entrepreneurial intention. Mediterranean Journal of Social Science, 5(20), 1020-1028. doi.org/10.5901/mjss.2014.v5n20p1020

Malhotra, N. K. (2008). Investigación de mercados (5ta ed.). México, D. F., México: Pearson Educación.

Marcoulides, G. A., \& Saunders, C. (2006). PLS: A silver bullet? MIS Quarterly, 30(2), iiiix.

Martin, B. C., McNally, J. J., \& Kay, M. J. (2013). Examining the formation of human capital in entrepreneurship: A meta-analysis of entrepreneurship education outcomes. Journal of Business Venturing, 28(2), 211-224. doi.org/10.1016/j.jbusvent.2012.03.002

Mat, S. C., Maat, S. M., \& Mohd, N. (2015). Identifying factors that affecting the entrepreneurial intention among engineering technology students. Procedia - Social and Behavioral Sciences, 211, 1016-1022. doi.org/10.1016/j.sbspro.2015.11.135

Ministerio de la Producción. (2015). Anuario estadístico industrial, Mipyme y comercio interno 2015 (1ra ed.). Recuperado de http://www.produce.gob.pe/documentos/estadisticas/anuarios/anuario-estadistico-mype2015.pdf

Minniti, M., \& Bygrave, W. (1999). The microfoundations of entrepreneurship. Entrepreneurship: Theory \& Practice, 23(4), 41-52. 
Montiel, O., Marquez, B., Arambula, Z., \& Ordoñez, L. (2012). Intención de emprendimiento en estudiantes: El caso de una universidad pública en Ciudad Juárez, México (pp. 12311243). Presentado en Global Conference on Business and Finance Proceedings, The Institute for Business and Finance Research.

Moreno Zacarías, H. M., \& Olmos, R. E. (2010). Análisis de las características del emprendimiento y liderazgo en los países de Asia y Latinoamérica. Revista Mexicana de Estudios Sobre la Cuenca del Pacifico, 4(8), 101-122.

Moriano, J. A., Palací, F. J., \& Morales, J. F. (2006). Adaptación y validación en España de la escala de autoeficacia emprendedora. Revista de Psicología Social, 21(1), 51-64. doi.org/10.1174/021347406775322223

Nabi, G., \& Holden, R. (2008). Graduate entrepreneurship: Intentions, education and training. Education + Training, 50(7), 545-551. doi.org/10.1108/00400910810909018

Nabi, G., Liñán, F., Krueger, N., Fayolle, A., \& Walmsley, A. (2016). The impact of entrepreneurship education in higher education: A systematic review and research agenda. Academy of Management Learning \& Education, amle-2015.

Nabi, G., Walmsley, A., Liñán, F., Akhtar, I., \& Neame, C. (2016). Does entrepreneurship education in the first year of higher education develop entrepreneurial intentions? The role of learning and inspiration. Studies in Higher Education, 0(0), 1-16. doi.org/10.1080/03075079.2016.1177716

Nahapiet, J., \& Ghoshal, S. (1998). Social capital, intellectual capital, and the organizational advantage. The Academy of Management Review, 23(2), 242. doi.org/10.2307/259373

Nishantha, B. (2009). Influence of personality traits and socio-demographic background of undergraduate students on motivation for entrepreneurial career: The case of Sri Lanka. Research Gate, 49(2), 71-82.

Nunnally, J. C. (1978). Psycometric theory. New York, NY: McGraw-Hill. 
Paredes, L. J. (2016, julio 31). Universidades por el kambio. El Comercio.

Peterman, N. E., \& Kennedy, J. (2003). Enterprise education: Influencing students' perceptions of entrepreneurship. Entrepreneurship Theory and Practice, 28(2), 129-144. doi.org/10.1046/j.1540-6520.2003.00035.x

Pittaway, L., \& Cope, J. (2007). Entrepreneurship education: A systematic review of the evidence. International Small Business Journal, 25(5), 479-510. doi.org/10.1177/0266242607080656

RaguŽ, I. V., \& MatiĆ, M. (2011). Student's perceptions and intentions towards enterpreneurship: The empirical findings from the university of Dubrovnik-Croatia. International Journal of Management Cases, 13(3), 38-49.

Rivera, E. O., \& Pizarro, L. O. (2009). Características emprendedoras de egresados de contador auditor e ingeniería en administración de empresas de la universidad católica del Maule. (spanish). Enterprising Characteristics of Accounting Auditors and Business Administration Graduates from Uuniversidad Católica del Maule, 37, 47-72.

Roldán, J. L., \& Leal, A. (2003). A validation test of an adaptation of the DeLone and McLean's model in the Spanish EIS field. Recuperado de http://www.igiglobal.com/viewtitlesample.aspx id=7266\&ptid=213\&t=A Validation Test of an Adaptation of the DeLone and McLean's Model in the Spanish EIS Field

Sánchez, J. C. (2009). Aprendizaje social e intenciones emprendedoras: Un estudio comparativo entre México, España y Portugal, 41(1), 109-119.

Schumpeter, J. A. (1934). The theory of economic development. Recuperado de http://www.hup.harvard.edu/catalog.php?isbn=9780674879904

Scott, M. G., \& Twomey, D. F. (1988). The long-term supply of entrepreneurs: Students' career aspirations in relation to entrepreneurship. Journal of Small Business Management, 26(4), 5-13. 
Segal, G., Borgia, D., \& Schoenfeld, J. (2005). The motivation to become an entrepreneur. International Journal of Entrepreneurial Behavior \& Research, 11(1), 42-57. doi.org/10.1108/13552550510580834

Serida, J., Alzamora, J., Guerrero, C., Borda, A., \& Morales, O. (2016). Global entrepreneurship monitor, Perú 2015 - 2016. Recuperado de http://www.esan.edu.pe/publicaciones/libros/2016/global-entrepreneurship-monitorperu-2015-2016/

Shapero, A. (1984). The entrepreneurial eEvent. Recuperado de https://books.google.com.pe/books/about/The_Entrepreneurial_Event.html?hl=es\&id=Fx C_nQEACAAJ

Shapero, A., \& Sokol, L. (1982). Social dimensions of entrepreneurship. Encyclopedia of Entrepreneurship, 72-90.

Shinnar, R. S., Giacomin, O., \& Janssen, F. (2012). Entrepreneurial perceptions and intentions: The role of gender and culture. Entrepreneurship: Theory \& Practice, 36(3), 465-493. doi.org/10.1111/j.1540-6520.2012.00509.x

Shook, C. L., Ketchen, D. J., Hult, G. T. M., \& Kacmar, K. M. (2004). An assessment of the use of structural equation modeling in strategic management research. Strategic Management Journal, 25(4), 397-404. doi.org/10.1002/smj.385

Skjong, R., \& Wentworth, B. H. (2000). Expert judgement and risk perception. Recuperado de http://research.dnv.com/skj/Papers/SkjWen.pdf

Spies Blair, B. (2011, junio 20). Does entrepreneurship education have value? Can entrepreneurship be taught? Recuperado de http://www.babson.edu/news-events/babsonnews/Pages/110620-does-entrepreneurship-education-have-value-can-entrepreneurshipbe-taught.aspx 
Superintendencia Nacional de Educación Superior Universitaria - SUNEDU. (2016). Información estadística de universidades. Recuperado de https://www.sunedu.gob.pe/

Thomas, A. S., \& Mueller, S. (2000). A case for comparative entrepreneurship: Assessing the relevance of culture. Journal of International Business Studies, 31(2), 287-301.

Thompson, E. R. (2009). Individual entrepreneurial intent: Construct clarification and development of an internationally reliable metric. Entrepreneurship Theory and Practice, 33(3), 669-694. doi.org/10.1111/j.1540-6520.2009.00321.x

Tong, X. F., Tong, D. Y. K., \& Loy, L. C. (2011). Factors influencing entrepreneurial intention among university students. International Journal of Social Sciences and Humanity Studies, 3, 487-496.

Uddin, M. R., \& Kanti Bose, T. (2012). Determinants of entrepreneurial intention of business students in Bangladesh. International Journal of Business \& Management, 7(24), 128137. doi.org/10.5539/ijbm.v7n24p128

Ullah, H., Farooq, M. A., \& Ahmad, Z. M. (2012). A study of psychological and non psychological factors of owner influencing entrepreneurial orientation: Evidence from Khyber Pakhtunkhwa-Pakistan. Management Science \& Engineering, 6(1), 44-55. doi.org/10.3968/j.mse.1913035X20120601.2700

Van, M., Brand, M., Van Praag, M., Bodewes, W., Poutsma, E., \& van Gils, A. (2008). Explaining entrepreneurial intentions by means of the theory of planned behaviour. Career Development International, 13(6), 538-559. doi.org/10.1108/13620430810901688

Weaver, M., Dickson, P., \& Solomon, G. (2006). The small business economy: A report to the president. Washington, DC: Small Business Administration, Office of Advocacy. 
Wennekers, S., Uhlaner, L., \& Thurik, R. (2002). Entrepreneurship and its conditions: A macro perspective. International Journal of Entrepreneurship Education (IJEE), 1(1), $25-64$.

Wu, S., \& Wu, L. (2008). The impact of higher education on entrepreneurial intentions of university students in China. Journal of Small Business and Enterprise Development, 15(4), 752-774. doi.org/10.1108/14626000810917843

Yusoff, M. N. H. B., Zainol, F. A., \& Ibrahim, M. D. B. (2015). Entrepreneurship education in Malaysia's public institutions of higher learning: A review of the current practices. International Education Studies, 8(1), 17-28.

Zahra, S. A., Jennings, D. F., \& Kuratko, D. F. (1999). The antecedents and consequences of firm-level entrepreneurship: The state of the field. Entrepreneurship: Theory \& Practice, $24,45-65$.

Zhao, H., Seibert, S. E., \& Hills, G. E. (2005). The mediating role of self-efficacy in the development of entrepreneurial intentions. Journal of Applied Psychology, 90(6), 12651272. doi.org/10.1037/0021-9010.90.6.1265 


\section{Apéndice A}

\section{Entrepreneurial Intention Questionnaire (EIQ) versión 3 de Liñán et al., (2011):}

A. Indicate your level of agreement with the following statements about the entrepreneurial activity from 1 (total disagreement) to 7 (total agreement).

A01. Starting a firm and keeping it viable would be easy for me A02. A career as an entrepreneur is totally unattractive to me A03. My friends would approve of my decision to start a business A04. I am ready to do anything to be an entrepreneur A05. I believe I would be completely unable to start a business A06. I will make every effort to start and run my own business A07. I am able to control the creation process of a new business A08. My immediate family would approve of my decision to start a business

A09. I have serious doubts about ever starting my own business A10. If I had the opportunity and resources, I would love to start a business

A11. My colleagues would approve of my decision to start a business A12. Amongst various options, I would rather be anything but an entrepreneur

A13. I am determined to create a business venture in the future A14. If I tried to start a business, I would have a high chance of being successful

A15. Being an entrepreneur would give me great satisfaction

A16. It would be very difficult for me to develop a business idea

A17. My professional goal is to be an entrepreneur

A18. Being an entrepreneur implies more advantages than disadvantages to me

A19. I have a very low intention of ever starting a business

A20. I know all about the practical details needed to start a business

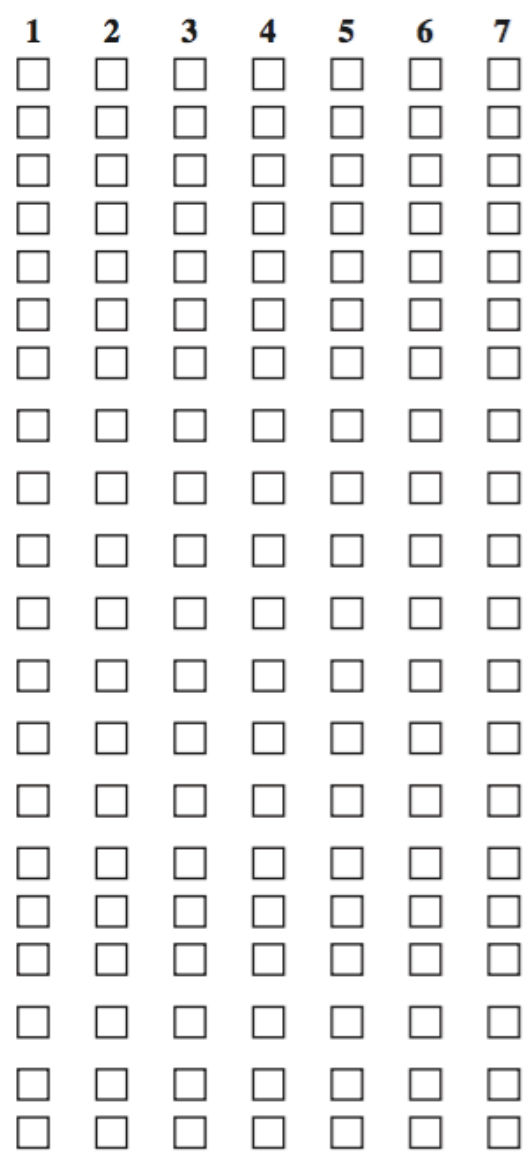

C. Indicate your level of agreement with the following sentences about the values society put on entrepreneurship from 1 (total disagreement) to 7 (total agreement).

C1. My immediate family values entrepreneurial activity above other activities and careers

C2. The culture in my country is highly favourable towards

entrepreneurial activity

C3. The entrepreneur's role in the economy is generally undervalued in my country

C4. My friends value entrepreneurial activity above other activities and careers

C5. Most people in my country consider it unacceptable to be an entrepreneur

C6. In my country, entrepreneurial activity is considered to be worthwhile, despite the risks

C7. My colleagues value entrepreneurial activity above other activities and careers

C8. It is commonly thought in my country that entrepreneurs take advantage of others

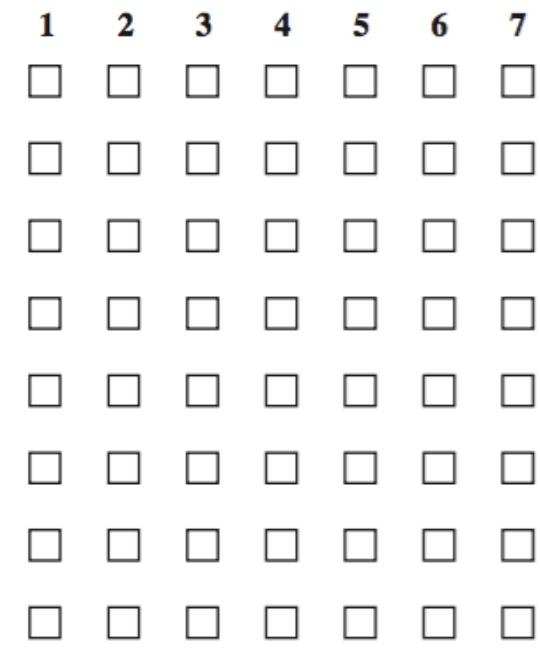




\begin{tabular}{|c|c|c|c|c|c|c|}
\hline \multirow{27}{*}{$\begin{array}{l}\text { Modelo de } \\
\text { Ajzen }\end{array}$} & \multirow{7}{*}{$\begin{array}{c}\text { Intención } \\
\text { Empresarial }\end{array}$} & \multirow{7}{*}{$\begin{array}{l}\text { Intención } \\
\text { Empresarial } \\
\text { IE }\end{array}$} & \multirow{4}{*}{$\begin{array}{l}\text { Grado de } \\
\text { esfuerzo }\end{array}$} & I am ready to do anything to be an entrepreneur & & Estoy listo para hacer de todo para ser empresario \\
\hline & & & & & 1 & He realizado algunas actividades para crear mi propia empresa \\
\hline & & & & I will make every effort to start and run my own business & 8 & Realizaré todos los esfuerzos necesarios para crear mi propia empresa \\
\hline & & & & I have serious doubts about ever starting my own business & & Estoy seguro que crearé mi propia empresa \\
\hline & & & \multirow{3}{*}{ Certeza } & I am determined to create a business venture in the future & 15 & Estoy decidido a crear mi propia empresa \\
\hline & & & & My professional goal is to be an entrepreneur & 22 & Mi objetivo profesional es ser empresario \\
\hline & & & & I have a very low intention of ever starting a business & & Tengo toda la intención de crear mi empresa \\
\hline & \multirow{20}{*}{$\begin{array}{c}\text { Factores } \\
\text { Motivacionales }\end{array}$} & \multirow{6}{*}{$\begin{array}{c}\text { Actitud hacia } \\
\text { la conducta } \\
\text { AHC }\end{array}$} & & A career as an entrepreneur is totally unattractive to me & & Para mi, la carrera de emprendedor es la más atractiva de todas \\
\hline & & & & If I had the opportunity and resources. I would love to start a business & & Me gustaría buscarme la oportunidad y los recursos para crear mi empre \\
\hline & & & \multirow{2}{*}{$\begin{array}{l}\text { Valoración } \\
\text { emocional }\end{array}$} & Among various options, I would rather be anything but an entrepreneur & 2 & De todas las carreras, elegiría ser empresario \\
\hline & & & & Being an entrepreneur would give me great satisfaction & 9 & Ser empresario me representaría una gran satisfacción \\
\hline & & & \multirow{2}{*}{$\begin{array}{l}\text { Valoración } \\
\text { racional }\end{array}$} & & 16 & Ser empresario mejoraría mi situación laboral \\
\hline & & & & Being an entrepreneur implies more advantages than disadvantages to me & 23 & Ser empresario me traería más ventajas que inconvenientes \\
\hline & & \multirow{8}{*}{$\begin{array}{c}\text { Control } \\
\text { percibido de } \\
\text { la conducta } \\
\text { PBC }\end{array}$} & \multirow{2}{*}{$\begin{array}{l}\text { Facilidad / } \\
\text { Dificultad }\end{array}$} & Starting a firm and keeping it viable would be easy for me & 3 & Sería fácil para mi, crear mi propia empresa \\
\hline & & & & & 10 & Sería fácil para mi, desarrollar conocimiento y habilidades para crear mi \\
\hline & & & & It would be very difficult for me to develop a business idea & & Sería muy fácil para mi, implementar una idea de negocio \\
\hline & & & \multirow{2}{*}{$\begin{array}{l}\text { Control / Sentir } \\
\text { que se puede }\end{array}$} & I believe I would be completely unable to start a business & 17 & Soy capaz de crear una empresa exitosa \\
\hline & & & & & 24 & Tengo el conocimiento y habilidades para crear mi propia empresa \\
\hline & & & & I am able to control the creation process of a new business & & Soy capaz de controlar todo el proceso de creación de mi empresa \\
\hline & & & & If I tried to start a business, I would have a high chance of being successful & & Si intento crear mi empresa, tendré una alta probabilidad de ser exitoso \\
\hline & & & & I know all about the practical details needed to start a business & & Conozco todos los detalles prácticos necesarios para crear mi empresa \\
\hline & & \multirow{6}{*}{$\begin{array}{c}\text { Norma } \\
\text { subjetiva } \\
\text { NS }\end{array}$} & \multirow{4}{*}{$\begin{array}{l}\text { Aprobación de } \\
\text { personas } \\
\text { cercanas }\end{array}$} & My inmediate family would approve of my decision to start a business & 4 & Mis padres y hermanos aprobarían la decisión de crear mi empresa \\
\hline & & & & & 11 & Mi esposo(a) e hijos aprobarían la decisión de crear mi empresa \\
\hline & & & & My friends would approve of my decision to start a business & 18 & Mis amigos aprobarían la decisión de crear mi empresa \\
\hline & & & & & 25 & Mis colegas de estudio y trabajo aprobarían la decisión de crear mi empı \\
\hline & & & \multirow{2}{*}{$\begin{array}{l}\text { Importancia de } \\
\text { la aprobación }\end{array}$} & & 29 & Me importa que mi familia (padres, hermanos, esposo(a) e hijos aprueben mi \\
\hline & & & & & 31 & Me importa que mis amigos y colegas de estudio y trabajo aprueben mi \\
\hline \multirow{4}{*}{$\begin{array}{l}\text { Modelo } \\
\text { Liñan, } \\
\text { Urbano y } \\
\text { Guerrero }\end{array}$} & \multirow{15}{*}{$\begin{array}{c}\text { Factores } \\
\text { Ambientales }\end{array}$} & \multirow{4}{*}{$\begin{array}{l}\text { Capital } \\
\text { Social: } \\
\text { Valoración } \\
\text { cercana } \\
\text { VC }\end{array}$} & \multirow{2}{*}{ Familia } & My inmediate family values entrepreneurial activity above other activities and careers & 5 & Mis padres y hermanos valoran la actividad empresarial por encima de $\mathrm{c}$ \\
\hline & & & & & 12 & Mis esposo(a) e hijos valoran la actividad empresarial por encima de otr \\
\hline & & & \multirow{2}{*}{$\begin{array}{l}\text { Amigos y } \\
\text { Colegas }\end{array}$} & My friends values entrepreneurial activity above other activities and careers & 19 & Mis amigos valoran la actividad empresarial por encima de otras activid \\
\hline & & & & My colleagues values entrepreneurial activity above other activities and careers & 26 & Mis colegas de estudio y trabajo valoran la actividad empresarial por encima de otras actividade \\
\hline \multirow{11}{*}{$\begin{array}{l}\text { Constructos } \\
\text { del Modelo } \\
\text { Propuesto en } \\
\text { Estudio }\end{array}$} & & \multirow{11}{*}{$\begin{array}{l}\text { Capital } \\
\text { Social: } \\
\text { Valoración } \\
\text { social } \\
\text { VS }\end{array}$} & \multirow{5}{*}{ Cultura País } & The culture in my country is highly favourable towards entrepreneurial activity & & La cultura de mi país es muy favorable a la actividad empresarial \\
\hline & & & & Most people in my country consider it unacceptable to be an entrepreneur & & En mi país, se considera muy adecuado ser empresario \\
\hline & & & & It is commonly thought in my country tat entrepreneurs take advantage of other & & En mi país, se tiende a pensar que los empresarios contribuyen con los d \\
\hline & & & & The entrepreneur's role in the economy is generally undervalued in my country & & En mi país, se valora mucho el aporte del empresario a nuestra economí: \\
\hline & & & & In my country entrepreneurial activity is considered to be worthwhile, despite the risks & & En mi país se considera que la actividad empresarial merece la pena a p£ \\
\hline & & & \multirow{2}{*}{\multicolumn{2}{|c|}{ Instituciones }} & & En el Perú, existen instituciones que asesoran en la creación de empresa: \\
\hline & & & & & 3 & En el Perú, existen alternativas de financiamiento para la creación de en \\
\hline & & & \multicolumn{2}{|c|}{ Normas Legales } & 0 & En el Perú, el marco legal fomenta la creación de nuevas empresas \\
\hline & & & Experiencia & & 7 & He tenido contacto directo con instituciones que apoyan la creación de e \\
\hline & & & & & & En el transcurso de mi carrera he recibido formación en emprendimientc \\
\hline & & & Cursos de car & & & eral mis curses universitarios me sirven nara formar mi emnresa \\
\hline
\end{tabular}




\section{Apéndice C}

\section{Validez de Contenido - Juicio de Expertos}

A continuación se presenta un ejemplo del proceso de validación de contenido:

\section{CARTA}

Estimado:

Sr. Jorge Mesa Cano

Coordinador Académico Innovación y Emprendimiento

Departamento de Organización y Gerencia Escuela Administración de Negocios Universidad EAFIT

Presente.

Me dirijo a usted con la finalidad de solicitar su valiosa colaboración en calidad de JUEZ para validar el contenido del instrumento "Cuestionario de Intención de Emprendimiento para Universitarios Adultos con Experiencia Laboral" que hace parte de mi investigación doctoral que lleva por título "Factores que Inciden en la Intención de Emprendimiento de Universitarios Adultos con Experiencia Laboral".

Para dar cumplimiento a lo anteriormente expuesto le hago entrega de un Resumen de mi tesis y los formatos de validación para ser llenados de acuerdo a sus observaciones, lo que permitirá que los resultados obtenidos a partir de este instrumento sean utilizados eficientemente para aportar tanto al área de investigación, las universidades, los estudiantes universitarios y el sector empresarial público y privado en general.

Agradezco de antemano su receptividad y valiosa colaboración. Su apoyo me permitirá adquirir habilidades y competencias profesionales y científicas que forman parte del proceso de investigación doctoral. trabajo.

Quedo de Ud. en espera del feedback respectivo para mejorar del presente

Atentamente,

Mag. Jessika Vásquez Neyra

Candidata a Doctora en Administración de Empresas 


\section{INSTRUMENTO PARA LA VALIDEZ DE CONTENIDO POR JUICIO DE EXPERTOS}

\section{Objetivos de la Validez del Contenido del Cuestionario}

\subsection{Objetivo de la Investigación Doctoral}

Identificar los factores motivacionales y ambientales que influyen en la intención de emprender de universitarios adultos con experiencia laboral.

\subsection{Objetivo del Juicio de Expertos}

El cuestionario se basa en el Entrepreneurial Intention Questionnaire (EIQ) versión 3 de los autores Liñan, Urbano y Guerrero (2011), el cual ha sido aplicado en Europa y otras regiones en estudiantes universitarios. En ese sentido, los objetivos de la revisión del experto se enmarcan en:

\subsubsection{Evaluar la adaptación cultural}

El objetivo es evaluar si los ítems adaptados del EIQ miden el mismo constructo en el contexto de la cultura peruana y en estudiantes adultos con experiencia laboral.

\subsubsection{Validar los nuevos indicadores diseñados por la investigadora}

El objetivo es evaluar si los nuevos ítems diseñados para las variables instituciones/normas legales y educación emprendedora, que son las variables agregadas al modelo original como aporte de esta investigación, miden el constructo al que están asociados.

\subsection{Objetivos del Cuestionario}

El presente instrumento tiene como finalidad medir la Intención de Emprendimiento de universitarios adultos con experiencia laboral. El cuestionario será aplicado a una muestra de estudiantes de todas las carreras para personas con experiencia laboral en las universidades San Ignacio de Loyola, Tecnológica del Perú y Peruana de Ciencias Aplicadas; que cursan el último año de estudios. 


\section{Instrucciones}

La evaluación requiere de la lectura detallada y completa de cada uno de los ítems propuestos a fin de cotejarlos de manera cualitativa con los criterios propuestos relativos a: claridad, congruencia, contexto y relevancia. Para ello deberá asignar una valoración si el ítem presenta o no los criterios propuestos, y de ser necesario se ofrece un espacio para las observaciones del caso.

Esta parte corresponde al objetivo 2.2.1 referida a Evaluar la adaptación cultural (EI objetivo es evaluar si los ítems adaptados del EIQ miden el mismo constructo en el contexto de la cultura peruana y en estudiantes adultos con experiencia laboral) y al objetivo 2.2.2 referida a Validar nuevos indicadores (El objetivo es evaluar si los nuevo ítems propuestos por la investigadora miden la influencia de las instituciones y normas legales, así como de la educación emprendedora), para lo cual deberá utilizar la siguiente tabla para calificar cada uno de los ítems según corresponda:

\begin{tabular}{|l|c|l|}
\hline \multicolumn{1}{|c|}{ Categoría } & Calificación & \multicolumn{1}{|c|}{ Significado } \\
\hline Claridad & SI & $\begin{array}{l}\text { El ítem es claro, es decir, se comprende } \\
\text { fácilmente. Su sintáctica y semántica son } \\
\text { adecuadas. }\end{array}$ \\
\cline { 2 - 3 } & NO & $\begin{array}{l}\text { El ítem no cumple con el criterio. No es claro, no } \\
\text { tiene sintáctica ni semántica adecuadas. }\end{array}$ \\
\hline Contexto & SI & $\begin{array}{l}\text { En el ítem todas las palabras son usuales para } \\
\text { nuestro contexto. }\end{array}$ \\
\hline Relevancia & SI & $\begin{array}{l}\text { El ítem no cumple con el criterio. En el ítem las } \\
\text { palabras no son usuales para nuestro contexto. } \\
\text { El ítem es esencial o importante, es decir debe } \\
\text { ser incluido. }\end{array}$ \\
\hline Coherencia & NO & $\begin{array}{l}\text { El ítem no cumple con el criterio. El ítem puede } \\
\text { ser eliminado sin que se vea afectada la } \\
\text { medición de la dimensión. }\end{array}$ \\
\hline & SI & $\begin{array}{l}\text { El ítem tiene relación lógica con el constructo que } \\
\text { está midiendo. }\end{array}$ \\
\hline \multirow{2}{*}{ NO } & $\begin{array}{l}\text { El ítem no cumple con el criterio. No tiene } \\
\text { relación lógica con el constructo que está } \\
\text { midiendo. }\end{array}$ \\
\hline
\end{tabular}


EJEMPLO de calificación:

\section{Calificación de ítems. Marque con un aspa}

\begin{tabular}{|c|c|c|c|c|c|c|c|c|c|c|}
\hline \multirow{2}{*}{ № } & \multirow{2}{*}{ Indicadores } & \multicolumn{2}{|c|}{ Claridad } & \multicolumn{2}{|c|}{ Contexto } & \multicolumn{2}{|c|}{ Relevancia } & \multicolumn{2}{|c|}{ Coherencia } & \multirow{2}{*}{ Observaciones } \\
\hline & & Si & No & Si & No & Si & No & Si & No & \\
\hline 1 & $\begin{array}{l}\text { Estoy dispuesto a hacer todo para ser } \\
\text { empresario }\end{array}$ & & $x$ & $\mathrm{x}$ & & $x$ & & $x$ & & $\begin{array}{l}\text { Cambiar el término "hacer } \\
\text { todo" }\end{array}$ \\
\hline 7 & Mi objetivo profesional es ser empresario & $x$ & & $x$ & & $x$ & & $X$ & & \\
\hline
\end{tabular}

\section{Suficiencia: ¿Todos los ítems presentados para este constructo denominado Intención de} Emprendimiento bastan para obtener su medición?. Marque con un color

1

No cumple con el criterio (Los ítems no son suficientes para medir la dimensión)

2

Bajo Nivel (Los ítems miden algún aspecto de la dimensión pero no corresponden con la dimensión total)

3

Moderado nivel (Se deben incrementar algunos ítems para poder evaluar la dimensión completamente)

$4 \quad$ Alto nivel (Los ítems son suficientes) 
1. Calificación de ítems. Marque con un aspa

\begin{tabular}{|c|c|c|c|c|c|c|c|c|c|c|c|c|c|c|}
\hline \multirow{2}{*}{ Constructo } & \multirow{2}{*}{ Definición } & \multirow{2}{*}{ Objetivo } & \multirow{2}{*}{$\begin{array}{c}\text { Sub } \\
\text { Dimensión }\end{array}$} & \multirow{2}{*}{$\mathbf{N}^{\circ}$} & \multirow{2}{*}{ Indicadores } & \multicolumn{2}{|c|}{ Claridad } & \multicolumn{2}{|c|}{ Contexto } & \multicolumn{2}{|c|}{ Relevancia } & \multicolumn{2}{|c|}{ Coherencia } & \multirow{2}{*}{ Observaciones } \\
\hline & & & & & & Si & No & $\mathbf{S i}$ & No & Si & No & Si & No & \\
\hline \multirow{4}{*}{$\begin{array}{l}\text { Intención de } \\
\text { Emprendimiento }\end{array}$} & \multirow{4}{*}{$\begin{array}{l}\text { El individuo reconoce con certeza que } \\
\text { tiene la intención de establecer un nuevo } \\
\text { negocio y ha previsto conscientemente } \\
\text { hacerlo en algún momento en el futuro. } \\
\text { La escalera empresarial distingue entre } \\
\text { diferentes grados de esfuerzo que el } \\
\text { individuo ha invertido en el proceso de } \\
\text { creación de una empresa. } \\
\text { No son simplemente preguntas de "si o } \\
\text { no"; sino que también, una cuestión de } \\
\text { rangos de "muy poco" a "muy alto". }\end{array}$} & \multirow{4}{*}{\begin{tabular}{|c} 
¿Qué tan \\
probable es \\
que inicie un \\
negocio \\
propio?
\end{tabular}} & \multirow{2}{*}{$\begin{array}{l}\text { Grado de } \\
\text { esfuerzo }\end{array}$} & 1 & $\begin{array}{l}\text { He realizado algunas actividades para } \\
\text { crear mi propia empresa }(N)\end{array}$ & $\mathrm{x}$ & & $\mathrm{x}$ & & $\mathrm{x}$ & & $\mathrm{x}$ & & \\
\hline & & & & 8 & $\begin{array}{l}\text { Realizaré todos los esfuerzos necesarios } \\
\text { para crear mi propia empresa }\end{array}$ & $\mathrm{x}$ & & $\mathrm{x}$ & & $\mathrm{x}$ & & $\mathrm{x}$ & & \\
\hline & & & \multirow[b]{2}{*}{ Certeza } & 15 & $\begin{array}{l}\text { Estoy decidido a crear mi propia } \\
\text { empresa }\end{array}$ & $\mathrm{x}$ & & $\mathrm{x}$ & & $\mathrm{x}$ & & $\mathrm{x}$ & & \\
\hline & & & & 22 & $\begin{array}{l}\text { Mi objetivo profesional es ser } \\
\text { empresario }\end{array}$ & $\mathrm{x}$ & & $\mathrm{x}$ & & $\mathrm{x}$ & & $\mathrm{x}$ & & $\begin{array}{l}\text { No se si se debería colocarle un } \\
\text { horizonte de tiempo, para estar mas } \\
\text { seguros, por ejemplo Mi OBJETIVO } \\
\text { PROFESIONAL ES SER } \\
\text { EMPRESARIO EN DOS AÑOS }\end{array}$ \\
\hline
\end{tabular}

$(N)=$ Nuevo

2. Suficiencia: ¿Todos los ítems presentados para este constructo denominado Intención de Emprendimiento bastan para obtener su medición?. Marque con un color

1 No cumple con el criterio (Los ítems no son suficientes para medir la dimensión)

2 Bajo Nivel (Los ítems miden algún aspecto de la dimensión pero no corresponden con la dimensión total)

3 Moderado nivel (Se deben incrementar algunos ítems para poder evaluar la dimensión completamente)

$4 \quad$ Alto nivel (Los ítems son suficientes)

\section{Si en la pregunta anterior marcó la opción 3, indique qué ítems sugiere agregar}

Ninguna. 


\section{Calificación de ítems. Marque con un aspa}

\begin{tabular}{|c|c|c|c|c|c|c|c|c|c|c|c|c|c|c|}
\hline \multirow{2}{*}{ Constructo } & \multirow{2}{*}{ Definición Operacional } & \multirow{2}{*}{ Objetivo } & \multirow{2}{*}{$\begin{array}{c}\text { Sub } \\
\text { Dimensión }\end{array}$} & \multirow{2}{*}{$\mathbf{N}^{\circ}$} & \multirow{2}{*}{ Indicadores } & \multicolumn{2}{|c|}{ Claridad } & \multicolumn{2}{|c|}{ Contexto } & \multicolumn{2}{|c|}{ Relevancia } & \multicolumn{2}{|c|}{ Coherencia } & \multirow{2}{*}{ Observaciones } \\
\hline & & & & & & Si & No & Si & No & $\mathbf{S i}$ & No & $\mathbf{S i}$ & No & \\
\hline \multirow{4}{*}{$\begin{array}{l}\text { Actitud hacia la } \\
\text { conducta } \\
\text { (AHC) - } \\
\text { Creencias de } \\
\text { comportamiento }\end{array}$} & \multirow{4}{*}{$\begin{array}{l}\text { Grado de valoración positiva o negativa de } \\
\text { convertirse en un emprendedor. Incluye } \\
\text { aspectos emocionales (me gustaria, es } \\
\text { atractivo) y racionales (tiene ventajas). } \\
\text { Se espera que la intención de emprender de un } \\
\text { estudiante esté asociada positivamente con las } \\
\text { creencias de comportamiento sobre esta } \\
\text { intención de emprender. } \\
\text { Hipótesis ejemplo: La intención de emprender } \\
\text { tiene una relación positiva con la creencia de } \\
\text { comportamiento del estudiante }\end{array}$} & \multirow{4}{*}{$\begin{array}{l}\text { ¿Abrir un } \\
\text { negocio } \\
\text { propio es } \\
\text { atractivo } \\
\text { para Ud.? }\end{array}$} & \multirow{2}{*}{$\begin{array}{l}\text { Valoración } \\
\text { emocional }\end{array}$} & 2 & $\begin{array}{l}\text { De todas las carreras, elegiría ser } \\
\text { empresario }\end{array}$ & $\mathrm{x}$ & & $\mathrm{x}$ & & $\mathrm{x}$ & & & $\mathrm{x}$ & $\begin{array}{l}\text { pensar en De todas las opciones } \\
\text { laborales, elegiria ser empresario }\end{array}$ \\
\hline & & & & 9 & $\begin{array}{l}\text { Ser empresario me representaria } \\
\text { una gran satisfacción }\end{array}$ & $\mathrm{x}$ & & $\mathrm{x}$ & & $\mathrm{x}$ & & $\mathrm{x}$ & & \\
\hline & & & \multirow[t]{2}{*}{$\begin{array}{l}\text { Valoración } \\
\text { racional }\end{array}$} & 16 & $\begin{array}{l}\text { Ser empresario mejoraría mi } \\
\text { situación laboral }(N)\end{array}$ & $\mathrm{x}$ & & $\mathrm{x}$ & & $\mathrm{x}$ & & & $\mathrm{x}$ & $\begin{array}{l}\text { me genera inquietud hablar de mejoria } \\
\text { laboral y esto se puede asociar es a ser } \\
\text { empleado o intraemprendedor }\end{array}$ \\
\hline & & & & 23 & $\begin{array}{l}\text { Ser empresario me traería más } \\
\text { ventajas que inconvenientes }\end{array}$ & $\mathrm{x}$ & & $\mathrm{x}$ & & $\mathrm{x}$ & & $\mathrm{x}$ & & \\
\hline
\end{tabular}

$(N)=$ Nuevo

2. Suficiencia: ¿Todos los ítems presentados para este constructo denominado Intención de Emprendimiento bastan para obtener su medición?. Marque con un color

\begin{tabular}{|c|c|}
\hline $\mathbf{I}$ & No cumple con el criterio (Los ítems no son suficientes para medir la dimensión) \\
\hline 2 & Bajo Nivel (Los ítems miden algún aspecto de la dimensión pero no corresponden con la dimensión total) \\
\hline 3 & Moderado nivel (Se deben incrementar algunos ítems para poder evaluar la dimensión completamente) \\
\hline 4 & Alto nivel (Los items son suficientes) \\
\hline
\end{tabular}

\section{Si en la pregunta anterior marcó la opción 3, indique qué ítems sugiere agregar}

Invitaría a realizar alguna pregunta que indague pro los sueños o retos que tiene la persona en pro de emprender. 
1. Calificación de ítems. Marque con un aspa

\begin{tabular}{|c|c|c|c|c|c|c|c|c|c|c|c|c|c|c|}
\hline \multirow{2}{*}{ Constructo } & \multirow{2}{*}{ Definición } & \multirow{2}{*}{ Objetivo } & \multirow{2}{*}{ Sub Dimensión } & \multirow[b]{2}{*}{$\mathbf{N}^{\circ}$} & \multirow{2}{*}{ Indicadores } & \multicolumn{2}{|c|}{\begin{tabular}{|l|} 
Claridad \\
\end{tabular}} & \multicolumn{2}{|c|}{ Contexto } & \multicolumn{2}{|c|}{ Relevancia } & \multicolumn{2}{|c|}{ Coherencia } & \multirow{2}{*}{ Observaciones } \\
\hline & & & & & & Si & No & $\mathbf{S i}$ & No & Si & No & Si & No & \\
\hline \multirow{6}{*}{$\begin{array}{c}\text { Norma } \\
\text { subjetiva } \\
\text { (NS) - } \\
\text { Creencias } \\
\text { normativas }\end{array}$} & \multirow{6}{*}{$\begin{array}{l}\text { Mide la percepción de presión social que se tiene para } \\
\text { ejecutar o no un comportamiento emprendedor. } \\
\text { Especificamente está referido a la percepción de que } \\
\text { "personas cercanas" aprueben la decisión de convertirse } \\
\text { en emprendedor. } \\
\text { Ser empresario es probable que esté influenciado por las } \\
\text { opiniones y valores de las personas cercanas. } \\
\text { Se espera una asociación entre las intenciones de los } \\
\text { estudiantes para poner en marcha un negocio y las } \\
\text { percepciones acerca de las actitudes de los individuos, } \\
\text { grupos y redes, tales como la familia, amigos, } \\
\text { compañeros y otras personas importantes. } \\
\text { Hipótesis ejemplo: La intención de emprender tiene una } \\
\text { relación positiva con la creencia normativa del } \\
\text { estudiante. }\end{array}$} & \multirow{6}{*}{$\begin{array}{c}\text { ¿Si inicia un } \\
\text { negocio propio, } \\
\text { contaria con el } \\
\text { respaldo de las } \\
\text { personas que más } \\
\text { le importan } \\
\text { (familiares, } \\
\text { amigos, etc.) Y } \\
\text { ¿Qué importancia } \\
\text { tiene para Ud. lo } \\
\text { que piensen } \\
\text { ellos? }\end{array}$} & \multirow{4}{*}{$\begin{array}{c}\text { Aprobación de } \\
\text { personas } \\
\text { cercanas }\end{array}$} & 4 & $\begin{array}{l}\text { Mis padres y hermanos aprobarían la decisión de crear mi } \\
\text { empresa }\end{array}$ & $\mathrm{x}$ & & $\mathrm{x}$ & & $\mathrm{x}$ & & $\mathrm{x}$ & & \\
\hline & & & & 11 & $\begin{array}{l}\text { Mi esposo(a) e hijos aprobarían la decisión de crear mi } \\
\text { empresa }(N)\end{array}$ & $\mathrm{x}$ & & $\mathrm{x}$ & & $\mathrm{x}$ & & $\mathrm{x}$ & & \\
\hline & & & & 18 & Mis amigos aprobarían la decisión de crear mi empresa & $\mathrm{x}$ & & $\mathrm{x}$ & & $\mathrm{x}$ & & $\mathrm{x}$ & & \\
\hline & & & & 25 & $\begin{array}{l}\text { Mis colegas de estudio y trabajo aprobarían la decisión de } \\
\text { crear mi empresa }(N)\end{array}$ & $\mathrm{x}$ & & $\mathrm{x}$ & & $\mathrm{x}$ & & $\mathrm{x}$ & & \\
\hline & & & \multirow{2}{*}{$\begin{array}{l}\text { Importancia de } \\
\text { la aprobación }\end{array}$} & 29 & $\begin{array}{l}\text { Me importa que mi familia (padres, hermanos, esposo(a) e } \\
\text { hijos aprueben mi decisión de crear mi empresa }(N)\end{array}$ & $\mathrm{x}$ & & $\mathrm{x}$ & & $\mathrm{x}$ & & $\mathrm{x}$ & & \\
\hline & & & & 31 & $\begin{array}{l}\text { Me importa que mis amigos y colegas de estudio y trabajo } \\
\text { aprueben mi decisión de crear mi empresa }(N)\end{array}$ & $\mathrm{x}$ & & $\mathrm{x}$ & & $\mathrm{x}$ & & $\mathrm{x}$ & & \\
\hline
\end{tabular}

$(N)=$ Nuevo

2. Suficiencia: ¿Todos los ítems presentados para este constructo denominado Intención de Emprendimiento bastan para obtener su medición?. Marque con un color

1 No cumple con el criterio (Los ítems no son suficientes para medir la dimensión)

2 Bajo Nivel (Los ítems miden algún aspecto de la dimensión pero no corresponden con la dimensión total)

3 Moderado nivel (Se deben incrementar algunos ítems para poder evaluar la dimensión completamente)

4 Alto nivel (Los items son suficientes)

3. Si en la pregunta anterior marcó la opción 3, indique qué ítems sugiere agregar Ninguna. 
1. Calificación de ítems. Marque con un aspa

\begin{tabular}{|c|c|c|c|c|c|c|c|c|c|c|c|c|c|c|}
\hline \multirow{2}{*}{ Constructo } & \multirow{2}{*}{ Definición } & \multirow{2}{*}{ Objetivo } & \multirow{2}{*}{$\begin{array}{c}\text { Sub } \\
\text { Dimensión }\end{array}$} & \multirow{2}{*}{$\mathrm{N}^{\circ}$} & \multirow{2}{*}{ Indicadores } & \multicolumn{2}{|c|}{ Claridad } & \multicolumn{2}{|c|}{ Contexto } & \multicolumn{2}{|c|}{ Relevancia } & \multicolumn{2}{|c|}{ Coherencia } & \multirow{2}{*}{ Observaciones } \\
\hline & & & & & & Si & No & Si & No & Si & No & Si & No & \\
\hline \multirow{4}{*}{$\begin{array}{c}\text { Control } \\
\text { percibido de } \\
\text { la conducta } \\
\text { (CPB) - } \\
\text { Creencias de } \\
\text { control }\end{array}$} & \multirow{4}{*}{$\begin{array}{l}\text { Percepción de facilidad o dificultad de convertirse en } \\
\text { emprendedor. } \\
\text { Aplicada al contexto de la creación de empresas, son el grado en } \\
\text { que una persona siente que puede controlar el éxito de poner en } \\
\text { marcha un nuevo negocio. Este factor es similar a Bandura } \\
\text { (1986) el concepto de auto-eficacia (Krueger et al., 2000). De } \\
\text { acuerdo con este punto de vista, nuestras intenciones se ven } \\
\text { afectados no sólo por el deseo de iniciar un negocio, sino } \\
\text { también por el hecho de que sentimos que podemos iniciar un } \\
\text { negocio. Al igual que la auto-eficacia, este factor es, en parte, } \\
\text { influenciada por nuestras experiencias pasadas, que influyen en } \\
\text { la facilidad o dificultad percibida de tener éxito en iniciar una } \\
\text { nueva empresa } \\
\text { Un emprendedor potencial puede estar ansioso de empezar un } \\
\text { negocio nuevo porque siente que tiene la visión de negocio y los } \\
\text { fondos necesarios. Por el contrario la intención de emprender } \\
\text { puede ser baja para una persona que tiene mucha experiencia } \\
\text { pero carece de la percepción de tiempo necesario para hacer } \\
\text { exitoso un nuevo negocio. } \\
\text { Hipótesis ejemplo: La intención de emprender tiene una relación } \\
\text { positiva con la creencia de control }\end{array}$} & \multirow{4}{*}{$\begin{array}{l}\text { ¿Ud. Cree que } \\
\text { tiene o puede } \\
\text { desarrollar las } \\
\text { habilidades y } \\
\text { conocimientos } \\
\text { necesarios } \\
\text { para iniciar un } \\
\text { negocio con } \\
\text { éxito? } \\
\end{array}$} & \multirow[b]{2}{*}{$\begin{array}{l}\text { Facilidad / } \\
\text { Dificultad } \\
\\
\end{array}$} & 3 & $\begin{array}{l}\text { Sería fácil para mi, crear mi } \\
\text { propia empresa }\end{array}$ & $\mathrm{x}$ & & $\mathrm{x}$ & & $\mathrm{x}$ & & & $\mathrm{x}$ & $\begin{array}{l}\text { considero que la mayoria d } \\
\text { ela gente va a tender a decir } \\
\text { que no, la pregunta invita a } \\
\text { contestar que no }\end{array}$ \\
\hline & & & & 10 & $\begin{array}{l}\text { Sería fácil para mi, } \\
\text { desarrollar conocimiento y } \\
\text { habilidades para crear mi } \\
\text { propia empresa }(N)\end{array}$ & $\mathrm{x}$ & & $\mathrm{x}$ & & $\mathrm{x}$ & & & $\mathrm{x}$ & $\begin{array}{l}\text { considero que la mayoria d } \\
\text { ela gente va a tender a decir } \\
\text { que no, la pregunta invita a } \\
\text { contestar que no }\end{array}$ \\
\hline & & & \multirow{2}{*}{\begin{tabular}{|c|} 
\\
Control / \\
Sentir que \\
se puede
\end{tabular}} & 17 & $\begin{array}{l}\text { Soy capaz de crear una } \\
\text { empresa exitosa }\end{array}$ & $\mathrm{x}$ & & $\mathrm{x}$ & & $\mathrm{x}$ & & $\mathrm{x}$ & & \\
\hline & & & & 24 & $\begin{array}{l}\text { Tengo el conocimiento y } \\
\text { habilidades para crear mi } \\
\text { propia empresa }(N)\end{array}$ & $\mathrm{x}$ & & $\mathrm{x}$ & & $\mathrm{x}$ & & $\mathrm{x}$ & & \\
\hline
\end{tabular}

$(N)=$ Nuevo

2. Suficiencia: ¿Todos los ítems presentados para este constructo denominado Intención de Emprendimiento bastan para obtener su medición?. Marque con un color

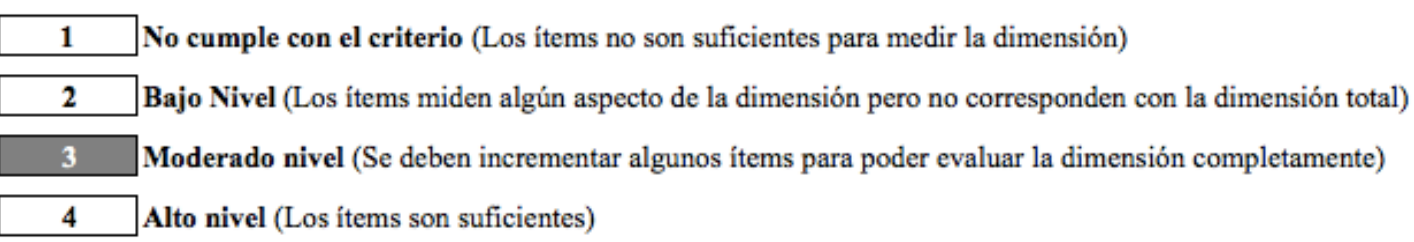

\section{Si en la pregunta anterior marcó la opción 3, indique qué ítems sugiere agregar}

Redactar de otra forma, dado mis conocimientos y capacidades soy capaz de montar empresa o algo así. 
1. Calificación de ítems. Marque con un aspa

\begin{tabular}{|c|c|c|c|c|c|c|c|c|c|c|c|c|c|c|}
\hline \multirow{2}{*}{ Constructo } & \multirow{2}{*}{ Definición } & \multirow{2}{*}{ Objetivo } & \multirow{2}{*}{$\begin{array}{c}\text { Sub } \\
\text { Dimensión }\end{array}$} & \multirow{2}{*}{$\mathbf{N}^{\mathrm{o}}$} & \multirow{2}{*}{ Indicadores } & \multicolumn{2}{|c|}{ Claridad } & \multicolumn{2}{|c|}{ Contexto } & \multicolumn{2}{|c|}{ Relevancia } & \multicolumn{2}{|c|}{ Coherencia } & \multirow{2}{*}{ Observaciones } \\
\hline & & & & & & $\mathbf{S i}$ & No & Si & No & $\mathbf{S i}$ & No & Si & No & \\
\hline \multirow{4}{*}{$\begin{array}{c}\text { Capital } \\
\text { social: } \\
\text { Valoración } \\
\text { cercana (VC) }\end{array}$} & \multirow{4}{*}{\begin{tabular}{|l} 
Mide la influencia positiva o negativa \\
que ejercen la familia, los amigos y \\
compañeros sobre: a) sus creencias \\
emocionales y racionales sobre \\
emprender, y b) sus creencias referidas al \\
respaldo que le puede proporcionar su \\
propio entorno \\
También mide la influencia positiva o \\
negativa sobre el conocimiento que \\
pueda tener el estudiante sobre casos de \\
emprendimiento en su entorno cercano
\end{tabular}} & \multirow{4}{*}{$\begin{array}{c}\text { ¿La valoración } \\
\text { de su ambiente } \\
\text { cercano } \\
\text { favorece la } \\
\text { actividad } \\
\text { emprendedora? }\end{array}$} & \multirow{2}{*}{ Familia } & 5 & $\begin{array}{l}\text { Mis padres y hermanos valoran la actividad empresarial por } \\
\text { encima de otras actividades y carreras }\end{array}$ & $\mathrm{x}$ & & $\mathrm{x}$ & & $\mathrm{x}$ & & $\mathrm{x}$ & & \\
\hline & & & & 12 & $\begin{array}{l}\text { Mis esposo(a) e hijos valoran la actividad empresarial por } \\
\text { encima de otras actividades y carreras }(N)\end{array}$ & $\mathrm{x}$ & & $\mathrm{x}$ & & $\mathrm{x}$ & & $\mathrm{x}$ & & \\
\hline & & & \multirow{2}{*}{$\begin{array}{c}\text { Amigos y } \\
\text { Colegas }\end{array}$} & 19 & $\begin{array}{l}\text { Mis amigos valoran la actividad empresarial por encima de } \\
\text { otras actividades y carreras }\end{array}$ & $\mathrm{x}$ & & $\mathrm{x}$ & & $\mathrm{x}$ & & $\mathrm{x}$ & & \\
\hline & & & & 26 & $\begin{array}{l}\text { Mis colegas de estudio y trabajo valoran la actividad } \\
\text { empresarial por encima de otras actividades y carreras }(N)\end{array}$ & $\mathrm{x}$ & & $\mathrm{x}$ & & $\mathrm{x}$ & & $\mathrm{x}$ & & \\
\hline
\end{tabular}

$(N)=$ Nuevo

2. Suficiencia: ¿Todos los ítems presentados para este constructo denominado Intención de Emprendimiento bastan para obtener su medición?. Marque con un color

1

No cumple con el criterio (Los ítems no son suficientes para medir la dimensión)

2 Bajo Nivel (Los ítems miden algún aspecto de la dimensión pero no corresponden con la dimensión total)

3 Moderado nivel (Se deben incrementar algunos ítems para poder evaluar la dimensión completamente)

4 Alto nivel (Los items son suficientes)

3. Si en la pregunta anterior marcó la opción 3, indique qué ítems sugiere agregar

Considero que falta algo sobre la influencia positiva o negativa sobre el conocimiento que pueda tener el estudiante sobre casos de emprendimiento en su entorno cercano. 


\section{Calificación de ítems. Marque con un aspa}

\begin{tabular}{|c|c|c|c|c|c|c|c|c|c|c|c|c|c|c|}
\hline \multirow{2}{*}{ Constructo } & \multirow{2}{*}{ Definición } & \multirow{2}{*}{ Objetivo } & \multirow{2}{*}{$\begin{array}{c}\text { Sub } \\
\text { Dimensión }\end{array}$} & \multirow{2}{*}{$\mathbf{N}^{a}$} & \multirow{2}{*}{ Indicadores } & \multicolumn{2}{|c|}{ Claridad } & \multicolumn{2}{|c|}{ Contexto } & \multicolumn{2}{|c|}{ Relevancia } & \multicolumn{2}{|c|}{ Coherencia } & \multirow{2}{*}{ Observaciones } \\
\hline & & & & & & $\mathbf{S i}$ & No & Si & No & Si & No & Si & No & \\
\hline \multirow{4}{*}{$\begin{array}{c}\text { Capital } \\
\text { social: } \\
\text { Valoración } \\
\text { social (VS) }\end{array}$} & \multirow{4}{*}{$\begin{array}{l}\text { Instituciones y Normas Legales: Mide la influencia } \\
\text { positiva o negativa de las Instituciones, programas y } \\
\text { financiamiento + las normas legales sobre: a) sus } \\
\text { creencias de respaldo que le ofrecen las instituciones } \\
\text { y lo importante que esto puede ser para el estudiante } \\
\text { en sus intenciones de emprender; asi como, b) sus } \\
\text { creencias referidas a sus habilidades y conocimientos } \\
\text { sobre emprender. } \\
\text { También mide la influencia positiva o negativa que le } \\
\text { generan el contacto y experiencia con instituciones y } \\
\text { normas legales. }\end{array}$} & \multirow{4}{*}{$\begin{array}{l}\text { ¿La valoración } \\
\text { de instituciones } \\
\text { y normas } \\
\text { legales favorece } \\
\text { la actividad } \\
\text { emprendedora? }\end{array}$} & \multirow{2}{*}{ Instituciones } & 6 & $\begin{array}{l}\text { En el Perú, existen instituciones que asesoran en } \\
\text { la creación de empresas }(N)\end{array}$ & $\mathrm{x}$ & & $\mathrm{x}$ & & $\mathrm{x}$ & & $\mathrm{x}$ & & \\
\hline & & & & 13 & $\begin{array}{l}\text { En el Perú, existen alternativas de financiamiento } \\
\text { para la creación de empresas }(N)\end{array}$ & $\mathrm{x}$ & & $\mathrm{x}$ & & $\mathrm{x}$ & & $\mathrm{x}$ & & \\
\hline & & & $\begin{array}{l}\text { Normas } \\
\text { Legales }\end{array}$ & 20 & $\begin{array}{l}\text { En el Perú, el marco legal fomenta la creación de } \\
\text { nuevas empresas }(N)\end{array}$ & $\mathrm{x}$ & & $\mathrm{x}$ & & $\mathrm{x}$ & & $\mathrm{x}$ & & \\
\hline & & & Experiencia & 27 & $\begin{array}{l}\text { He tenido contacto directo con instituciones que } \\
\text { apoyan la creación de empresas }(N)\end{array}$ & $\mathrm{x}$ & & $\mathrm{x}$ & & & $\mathrm{x}$ & $\mathrm{x}$ & & $\begin{array}{l}\text { falta identificar la experiencia } \\
\text { con instituciones }\end{array}$ \\
\hline
\end{tabular}

$(N)=$ Nuevo

2. Suficiencia: ¿Todos los ítems presentados para este constructo denominado Intención de Emprendimiento bastan para obtener su medición?. Marque con un color

1 No cumple con el criterio (Los ítems no son suficientes para medir la dimensión)

2 Bajo Nivel (Los ítems miden algún aspecto de la dimensión pero no corresponden con la dimensión total)

3 Moderado nivel (Se deben incrementar algunos ítems para poder evaluar la dimensión completamente)

4 Alto nivel (Los ítems son suficientes)

\section{Si en la pregunta anterior marcó la opción 3, indique qué ítems sugiere agregar}

Ha tenido experiencias satisfactorias con instituciones que apoyan el emprendimiento. 


\section{Calificación de ítems. Marque con un aspa}

\begin{tabular}{|c|c|c|c|c|c|c|c|c|c|c|c|c|c|c|}
\hline \multirow[b]{2}{*}{ Constructo } & \multirow[b]{2}{*}{ Definición } & \multirow[b]{2}{*}{ Objetivo } & \multirow[b]{2}{*}{ Sub Dimensión } & \multirow[b]{2}{*}{$\mathbf{N}^{\circ}$} & \multirow[b]{2}{*}{ Indicadores } & \multicolumn{2}{|c|}{ Claridad } & \multicolumn{2}{|c|}{ Contexto } & \multicolumn{2}{|c|}{ Relevancia } & \multicolumn{2}{|c|}{ Coherencia } & \multirow[b]{2}{*}{ Observaciones } \\
\hline & & & & & & Si & No & $\mathbf{S i}$ & No & Si & No & Si & No & \\
\hline \multirow{5}{*}{$\begin{array}{l}\text { Capital social: } \\
\text { Valoración } \\
\text { social (VS) }\end{array}$} & \multirow{5}{*}{$\begin{array}{c}\text { Educación Emprendedora: } \\
\text { Mide la influencia positiva o } \\
\text { negativa del enfoque de su } \\
\text { carrera, el contenido de los } \\
\text { cursos que lleva, la metodologia } \\
\text { de enseñanza y los cursos } \\
\text { complementarios a su malla } \\
\text { curricular sobre: a) sus creencias } \\
\text { de respaldo y lo importante que } \\
\text { esto puede ser para el estudiante } \\
\text { en sus intenciones de emprender; } \\
\text { asi como, b) sus creencias } \\
\text { referidas a sus habilidades y } \\
\text { conocimientos sobre emprender }\end{array}$} & \multirow{5}{*}{$\begin{array}{c}\text { ¿La valoración } \\
\text { de la formación } \\
\text { universitaria } \\
\text { favorece la } \\
\text { actividad } \\
\text { emprendedora? }\end{array}$} & \multirow{2}{*}{ Cursos de carrera } & 7 & $\begin{array}{l}\text { En el transcurso de mi carrera he recibido } \\
\text { formación en emprendimiento }(N)\end{array}$ & $\mathrm{x}$ & & $\mathrm{x}$ & & $\mathrm{x}$ & & $\mathrm{x}$ & & \\
\hline & & & & 14 & $\begin{array}{l}\text { En general, mis cursos universitarios me } \\
\text { sirven para formar mi empresa }(N)\end{array}$ & $\mathrm{x}$ & & $\mathrm{x}$ & & $\mathrm{x}$ & & $\mathrm{x}$ & & \\
\hline & & & $\begin{array}{l}\text { Metodología de } \\
\text { enseñanza }\end{array}$ & 21 & $\begin{array}{l}\text { En general, mis docentes universitarios guían } \\
\text { a los estudiantes hacia el emprendimiento }(N)\end{array}$ & & $\mathrm{x}$ & $\mathrm{x}$ & & & $\mathrm{x}$ & & $\mathrm{x}$ & $\begin{array}{l}\text { La pregunta no sugiere reflexionar } \\
\text { sobre la metodologia de enseñanza }\end{array}$ \\
\hline & & & $\begin{array}{c}\text { Actividades } \\
\text { complementarias }\end{array}$ & 28 & $\begin{array}{l}\text { Mi universidad ofrece actividades } \\
\text { complementarias sobre emprendimiento }(N)\end{array}$ & $\mathrm{x}$ & & $\mathrm{x}$ & & $\mathrm{x}$ & & $\mathrm{x}$ & & \\
\hline & & & $\begin{array}{c}\text { Cultura } \\
\text { Universitaria }\end{array}$ & 30 & $\begin{array}{l}\text { Mi universidad tiene una cultura de } \\
\text { emprendimiento }(N)\end{array}$ & & $\mathrm{x}$ & $\mathrm{x}$ & & $\mathrm{x}$ & & $\mathrm{x}$ & & $\begin{array}{l}\text { La cultura implcia muchas cosas, } \\
\text { deberia hacerse una pregunta mas } \\
\text { especifica }\end{array}$ \\
\hline
\end{tabular}

$(N)=$ Nuevo

2. Suficiencia: ¿Todos los ítems presentados para este constructo denominado Intención de Emprendimiento bastan para obtener su medición?. Marque con un color

No cumple con el criterio (Los ítems no son suficientes para medir la dimensión)

2 Bajo Nivel (Los ítems miden algún aspecto de la dimensión pero no corresponden con la dimensión total)

3 Moderado nivel (Se deben incrementar algunos items para poder evaluar la dimensión completamente)

4 Alto nivel (Los ítems son suficientes)

3. Si en la pregunta anterior marcó la opción 3, indique qué ítems sugiere agregar

Mi universidad brinda valores y espacios en pro del emprendimiento. 


\section{Apéndice D}

\section{Cuestionario Intención de Emprendimiento de Universitarios Adultos con Experiencia Laboral}

1) De las siguientes afirmaciones, indique su nivel de acuerdo o desacuerdo, sobre una escala de: (1) Totalmente en desacuerdo (2) En desacuerdo (3) Neutral (4) De acuerdo (5) Totalmente de acuerdo

\begin{tabular}{|c|c|c|c|c|c|c|}
\hline & & 1 & 2 & 3 & 4 & 5 \\
\hline 1 & En el transcurso de mi carrera he recibido formación en emprendimiento & & & & & \\
\hline 2 & Me importa que mi entorno familiar apruebe mi decisión de crear mi empresa & & & & & \\
\hline 3 & He realizado algunas actividades para crear mi propia empresa & & & & & \\
\hline 4 & En el Perú, existen instituciones que asesoran en la creación de empresas & & & & & \\
\hline 5 & De todas las carreras, elegiría ser empresario & & & & & \\
\hline 6 & Mi entorno familiar identifica potencial emprendedor en mi & & & & & \\
\hline 7 & Sería fácil para mi, crear mi propia empresa & & & & & \\
\hline 8 & En general, mis cursos universitarios me sirven para formar mi empresa & & & & & \\
\hline 9 & Me importa que mi grupo de amigos apruebe mi decisión de crear mi empresa & & & & & \\
\hline 10 & Realizaré todos los esfuerzos necesarios para crear mi propia empresa & & & & & \\
\hline 11 & En el Perú, existen alternativas de financiamiento para la creación de empresas & & & & & \\
\hline 12 & Ser empresario me representaría una gran satisfacción & & & & & \\
\hline 13 & Mi grupo de amigos afirma que sería un buen emprendedor & & & & & \\
\hline 14 & Sería fácil para mi, desarrollar conocimiento y habilidades para crear mi propia empresa & & & & & \\
\hline 15 & En general, mis docentes universitarios guían a los estudiantes hacia el emprendimiento & & & & & \\
\hline 16 & Me importa que mi entorno profesional apruebe mi decisión de crear mi empresa & & & & & \\
\hline 17 & Voy a crear mi propia empresa & & & & & \\
\hline 18 & En el Perú, el marco legal fomenta la creación de nuevas empresas & & & & & \\
\hline 19 & Ser empresario mejoraría mi situación laboral & & & & & \\
\hline 20 & Mi entorno laboral afirma que tengo condiciones para ser emprendedor & & & & & \\
\hline 21 & Soy capaz de crear mi propia empresa & & & & & \\
\hline 22 & Mi universidad ofrece actividades complementarias sobre emprendimiento & & & & & \\
\hline 23 & Tengo el conocimiento y habilidades para crear mi propia empresa & & & & & \\
\hline 24 & Mi objetivo profesional es ser empresario & & & & & \\
\hline 25 & He tenido contacto directo con instituciones que apoyan la creación de empresas & & & & & \\
\hline 26 & Ser empresario me traería más ventajas que inconvenientes & & & & & \\
\hline 27 & Mi universidad tiene una cultura de emprendimiento & & & & & \\
\hline
\end{tabular}




\section{Cuestionario Intención de Emprendimiento de Universitarios Adultos con Experiencia Laboral}

\section{2) Datos del encuestado}

28 Carrera que estudia

1 Administración de Empresas

2 Marketing y Gestión Comercial

3 Negocios Internacionales

4 Ingeniería Empresarial y de Sistemas

5 Contabilidad

6 Ingeniería Industrial

\section{Género \\ 1 Femenino \\ 2 Masculino}

32 Estado Civil

1 Soltero(a)

2 Casado(a)

3 Divorciado(a)

4 Viudo(a)

35 ¿Alguna vez ha creado una empresa?

$1 \mathrm{Si}$

2 No

36 ¿Cuál es el cargo que Ud. ocupa en la empresa donde labora?

1 Dueño

2 Gerente / Jefe

3 Supervisor / Coordinador

4 Empleado

5 Obrero

6 Otro:

38 Indique el máximo nivel educativo alcanzado por:

\begin{tabular}{|c|c|c|c|c|c|c|c|}
\hline & & Primaria & Secundaria & Técnico & Universitari & Maestría & Doctorado \\
\hline 1 & Mamá & & & & & & \\
\hline 2 & Papá & & & & & & \\
\hline 3 & Esposo(a) & & & & & & \\
\hline
\end{tabular}

\begin{tabular}{|c|c|c|c|c|}
\hline 39 & Indique el trabajo que tiene o tuvo: & Mamá & Papá & Esposo(a \\
\hline 1 & Empleador, dueño de su empresa & & & \\
\hline 2 & Trabajador/Consultor independiente & & & \\
\hline 3 & Gerente / Jefe & & & \\
\hline 4 & Supervisor / Coordinador & & & \\
\hline 5 & Empleado & & & \\
\hline 6 & Obrero & & & \\
\hline 7 & Su casa & & & \\
\hline 8 & Otro & & & \\
\hline
\end{tabular}

\author{
29 Ciclo Académico \\ 1 Octavo \\ 2 Noveno \\ 3 Décimo \\ 4 Otro:
}

31 Edad

33 Distrito donde vive

34 Lugar de Nacimiento

1 Lima

2 Provincias

37 En promedio, a cuánto ascienden sus ingresos brutos mensuales?

1 Menos de S/. 2,000

2 S/. 2,001-S/. 3,500

$3 \mathrm{~S} / .3,501-\mathrm{S} / .5,000$

4 S/. 5,001-S/. 6,500

5 S/. 6,501-S/. 8,000

6 S/. 8,001-S/. 10,000

7 Más de S/. 10,000

40 Si desea ser contactad@

para futuras

investigaciones,

ingrese los siguientes

datos:

Nombres y Apellidos:

Celular:

Correo electrónico: 


\section{Pregunta General 1}

¿Cuáles son los factores motivacionales que inciden en la intención de

emprendimiento de universitarios adultos

con experiencia laboral (UAEL)?

Pregunta General 2

¿Cuáles son los factores ambientales que inciden en la intención de emprendimiento

de universitarios adultos con experiencia laboral (UAEL)?

Preguntas Específicas

1. ¿Cómo incide la actitud hacia la

conducta en la intención de

emprendimiento de UAEL?

2. ¿Cómo incide el control percibido de la conducta en la intención de

emprendimiento de UAEL?

3. Como incide la norma subietiva en la

3. ¿Cómo incide la norma subjetiva en la actitud hacia la conducta de UAEL?

4. ¿Cómo incide la norma subjetiva en el control percibido de la conducta de UAEL?

control percibido de la conducta de UAEL?

5. ¿Cómo incide la valoración cercana en la actitud hacia la conducta de UAEL?

6. ¿Cómo incide la valoración cercana en la norma subjetiva de UAEL?

The

7. ¿Cómo inciden las instituciones y normas legales en la norma subjetiva de UAEL?

8. ¿Cómo inciden las instituciones y normas legales en el control percibido de la conducta de UAEL?

9. ¿Cómo incide la educación emprendedora en la norma subjetiva de UAEL?

Identificar los factores motivacionales que inciden en la intención de emprendimiento de UAEL.

\section{Objetivo General 2}

Identificar los factores ambientales

que inciden en la intención de

emprendimiento de UAEL.

\section{Objetivos Específicos}

1. Identificar la incidencia de la actitud hacia la conducta en la intención de emprendimiento de UAEL.

2. Identificar la incidencia del control percibido de la conducta en la intención de emprendimiento de UAEL.

3. Identificar la incidencia de la norma subjetiva en la actitud hacia la conducta de UAEL.

4. Identificar la incidencia de la norma subjetiva en el control percibido de la conducta de UAEL.

5. Identificar la incidencia de la

valoración cercana en la actitud hacia la conducta de UAEL.

6. Identificar la incidencia de la valoración cercana en la norma subjetiva de UAEL.

7. Identificar la incidencia de las instituciones y normas legales en la norma subjetiva de UAEL.

8. Identificar la incidencia de las instituciones y normas legales en el control percibido de la conducta de UAEL.

9. Identificar la incidencia de la educación emprendedora en la norma subjetiva de UAEL.
Hipótesis General 1

Los factores motivacionales tienen un impacto positivo en la intención de emprendimiento de UAEL.

Hipótesis General 2

Los factores ambientales tienen un impacto positivo en la intención de emprendimiento de UAEL.

\section{Hipótesis Específicas}

H1a. La actitud hacia la conducta tiene un impacto positivo en la intención de emprendimiento de UAEL.

H1b. El control percibido de la conducta tiene un impacto positivo en la intención de emprendimiento de UAEL.

H2a. La norma subjetiva tiene un impacto positivo en la actitud hacia la conducta de UAEL.

$\mathrm{H} 2 \mathrm{~b}$. La norma subjetiva tiene un impacto positivo en el control percibido de la conducta de UAEL. H3a. La valoración cercana tiene un impacto positivo en la actitud hacia la conducta de UAEL.

H3b. La valoración cercana tiene un impacto positivo en la norma subjetiva de UAEL.

H3c. Las instituciones y normas legales tienen un impacto positivo en la norma subjetiva de UAEL.

$\mathrm{H} 3 \mathrm{~d}$. Las instituciones y normas legales tienen un impacto positivo en el control percibido de la conducta de UAEL.

H3e. La educación emprendedora tiene un impacto positivo en la norma subjetiva de UAEL.

\begin{tabular}{|c|c|c|c|}
\hline \multirow{4}{*}{ Dependiente } & \multirow{4}{*}{$\begin{array}{l}\text { Intención de } \\
\text { Emprendimiento }\end{array}$} & \multirow{2}{*}{$\begin{array}{l}\text { Grado de } \\
\text { esfuerzo }\end{array}$} & P3 \\
\hline & & & P10 \\
\hline & & \multirow[b]{2}{*}{ Certeza } & P17 \\
\hline & & & P24 \\
\hline \multirow{4}{*}{ Independiente } & \multirow{4}{*}{$\begin{array}{l}\text { Actitud Hacia la } \\
\text { Conducta }\end{array}$} & \multirow{2}{*}{$\begin{array}{l}\text { Valoración } \\
\text { emocional }\end{array}$} & P5 \\
\hline & & & P12 \\
\hline & & \multirow{2}{*}{$\begin{array}{c}\text { Valoración } \\
\text { racional }\end{array}$} & P19 \\
\hline & & & P26 \\
\hline \multirow{4}{*}{ Independiente } & \multirow{4}{*}{$\begin{array}{l}\text { Control Percibido } \\
\text { de la Conducta }\end{array}$} & \multirow{2}{*}{$\begin{array}{l}\text { Facilidad / } \\
\text { Dificultad }\end{array}$} & $\mathrm{P7}$ \\
\hline & & & P14 \\
\hline & & \multirow{2}{*}{$\begin{array}{l}\text { Control / Sentir } \\
\text { que se puede }\end{array}$} & $\mathrm{P} 21$ \\
\hline & & & $\mathrm{P} 23$ \\
\hline \multirow{3}{*}{ Independiente } & \multirow{3}{*}{ Norma Subjetiva } & \multirow{3}{*}{$\begin{array}{l}\text { Importancia de } \\
\text { aprobación de } \\
\text { entorno cercano } \\
\text { y social }\end{array}$} & $\mathrm{P} 2$ \\
\hline & & & P9 \\
\hline & & & P16 \\
\hline \multirow{3}{*}{ Independiente } & \multirow{3}{*}{$\begin{array}{l}\text { Valoración } \\
\text { Cercana }\end{array}$} & Entorno familiar & P6 \\
\hline & & Amigos & P13 \\
\hline & & Entorno laboral & P20 \\
\hline \multirow{4}{*}{ Independiente } & \multirow{4}{*}{$\begin{array}{l}\text { Instituciones y } \\
\text { Normas Legales }\end{array}$} & \multirow{2}{*}{ Instituciones } & P4 \\
\hline & & & P11 \\
\hline & & Normas Legales & P18 \\
\hline & & Experiencia & P25 \\
\hline \multirow[b]{3}{*}{. } & \multirow[b]{3}{*}{ Educación } & \multirow{2}{*}{ Cursos de carrera } & $\mathrm{P} 1$ \\
\hline & & & P8 \\
\hline & & Metodología de & D15 \\
\hline
\end{tabular}


